\title{
Spin-flip luminescence
}

\author{
Winald Robert Kitzmann ${ }^{1}\left[\right.$ ] Johannes Moll ${ }^{1} \cdot$ Katja Heinze $^{1}[$
}

Received: 23 December 2021 / Accepted: 1 February 2022 / Published online: 5 March 2022

(c) The Author(s) 2022

\begin{abstract}
In molecular photochemistry, charge-transfer emission is well understood and widely exploited. In contrast, luminescent metal-centered transitions only came into focus in recent years. This gave rise to strongly phosphorescent $\mathrm{Cr}^{\mathrm{III}}$ complexes with a $d^{3}$ electronic configuration featuring luminescent metal-centered excited states which are characterized by the flip of a single spin. These so-called spin-flip emitters possess unique properties and require different design strategies than traditional charge-transfer phosphors. In this review, we give a brief introduction to ligand field theory as a framework to understand this phenomenon and outline prerequisites for efficient spin-flip emission including ligand field strength, symmetry, intersystem crossing and common deactivation pathways using $\mathrm{Cr}^{\mathrm{III}}$ complexes as instructive examples. The recent progress and associated challenges of tuning the energies of emissive excited states and of emerging applications of the unique photophysical properties of spin-flip emitters are discussed. Finally, we summarize the current state-of-the-art and challenges of spin-flip emitters beyond $\mathrm{Cr}^{\mathrm{III}}$ with $d^{2}, d^{3}, d^{4}$ and $d^{8}$ electronic configuration, where we mainly cover pseudooctahedral molecular complexes of $\mathrm{V}, \mathrm{Mo}, \mathrm{W}, \mathrm{Mn}, \mathrm{Re}$ and $\mathrm{Ni}$, and highlight possible future research opportunities.
\end{abstract}

\section{Graphical abstract}

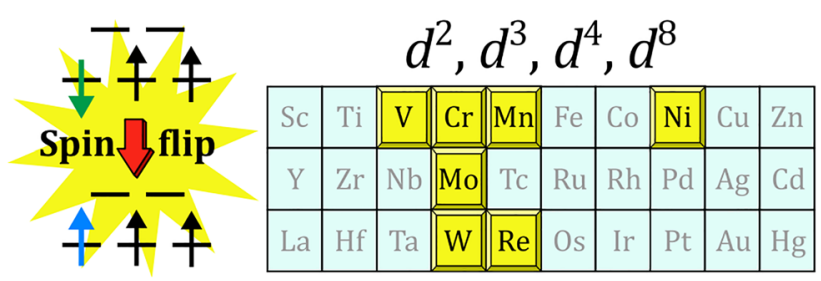

Keywords Transition metal complex $\cdot$ Photochemistry $\cdot$ Excited states $\cdot$ Ligand field theory $\cdot$ Spin-flip phosphorescence . Intersystem crossing

\section{Introduction and scope of the review}

Photoactive complexes are both fundamentally interesting and highly valuable in many applications, e.g., optical devices, catalysis and biomedicine [1-4]. Traditionally there is an excessive reliance on compounds containing precious transition metal ions like $\mathrm{Ru}^{\mathrm{II}}$, $\mathrm{Ir}^{\mathrm{III}}$, Os ${ }^{\mathrm{II}}$ or $\mathrm{Pt}^{\mathrm{II}}$ due to their

Winald Robert Kitzmann

Kitzmann@Uni-Mainz.de

Katja Heinze

Katja.Heinze@Uni-Mainz.de

1 Department of Chemistry, Johannes Gutenberg University Mainz, Duesbergweg 10-14, Mainz, Germany favorably high intrinsic ligand field splitting and strong spin-orbit coupling (SOC) [5-9]. In most cases, the emissive states are of charge transfer (CT) character, be it metal-toligand (MLCT), ligand-to-metal (LMCT), ligand-to-ligand (LL'CT) or intra-ligand charge transfer (ILCT), while metalcentered (MC) states are often non-emissive and facilitate non-radiative deactivation $[10,11]$.

Most prominently, this occurs in $\mathrm{Fe}^{\mathrm{II}}$ complexes where efficient relaxation via low-energy MC states had precluded long MLCT lifetimes and phosphorescence for a long time [12-20]. An octahedral $\mathrm{Fe}^{\mathrm{II}}$ complex with tridentate $\mathrm{N}^{\wedge} \mathrm{N}^{\wedge} \mathrm{N}$ ligands showed a ${ }^{3 / 5} \mathrm{MC}$ lifetime of $>1.6 \mathrm{~ns}$ and sensitized ${ }^{1} \mathrm{O}_{2}$ [15] and an iron(II) complex with a hexadentate tren(py $)_{3}$ ligand reduces quinones by photoinduced electron 
transfer from its ${ }^{5} \mathrm{MC}$ state (tren $(\mathrm{py})_{3}=$ tris (2-pyridyl-methyliminoethyl)amine) [18]. An excited ${ }^{3} \mathrm{CT}$ state lifetime of $3 \mathrm{~ns}$ was achieved by an iron(II) complex with strongly covalent $\mathrm{Fe}-\mathrm{N}_{\text {amido }}$ bonds due to a high barrier for the ${ }^{3} \mathrm{MC} /{ }^{3} \mathrm{CT}$ interconversion [21]. Most recently, the first emissive mononuclear $\mathrm{Fe}^{\mathrm{II}}$ complex has been reported [22]. It shows NIRII luminescence in the range of $1030-1600 \mathrm{~nm}$ originating from a ${ }^{3} \mathrm{MLCT}$ state with a lifetime of $1 \mathrm{~ns}$ in benzene solution at room temperature.

Rare examples of $d^{6}$ complexes showing luminescent ${ }^{3} \mathrm{MC}$ states were presented with $\left[\mathrm{Co}^{\mathrm{III}}(\mathrm{CN})_{6}\right]^{3-}$ and more recently with a hexacarbene $\mathrm{Co}^{\mathrm{III}}$ complex $[23,24]$. The strongly $\sigma$-donating ligands imposed a very high ligand field splitting. This raised the energy of MC states so they can act as long-lived emissive excited states [24].

A fundamentally different type of phosphorescence from MC states appears in octahedral $d^{3}-\mathrm{Cr}^{\mathrm{III}}$ complexes. Instead of interconfigurational states with occupied antibonding orbitals, associated emissive MC states feature the same electronic configuration as the ground state $\left(t_{2 \mathrm{~g}}\right)^{3}$, but differ by a single flipped electron spin. Hence, this luminescence from intraconfigurational states was named 'spin-flip emission'. Although $\mathrm{Cr}^{\mathrm{III}}$ complexes have been known for many years, a conceptual breakthrough toward intense spin-flip emission led to an increased interest in the past six years [11, 25-29].

Beyond the $d^{3}$ electronic configuration, spin-flip emission is also conceivable in octahedral $d^{2}, d^{4}$ and $d^{8}$ complexes, but examples are much less prevalent in the literature than for $d^{3}$ complexes. In this review, we outline the theoretical frame required to understand spin-flip luminescence with respect to ligand field theory, symmetry, intersystem crossing (ISC) and relaxation pathways using various well-described $\mathrm{Cr}^{\mathrm{III}}$ complexes. We also show how emission energies can be tuned in these systems over a range of $5800 \mathrm{~cm}^{-1}$, and which applications exploit their unique excited state properties. Finally, we summarize the advances of the field with special emphasis on the often-undervalued central ions $\mathrm{V}^{\mathrm{II}}$, $\mathrm{V}^{\mathrm{III}}, \mathrm{Cr}^{\mathrm{IV}}, \mathrm{Mo}^{\mathrm{III}}, \mathrm{W}^{\mathrm{III}}, \mathrm{Mn}^{\mathrm{IV}}, \mathrm{Re}^{\mathrm{IV}}$ and $\mathrm{Ni}^{\mathrm{II}}$. While spin-flip emission has been observed in many solids doped with suitable transition metal ions [30-46] and many lanthanide complexes show emissive metal-centered ff-transitions [47-49], this review focuses on mononuclear molecular systems with $d$-block transition metal ions.

\section{Implications from ligand field theory}

Ligand field theory is a powerful tool to understand and design spin-flip emitters. In an octahedral ligand field the five degenerate $d$-orbitals split into two sets, three lower $t_{2 \mathrm{~g}}$ and two higher $e_{\mathrm{g}}{ }^{*}$ orbitals ( $O_{h}$ notation), which differ in energy by the ligand field splitting $\Delta_{\mathrm{O}}[50,51]$. The ligand field concomitantly leads to splitting of the atomic terms of the central metal forming ligand field terms of different symmetries. The energies of these terms in dependence of $\Delta_{O}$ are visualized in Tanabe-Sugano (TS) diagrams and depend on $\Delta_{\mathrm{O}}$ as well as the Racah parameters $B$ and $C$ (Fig. 1) [52, 53]. While both $B$ and $C$ describe the interelectronic repulsion, the parameter $C$ only affects the energies of states with multiplicities lower than the maximum for a given electronic configuration (for example those of the doublet states in $d^{3}$ ions) [54]. The relative state energies in a TS diagram depend on the ratio $C / B$ which is often arbitrarily set to 4.0 but in reality varies between complexes [55]. Figure 1 shows the TS diagrams for octahedral $d^{2}, d^{3}, d^{4}$ and $d^{8}$ complexes $[52,53]$. These electronic configurations feature a set of intraconfigurational states with low energy at high $\Delta_{\mathrm{O}}$ (e.g., ${ }^{2} \mathrm{E}$ and ${ }^{2} \mathrm{~T}_{1}$ for $d^{3}, O_{h}$ notation with $g / u$ omitted). These intraconfigurational states possess a nearly unchanged electron distribution compared to the ground state, e.g., $\left(t_{2 \mathrm{~g}}\right)^{3}$ for the ${ }^{4} \mathrm{~A}_{2}$ state in $d^{3}$. This has two consequences: their energy is essentially ligand field-independent (Eqs. 1 and 2) and they show a geometry close to the ground-state geometry (nested states, ${ }^{2} \mathrm{E} /{ }^{2} \mathrm{~T}_{1}$ states in Fig. 2, weak coupling limit). In contrast, the occupation of orbitals of different energies in interconfigurational states like the ${ }^{4} \mathrm{~T}_{2}$ and ${ }^{4} \mathrm{~T}_{1}$ states in $d^{3}$ ions (Eqs. 3 and 4) or charge-transfer states results in horizontally shifted and broad potential wells $\left({ }^{4} \mathrm{~T}_{2}\right.$ state in Fig. 2, strong coupling limit). Consequently, this shift can lead to enhanced non-radiative relaxation to the ground state and broader emission bands, while spin-flip emission is typically very sharp [56].

In general, the transition energies from the ground state to excited MC states with the highest possible multiplicity like ${ }^{4} \mathrm{~T}_{2}$ and ${ }^{4} \mathrm{~T}_{1}$ in the $d^{3}$ electron configuration can be described with $\Delta_{\mathrm{O}}$ and the Racah parameter $B$ (Eqs. 3 and 4), while those with lower multiplicity like the ${ }^{2} \mathrm{E}$ and ${ }^{2} \mathrm{~T}_{1}$ states also require the Racah parameter $C$ (Eqs. 1 and 2) [50, 57]. It should be noted that Eqs. 1 and 2 were generated by assuming $C / B=4$ for the calculation of the configurational interaction terms as multiples of $B^{2} / \Delta_{\mathrm{O}}[50,57]$. For exact solutions, the reader is referred to Ref. [58].

$$
E\left({ }^{2} E\right)-E\left({ }^{4} A_{2}\right) \approx 9 B+3 C-50\left(\frac{B^{2}}{\Delta_{O}}\right)
$$

$E\left({ }^{2} T_{1}\right)-E\left({ }^{4} A_{2}\right) \approx 9 B+3 C-24\left(\frac{B^{2}}{\Delta_{O}}\right)$

$E\left({ }^{4} T_{2}\right)-E\left({ }^{4} A_{2}\right)=\Delta_{O}$ 
Fig. 1 Tanabe-Sugano (TS) diagrams of $\mathbf{a} d^{2}, \mathbf{b} d^{3}, \mathbf{c} d^{4}$ and $\mathbf{d} d^{8}$ transition metal ions in octahedral fields with $C / B=4[50,52,53,58]$. Important crossing points are marked with circles. Exemplary intraconfigurational microstates relevant for spin-flip emission and detrimental interconfigurational microstates were empirically derived from complete active space self-consistent field (CASSCF) calculations of perfectly octahedral model complexes $\left[\mathrm{MH}_{6}\right]^{n-}\left(\mathrm{M}=\mathrm{V}^{\mathrm{III}}\right.$, $\mathrm{Cr}^{\mathrm{III}}, \mathrm{Mo}^{\mathrm{II}}$, $\mathrm{Ni}^{\mathrm{II}}$; see Supporting Information for computational details). Dotted lines in the microstates indicate strong mixing

$$
\begin{aligned}
E\left({ }^{4} T_{1}\right)-E\left({ }^{4} A_{2}\right) & = \\
& 1.5 \Delta_{O}+7.5 B-0.5 \sqrt{225 B^{2}+\left(\Delta_{O}\right)^{2}-18 \Delta_{O} B} .
\end{aligned}
$$

As discussed in more detail below, tuning of the excited MC state energies via the ligand field strength $\Delta_{\mathrm{O}}$ is well understood and heavily exploited in the design of spin-flip emitters (see Sect. 3.1). Yet designing systems with tailored Racah parameters $B$ and $C$ and thus spin-flip phosphorescence energy is difficult (see Sect. 4). Similarly, to achieve MLCT emission from $\mathrm{Fe}^{\mathrm{II}}$ complexes, many studies focused on imposing a high ligand field splitting $\Delta_{\mathrm{O}}$ to raise the MC states as potential deactivating states above the MLCT states [10, 19, 59]. Recently, a new design strategy featured increased metal-ligand covalency leading to decreased interelectronic repulsion, which counteracted the lower $\Delta_{\mathrm{O}}$ and yielded an excited state lifetime of $3 \mathrm{~ns}$ of a pseudo-octahedral iron(II) complex [21].

While ligand field theory and the derived TS diagrams are useful to identify certain trends, they come with some limitations: (1) The diagrams refer to a perfectly octahedral coordination geometry. (2) Spin-orbit coupling (SOC) and hence mixing of states with different multiplicity is neglected. (3) Both a lower symmetry of the ground state and SOC lead to splitting of degenerate ligand field terms. (4) TS diagrams reflect the state energies at the ground-state geometry (Franck-Condon state) and neglect excited state energy lowering by excited state distortion. (5) CT states are not considered but can sometimes play an important role in the photodynamics of spin-flip emitters as discussed below.

\section{Prerequisites for strong spin-flip emission}

In this section, parameters influencing spin-flip emission and excited state relaxation pathways are discussed using $d^{3}-\mathrm{Cr}^{\mathrm{III}}$ complexes as instructive and well-explored examples.

\subsection{Strong ligand field splitting to avoid relaxation via MC states}

Spin-flip phosphorescence is favored when the spin-flip states are the lowest energy excited states, even though it is a spin-forbidden process. As discussed in the previous
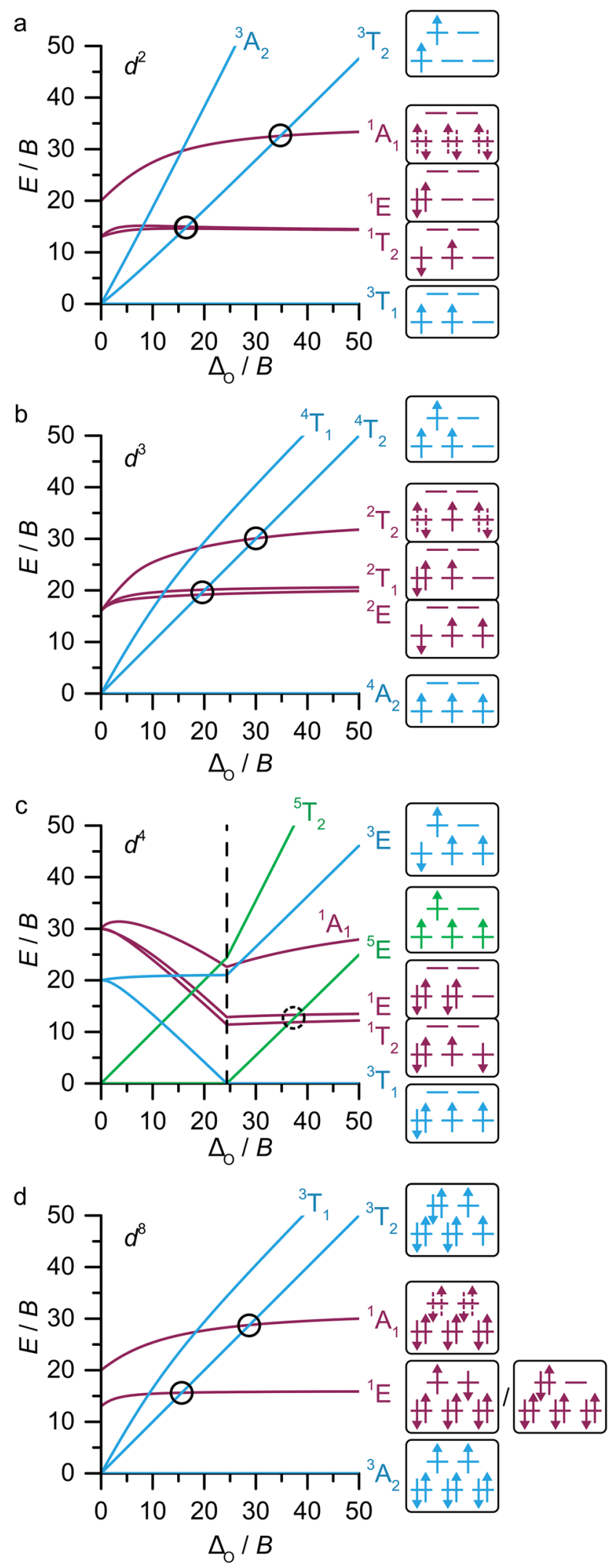


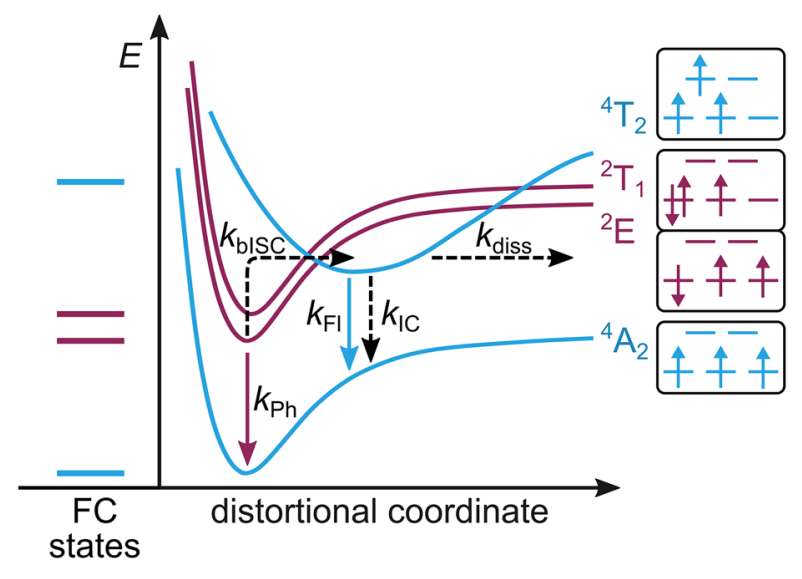

Fig. 2 Schematic potential energy diagram of an octahedral $d^{3}$ transition metal complex with $\Delta_{\mathrm{O}}$ beyond the first quartet-doublet crossing point ${ }^{4} \mathrm{~T}_{2}-{ }^{2} \mathrm{E}$ in the TS diagram (Fig. 1b) and energies of the FranckCondon (FC) states. Radiative (phosphorescence $k_{\mathrm{Ph}}$ and fluorescence $k_{\mathrm{Fl}}$ ) and non-radiative decay pathways (back-intersystem crossing $k_{\mathrm{bISC}}$, dissociation $k_{\mathrm{diss}}$ and internal conversion $k_{\mathrm{IC}}$ ) and exemplary microstates of the relevant states are depicted [56]

section, this energy level ordering requires a high ligand field splitting $\Delta_{\mathrm{O}}$. In case of $\mathrm{Cr}^{\mathrm{III}}$ this necessitates strongly $\sigma$-donating ligands, since the $3 d$ orbitals possess a rather contracted radial distribution function (primogenic effect) $[60,61]$. This limits overlap with ligand orbitals, which is referred to as a low intrinsic ligand field strength [62]. For $d^{3}$ ions in an octahedral ligand field, the ${ }^{4} \mathrm{~T}_{2}$ state rises above the ${ }^{2} \mathrm{E}$ and ${ }^{2} \mathrm{~T}_{1}$ states with increasing $\Delta_{\mathrm{O}}$ (Fig. 1b). For $\mathrm{Cr}^{\mathrm{III}}$ ions this could not be fully achieved using traditional ligands like en or tpy with their homoleptic complexes showing only weak spin-flip phosphorescence $\left(\left[\mathrm{Cr}^{\mathrm{III}}(\mathrm{en})_{3}\right]^{3+} \mathbf{C r}^{3+}: \Phi=0.0062 \%,\left[\mathrm{Cr}^{\mathrm{III}}(\text { tpy })_{2}\right]^{3+} \mathbf{C r 2}^{\mathbf{3 +}}\right.$ : $\Phi<0.001 \%$; en $=1,2$-ethylenediamine, tpy $=2,2^{\prime} ; 6^{\prime}, 2^{\prime \prime}$-terpyridine; Scheme 1, Table 1) [63, 64]. These ligands form five-membered chelate rings with the metal ion which leads to substantial deviation of $7^{\circ}-11^{\circ}$ from perfectly octahedral geometry $\left(\angle(\mathrm{N}-\mathrm{Cr}-\mathrm{N})=90^{\circ}\right.$ or $\left.180^{\circ}\right)$ and a weak $\sigma$-orbital overlap [56, 65]. As a result, $\mathbf{C r} 1^{3+}$ and $\mathbf{C r} 2^{3+}$ only reach the first ${ }^{4} \mathrm{~T}_{2}-{ }^{2} \mathrm{E}$ crossing point in the TS diagram (Fig. 1b). Weakly luminescent $\mathrm{Cr}^{\mathrm{III}}(\mathrm{acac})_{3} \mathbf{C r} \mathbf{3}$ serves to discuss the effects of a small $\Delta_{\mathrm{O}}\left(\mathrm{acac}^{-}=\right.$acetylacetonato, Scheme 1 , Table 1).

For Cr3, quantum chemical calculations placed the ${ }^{4} \mathrm{~T}_{2}$ state close to the ${ }^{2} \mathrm{~T}_{1}$ state in the $\mathrm{FC}$ region, i.e., close to the first quartet-doublet crossing point ${ }^{4} \mathrm{~T}_{2}-{ }^{2} \mathrm{E}$ in the TS diagram (Fig. 1b), leading to a high density of states. Furthermore, large SOC constants of $100-170 \mathrm{~cm}^{-1}$ were calculated between the ${ }^{4} T_{2}$ and ${ }^{2} T_{1}$ states [66]. This is in agreement with El Sayed' rule stating that SOC between two states is large when a change in spin multiplicity is accompanied by a change in orbital angular momentum. The orbital character changes during ISC from the ${ }^{4} \mathrm{~T}_{2}$ state with $\left(t_{2 \mathrm{~g}}\right)^{2}\left(e_{\mathrm{g}}{ }^{*}\right)^{1}$ to the
${ }^{2} \mathrm{~T}_{1}$ state with $\left(t_{2 \mathrm{~g}}\right)^{3}\left(e_{\mathrm{g}}{ }^{*}\right)^{0}$ electron configuration [67]. Consequently, wavepacket simulations predicted an ultrafast ${ }^{4} \mathrm{~T}_{2} \rightarrow$ ${ }^{2} \mathrm{~T}_{1}$ ISC for $\mathbf{C r} 3$ [66]. In fact, fs-transient absorption studies with ligand field excitation revealed ISC with $\tau_{\text {ISC }}<100 \mathrm{fs}$, that competes with vibrational cooling (VC) in the ${ }^{4} \mathrm{~T}_{2}$ state. An experimental time constant of $\tau=1.1(1)$ ps was assigned to $\mathrm{VC}$ in the doublet states state [68].

Apart from facilitating ISC, a small energy separation between ${ }^{4} \mathrm{~T}_{2}$ and ${ }^{2} \mathrm{E} /{ }^{2} \mathrm{~T}_{1}$ states enables back-intersystem crossing (bISC) from the doublet manifold to the ${ }^{4} \mathrm{~T}_{2}$ state [69]. This results in low phosphorescence quantum yields and a low photostability of the complexes, since the ${ }^{4} \mathrm{~T}_{2}$ state with its $\left(t_{2 \mathrm{~g}}\right)^{2}\left(e_{\mathrm{g}}{ }^{*}\right)^{1}$ electronic configuration is Jahn-Teller distorted and potentially dissociative $[25,70,71]$.

A conceptual breakthrough was achieved with $\left[\mathrm{Cr}^{\mathrm{III}}(\mathrm{ddpd})_{2}\right]^{3+} \mathbf{C r 4}^{\mathbf{3 +}}\left(\mathrm{ddpd}=N, N^{\prime}\right.$-dimethyl- $N, N^{\prime}$-dipyridin-2-ylpyridine-2,6-diamine, Scheme 1, Table 1) showing a very strong and long-lived dual emission in the near-infrared (NIR, 738 and $775 \mathrm{~nm}, \Phi=11 \%, \tau=899 \mu \mathrm{s}$ ) after ${ }^{4} \mathrm{~A}_{2} \rightarrow$ ${ }^{4} \mathrm{LMCT}$ or ${ }^{4} \mathrm{~A}_{2} \rightarrow{ }^{4} \mathrm{~T}_{2}$ excitation at $435 \mathrm{~nm}$ [25]. In $\mathbf{C r} 4^{3+}$, the tridentate tpy-like ligand was formally expanded by $\mathrm{NMe}$ bridges leading to six-membered chelate rings with almost perfectly octahedral coordination with respect to the $\left[\mathrm{CrN}_{6}\right]$ coordination polyhedron. The resulting very strong ligand field raised the ${ }^{4} \mathrm{~T}_{2}$ state to the level of the ${ }^{2} \mathrm{~T}_{2}$ state, close to the second quartet-doublet crossing point ${ }^{4} \mathrm{~T}_{2}-{ }^{2} \mathrm{~T}_{2}$ in the TS diagram (Fig. 1b) [72]. At this crossing point with roughly degenerate ${ }^{4} \mathrm{~T}_{2}$ and ${ }^{2} \mathrm{~T}_{2}$ states at the FC geometry, ISC from the ${ }^{4} \mathrm{~T}_{2}$ state to the ${ }^{2} \mathrm{~T}_{2}$ state might be facilitated by a high density of doublet states [67] as well as a large SOC constant of $42 \mathrm{~cm}^{-1}$ between the ${ }^{4} \mathrm{~T}_{2}(1)$ and ${ }^{2} \mathrm{~T}_{2}(2)$ states as calculated using multi-reference methods [73]. Furthermore, the internal conversion (IC) ${ }^{2} \mathrm{~T}_{2} \rightarrow{ }^{2} \mathrm{E} /{ }^{2} \mathrm{~T}_{1}$ might be faster than the bISC process ${ }^{2} \mathrm{~T}_{2} \rightarrow{ }^{4} \mathrm{~T}_{2}$ resulting in efficient population of the emissive ${ }^{2} \mathrm{E} /{ }^{2} \mathrm{~T}_{1}$ states. In fact, after excitation to the ${ }^{4} \mathrm{~T}_{2}$ states, fast ISC and vibrational cooling (VC) populate the thermalized doublet states ${ }^{2} \mathrm{E} /{ }^{2} \mathrm{~T}_{1}$ within $\tau=3.5 \mathrm{ps}$ [74]. The significant ${ }^{2} \mathrm{E}-{ }^{4} \mathrm{~T}_{2}$ energy gap of the relaxed excited states of $7100 \mathrm{~cm}^{-1}$ effectively prevents bISC and enables radiative relaxation $\left(k_{\mathrm{Ph}}\right)$ to the ground state [25]. $\mathbf{C r 4}^{\mathbf{3 +}}$ is called 'Molecular Ruby' because of its optical properties reminiscent of the gemstone ruby $\left(\mathrm{Al}_{2} \mathrm{O}_{3}: \mathrm{Cr}^{3+}\right)$ [25]. The nickname was recently adapted for the emerging class of strongly luminescent $\mathrm{Cr}^{\mathrm{III}}$ complexes $[25,28,73]$.

\subsection{Relaxation via CT states}

Aside from interconfigurational MC states, CT states need to be considered as relaxation pathways in spin-flip emitters as well. Complexes of $\mathrm{V}^{\mathrm{II}}, \mathrm{Cr}^{\mathrm{III}}$ and $\mathrm{Mn}^{\mathrm{IV}}$ all feature a $d^{3}$ electronic configuration. However, due to the different oxidation state of the central metal ions, low-energy MLCT and LMCT states can arise in $\mathrm{V}^{\mathrm{II}}$ and $\mathrm{Mn}^{\mathrm{IV}}$ complexes, 
<smiles></smiles>

$\mathrm{Cr}^{3+}$

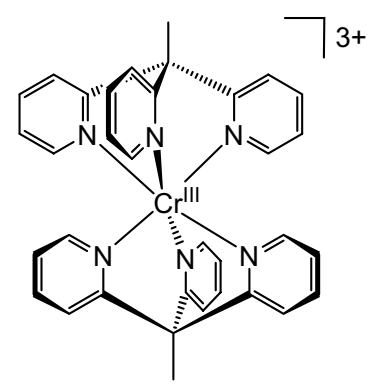
$\mathrm{Cr}^{3+}$

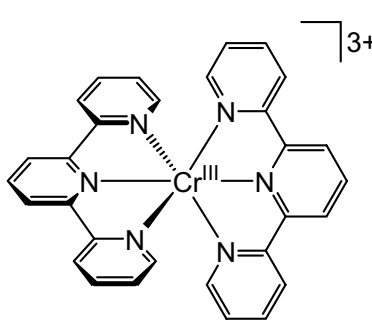

$\mathrm{Cr}^{3+}$

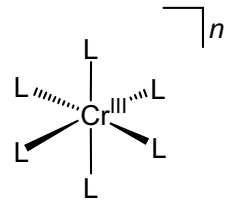

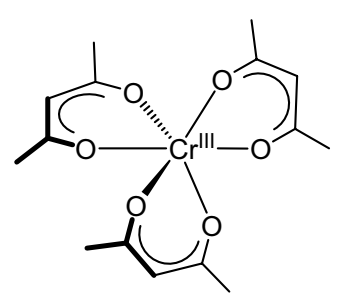

Cr3

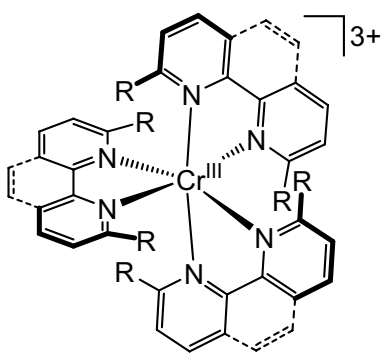

$\mathrm{Cr}^{3+} \mathrm{R}=\mathrm{H}$, without dotted bonds

$\mathrm{Cr}^{3+} \mathrm{R}=\mathrm{H}$, with dotted bonds

$\mathrm{Cr}^{3}{ }^{3+} \mathrm{R}=\mathrm{Ph}$, with dotted bonds

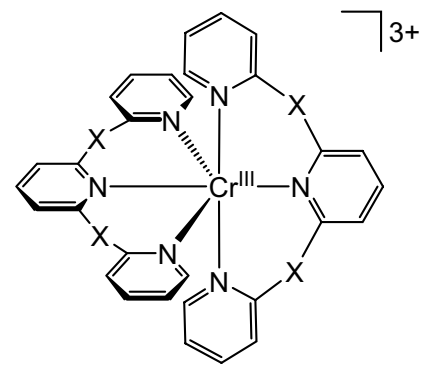

$\mathrm{Cr}^{3+} \quad(X=\mathrm{NMe})$

$\mathrm{Cr}^{3+}\left(\mathrm{X}=\mathrm{CH}_{2}\right)$

$\mathrm{Cr}^{3+}(\mathrm{X}=\mathrm{NH})$

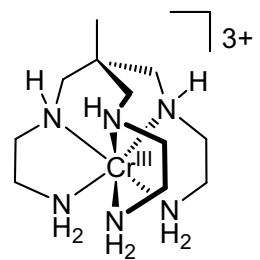

$\mathrm{Cr} 10^{3+}$

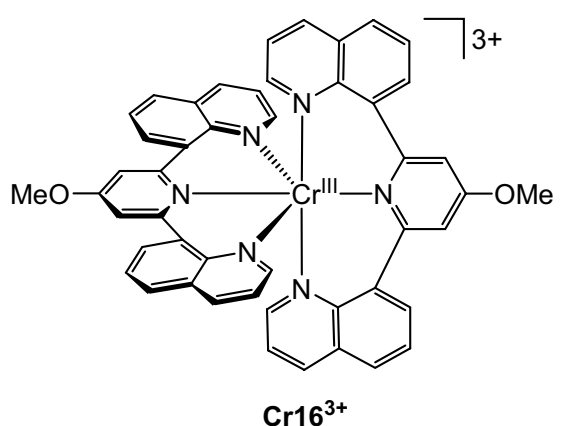

Scheme $1 \mathrm{Cr}^{\mathrm{III}}$ complexes discussed in this review

respectively (see below for more details) [42, 89]. For $\mathrm{Cr}^{\mathrm{III}}$, CT states are of relatively high energy (e.g., the superposition of ${ }^{4} \mathrm{LMCT}$ and ${ }^{4} \mathrm{~T}_{2}$ absorption bands at $435 \mathrm{~nm}$ in $\mathbf{C r} 4^{3+}$ [25]) or they can be avoided altogether in the region of the ${ }^{4} \mathrm{~T}_{2}$ absorption as demonstrated with $\left[\mathrm{Cr}^{\mathrm{III}}(\mathrm{bpmp})_{2}\right]^{3+} \mathbf{C r} 5^{3+}$ and $\left[\mathrm{Cr}^{\mathrm{III}}(\text { tpe })_{2}\right]^{3+} \mathbf{C r 6}^{\mathbf{3 +}}$ (bpmp = 2,6-bis(2-pyridylmethyl) pyridine, tpe $=1,1,1$-tris(pyrid-2-yl)ethane; Scheme 1, Table 1) [73, 78]. Since low-energy CT states or their admixture to spin-flip states as in $\left[\mathrm{V}^{\mathrm{II}}(\mathrm{bpy})_{3}\right]^{2+}\left(\mathrm{bpy}=2,2^{\prime}\right.$-bipyridine) may act as relaxation pathways for long-lived spinflip states [89], the relative energies of ligand and central metal orbitals need to be taken into account when designing ligands for spin-flip emitters.

\subsection{Symmetry}

The intraconfigurational spin-flip transition is governed by two selection rules: it is a spin-forbidden process and additionally Laporte's rule applies, which forbids electronic transitions between wave functions of the same parity [90]. In centrosymmetric $\left[\mathrm{Cr}^{\mathrm{III}}(\mathrm{CN})_{6}\right]^{3-} \mathbf{C r} 7^{\mathbf{3 -}}$ the combination of Laporte and spin selection rules leads to very long-lived emission ( $\tau=3.45 \mathrm{~ms}$ ) in frozen solution at $77 \mathrm{~K}$ with a low radiative rate constant of $k_{\mathrm{Ph}}=25 \mathrm{~s}^{-1}$ (Scheme 1, Table 1) [80, 91]. Irradiation of $\mathbf{C r} \mathbf{7}^{\mathbf{3 -}}$ in aqueous solution can lead to ligand substitution [70]. The tripodal chelating ligand tpe imposes inversion symmetry on $\left[\mathrm{Cr}^{\mathrm{III}}(\mathrm{tpe})_{2}\right]^{3+} \mathbf{C r 6}^{\mathbf{3 +}}$ (Scheme 1, Table 1) resulting in a record lifetime of $4.5 \mathrm{~ms}$ in $\mathrm{DClO}_{4} / \mathrm{D}_{2} \mathrm{O}$ at room temperature while retaining a high phosphorescence quantum yield of $8.2 \%$ [78]. Due to the 
Table 1 Optical properties of luminescent $\mathrm{Cr}^{\mathrm{III}}$ complexes with phosphorescence emission maximum $\lambda_{\text {max }}$, luminescence lifetime $\tau$ and quantum yield $\Phi$ measured in the absence of oxygen if not stated otherwise

\begin{tabular}{|c|c|c|c|c|c|c|}
\hline Number & Complex & Medium & $\lambda_{\max } / \mathrm{nm}$ & $\tau / \mu \mathrm{s}$ & $\Phi / \%$ & References \\
\hline $\mathrm{Cr}^{3+}$ & {$\left[\mathrm{Cr}^{\mathrm{III}}(\mathrm{en})_{3}\right]^{3+}$} & $\mathrm{H}_{2} \mathrm{O}$ & 670 & $1.85^{a}$ & 0.0062 & {$[63,75]$} \\
\hline $\mathrm{Cr} 2^{3+}$ & {$\left[\mathrm{Cr}^{\mathrm{III}}(\text { tpy })_{2}\right]^{3+}$} & $\mathrm{MeCN}$ & 770 & 0.14 & $<0.001^{\mathrm{b}}$ & {$[64,76]$} \\
\hline Cr3 & $\mathrm{Cr}^{\mathrm{III}}(\mathrm{acac})_{3}$ & $\mathrm{MeOH} / \mathrm{EtOH}(77 \mathrm{~K})$ & 785 & 431 & - & [77] \\
\hline \multirow[t]{2}{*}{$\mathrm{Cr}^{3+}$} & \multirow[t]{2}{*}[\mathrm{Cr}^{\mathrm{III}}(\mathrm{ddpd})]{$\left._{2}\right]^{3+}$} & $\mathrm{H}_{2} \mathrm{O}$ & 738,775 & 889 & 11.0 & {$[25]$} \\
\hline & & $\mathrm{D}_{2} \mathrm{O}$ & 738,775 & 1164 & 14.2 & [79] \\
\hline$\left[\mathrm{D}_{18}\right]-\mathbf{C r} 4^{3+}$ & 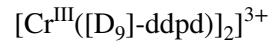 & $\mathrm{CD}_{3} \mathrm{CN}$ & 738,775 & 2300 & 30.1 & [79] \\
\hline $\mathrm{Cr}^{3+}$ & {$\left[\mathrm{Cr} \text { III }(\mathrm{bpmp})_{2}\right]^{3+}$} & $\mathrm{D}_{2} \mathrm{O} / \mathrm{DClO}_{4}$ & 709 & 1800 & 20.0 & [73] \\
\hline$\left[\mathrm{D}_{4}\right]-\mathbf{C r}^{3+}$ & {$\left[\mathrm{Cr}^{\mathrm{III}}\left(\left[\mathrm{D}_{2}\right]-\mathrm{bpmp}\right)_{2}\right]^{3+}$} & $\mathrm{D}_{2} \mathrm{O} / \mathrm{DClO}_{4}$ & 709 & 2500 & 24.6 & [73] \\
\hline \multirow[t]{3}{*}{$\mathrm{Cr}^{3+}$} & \multirow[t]{3}{*}[\mathrm{Cr}^{\mathrm{III}}(\mathrm{tpe})_{2}]{$^{3+}$} & $\mathrm{H}_{2} \mathrm{O}$ & 748 & - & 3.2 & {$[78]$} \\
\hline & & $\mathrm{H}_{2} \mathrm{O} / \mathrm{HClO}_{4}$ & 748 & 2800 & 5.4 & [78] \\
\hline & & $\mathrm{D}_{2} \mathrm{O} / \mathrm{DClO}_{4}$ & 748 & 4500 & 8.2 & {$[78]$} \\
\hline \multirow[t]{2}{*}{$\mathrm{Cr}^{3-}$} & \multirow[t]{2}{*}[\mathrm{Cr}^{\mathrm{III}}(\mathrm{CN})_{6}]{$^{3-}$} & $\mathrm{H}_{2} \mathrm{O}$ & 820 & $0.14^{\mathrm{a}}$ & $<5 \bullet 10^{-6}$ & [63] \\
\hline & & Rigid glass $^{\mathrm{c}}(77 \mathrm{~K})$ & - & $3450^{c}$ & - & [80] \\
\hline \multirow[t]{2}{*}{$\mathrm{Cr8}^{3+}$} & \multirow[t]{2}{*}[\mathrm{Cr}^{\mathrm{III}}(\mathrm{bpy})_{3}]{$^{3+}$} & $\mathrm{H}_{2} \mathrm{O}$ & 727 & 74 & $0.089^{\mathrm{a}}$ & {$[63,81]$} \\
\hline & & $1 \mathrm{M} \mathrm{HCl}_{(\mathrm{aq})}$ & 729 & 69 & 0.25 & {$[82]$} \\
\hline \multirow[t]{2}{*}{$\mathrm{Cr}^{3+}$} & \multirow[t]{2}{*}[\mathrm{Cr}^{\mathrm{III}}(\text{phen})_{3}]{$^{3+}$} & $\mathrm{H}_{2} \mathrm{O}$ & 689,726 & 356 & 0.15 & {$[27,81,83]$} \\
\hline & & $1 \mathrm{M} \mathrm{HCl}_{(\mathrm{aq})}$ & 730 & 304 & 1.2 & {$[82]$} \\
\hline $\mathrm{Cr}_{10}^{3+}$ & {$\left[\mathrm{Cr}^{\mathrm{III}}(\text { sen })\right]^{3+}$} & $\mathrm{H}_{2} \mathrm{O} / \mathrm{DMSO}(77 \mathrm{~K})$ & 675 & $0.0001^{\mathrm{d}}$ & - & [84] \\
\hline $\mathrm{Cr}_{11}^{+}$ & {$\left[\mathrm{Cr}^{\mathrm{III}}\left(\mathrm{H}_{2} \text { tpda }\right)_{2}\right]^{3+}$} & $\mathrm{MeCN}$ & 738,782 & 770 & 8.8 & [85] \\
\hline \multirow[t]{3}{*}{ Cr12 ${ }^{3+}$} & \multirow[t]{3}{*}[\mathrm{Cr}^{\mathrm{III}}(\mathrm{Ph}_{2}\text{phen})_{3}]{$^{3+}$} & $1 \mathrm{M} \mathrm{HCl}_{(\mathrm{aq})}$ & 744 & 304 & 3.0 & {$[82]$} \\
\hline & & $\mathrm{CH}_{3} \mathrm{NO}_{2}$ & 750 & 441 & - & {$[86]$} \\
\hline & & $\mathrm{CH}_{3} \mathrm{NO}_{2}$ & 750 & $13^{\mathrm{a}}$ & - & [86] \\
\hline $\mathrm{Cr}^{+} 3^{+}$ & {$\left[\mathrm{Cr}^{\mathrm{III}}(\mathrm{dpc})_{2}\right]^{+}$} & $\mathrm{MeCN}(77 \mathrm{~K})$ & 1067 & $2.0^{\mathrm{e}}$ & $<8.9 \times 10^{-4}$ & [87] \\
\hline \multirow[t]{2}{*}{ Cr14 } & \multirow[t]{2}{*}{$\mathrm{Cr}^{\mathrm{III}}(\mathrm{ppy})_{3}$} & 2-MeTHF & 910 & 9.5 & 0.03 & {$[88]$} \\
\hline & & $\begin{array}{l}\text { 2-MeTHF } \\
(77 \mathrm{~K})\end{array}$ & 890 & 48 & - & [88] \\
\hline $\mathrm{Cr}_{15}{ }^{3+}$ & {$\left[\mathrm{Cr}^{\mathrm{III}}\left(\mathrm{NH}_{3}\right)_{6}\right]^{3+}$} & $\mathrm{H}_{2} \mathrm{O}$ & 667 & $2.2^{\mathrm{a}}$ & $0.0055^{\mathrm{a}}$ & {$[63]$} \\
\hline $\mathrm{Cr}_{16}{ }^{3+}$ & {$\left[\mathrm{Cr}^{\mathrm{III}}\left(\mathrm{dqp}^{\mathrm{OMe}}\right)_{2}\right]^{3+}$} & $\mathrm{H}_{2} \mathrm{O}$ & 756 & 1350 & 17.0 & [29] \\
\hline
\end{tabular}

${ }^{\mathrm{a}}$ Measured in aerated solution

${ }^{\mathrm{b}}$ Measured in water

${ }^{c}$ Measured either in $\mathrm{MeOH} / \mathrm{H}_{2} \mathrm{O} /$ ethylene glycol $(2: 1: 1)$ or $\mathrm{MeOH} / \mathrm{EtOH}(1: 1)$

${ }^{\mathrm{d}}$ Extrapolated from temperature dependent lifetime measurements in glassy media at low temperatures

${ }^{\mathrm{e}}$ Amplitude averaged lifetime of biexponential fit with $\tau_{1}=1.4 \mu \mathrm{s}(88 \%)$ and $\tau_{2}=6.3 \mu \mathrm{s}(12 \%)$ inversion symmetry, the extinction coefficient for the ${ }^{4} \mathrm{~A}_{2} \rightarrow$ ${ }^{4} \mathrm{~T}_{2}$ transition is very low $\left(\varepsilon=30 \mathrm{M}^{-1} \mathrm{~cm}^{-1}\right.$, Laporte forbidden), as is the radiative rate constant of the NIR phosphorescence ( $k_{\mathrm{Ph}}=18 \mathrm{~s}^{-1}$, Laporte and spin-forbidden) [78]. On the other hand, the coordinating nitrogen atoms in the ddpd complex $\mathbf{C r} 4^{3+}$ are arranged around a center of symmetry $\left[\mathrm{CrN}_{6}\right]$ but the overall symmetry is lower due to the orientation of the pyridine rings (point group $D_{2}$ ). This allows for a faster radiative decay $k_{\mathrm{Ph}}$ and thus leads to a shorter lifetime of $899 \mu$ s [25]. Lower symmetry also lifts the degeneracy of the $\mathrm{E}$ and $\mathrm{T}$ states, which influences band shape and transition energy of the spin-flip luminescence [27, 72]. The radiative rate $k_{\mathrm{Ph}}$ increases by removing the center of inversion from $\mathbf{C r 6}^{3+}$ to $\mathbf{C r}^{3+}$ lifting Laporte's rule [78].

In addition, symmetry can also influence non-radiative relaxation pathways opened by geometric distortions. In
tris(bidentate)chromium(III) complexes with $D_{3}$ or $D_{3 h}$ symmetry like $\left[\mathrm{Cr}^{\mathrm{III}}(\mathrm{bpy})_{3}\right]^{3+} \mathbf{C r 8}^{3+}$, a trigonal distortion of the coordination sphere in the long-lived excited states can lead to surface crossing of the excited doublet states with the ground state $[84,92]$. This relaxation pathway limits phosphorescence quantum yields with $0.15 \%$ obtained for $\left[\mathrm{Cr}^{\mathrm{III}}\left(\text { phen) }{ }_{3}\right]^{3+} \mathbf{C r} 9^{3+}\right.$ in water (phen $=1,10$-phenanthroline, Scheme 1, Table 1) [93]. In $1 \mathrm{M}$ aqueous $\mathrm{HCl}$, the quantum yield is reported as $1.2 \%$ with $\tau=304 \mu \mathrm{s}$ [82]. The pair $\left[\mathrm{Cr}^{\mathrm{III}}(\mathrm{en})_{3}\right]^{3+} \mathbf{C r} \mathbf{1}^{3+}$ and the trigonally distorted cage complex $\left[\mathrm{Cr}^{\mathrm{III}}(\mathrm{sen})\right]^{3+} \mathbf{C r 1 0}^{3+}$ displays an even stronger effect with a reduction of the excited state lifetimes from $\tau=1.2-1.85 \mu$ s to $\tau=0.0001 \mu$ s ( $\operatorname{sen}=4,4$, 4"-ethylidenetris(3-azabutane-1-amine); Scheme 1, Table 1) [63, 75, 84]. The hexadentate ligand in $\mathbf{C r 1 0}{ }^{3+}$ apparently 
enables efficient non-radiative relaxation pathways due to trigonal distortion which are unavailable in $\mathbf{C r} 1^{3+}$.

\subsection{Multi-phonon relaxation}

The low energy of the doublet states in $\mathrm{Cr}^{\mathrm{III}}$-based spinflip emitters (typically $12,800-15,000 \mathrm{~cm}^{-1}$ ) [94] enables non-radiative decay via energy transfer to vibrational overtones of nearby $\mathrm{X}-\mathrm{H}$ oscillators $(\mathrm{X}=\mathrm{C}, \mathrm{N}, \mathrm{O})$ [95]. This constitutes a major obstacle for efficient molecular emitters with organic ligands but not for oxidic materials such as ruby. By almost quantitative deuteration of the ligand in $\left[\mathrm{Cr}{ }^{\mathrm{III}}\left(\left[\mathrm{D}_{9}\right]-\mathrm{ddpd}\right)_{2}\right]^{3+}\left[\mathrm{D}_{18}\right]-\mathbf{C r} 4^{3+}$, a record quantum yield of $30 \%$ could be achieved (Table 1) [79]. This effect is due to the lower energy of the C-D fundamental mode $\left(\approx 2200 \mathrm{~cm}^{-1}\right)$ and its overtones compared to $\mathrm{C}-\mathrm{H}$ vibrations $\left(\approx 3000 \mathrm{~cm}^{-1}\right)$. To deactivate the excited doublet state in the deuterated Molecular Ruby, energy transfer to a higher vibrational overtone $\left(v^{6}\right)$ with a lower $v_{0} \rightarrow v_{6}$ extinction coefficient is necessary than with $\mathrm{C}-\mathrm{H}$ oscillators $\left(v^{4}+v^{5}\right)$. In case of acetonitrile, solvent deuteration had a negligible effect, whereas $\tau$ and $\Phi$ of $\mathbf{C r} 4^{3+}$ significantly increased from 898 to $1164 \mu$ s and from 11.0 to $14.2 \%$, respectively, in $\mathrm{D}_{2} \mathrm{O}$ instead of $\mathrm{H}_{2} \mathrm{O}$ [79].

In $\left[\mathrm{Cr}^{\mathrm{III}}(\mathrm{bpmp})_{2}\right]^{3+} \mathbf{C r}^{\mathbf{3 +}}$ (Scheme 1, Table 1) with an emission maximum at $709 \mathrm{~nm}$, selective $\alpha$-deuteration of the ligand yielding $\left[\mathrm{Cr}^{\mathrm{III}}\left(\left[\mathrm{D}_{2}\right]-\text { bpmp }\right)_{2}\right]^{3+}\left[\mathrm{D}_{4}\right]-\mathbf{C r} 5^{3+}$ increased the quantum yield and lifetime from 20 to $25 \%$ and from 1.8 to $2.5 \mathrm{~ms}$, respectively (Table 1) [73]. Clearly, the $\mathrm{C}-\mathrm{H}$ oscillators closest to the $\mathrm{Cr}^{\mathrm{III}}$ center $(d \approx 3.0 \AA)$ affect the multiphonon energy transfer the most, while the more distant oscillators play only a minor role due to the $d^{-6}$ dependence of the corresponding rate constant [95].

Due to the higher energy of the $\mathrm{N}-\mathrm{H}$ vibrations $\left(3400 \mathrm{~cm}^{-1}\right)$ and their different anharmonicity, multiphonon quenching is very pronounced in complexes like $\mathbf{C r} \mathbf{1}^{3+}$, $\mathrm{Cr10}^{3+}$ and $\left[\mathrm{Cr}^{\mathrm{III}}\left(\mathrm{H}_{2} \text { tpda }\right)_{2}\right]^{3+} \mathbf{C r 1 1}^{3+}\left(\mathrm{H}_{2}\right.$ tpda $=2,6-$ bis $(2-$ pyridylamino)pyridine; Scheme 1, Table 1). N-H/N-D exchange on the ligands increased quantum yields by factors of 2.2-25 [84, 85]. Again, multiphonon quenching strongly depends on the $\mathrm{Cr} \cdots(\mathrm{H}-\mathrm{X})$ distance $d$ with $\mathrm{N}-\mathrm{H}$ bonds in $\mathrm{Cr}^{3+}(d=2.48 \AA)$ being closer to the metal center than in $\mathrm{Cr11}^{3+}(d=3.1-3.8 \AA)[65,85]$.

\subsection{Solvent effects and counter ions}

Apart from deuteration effects discussed in the previous section, solvents, salt additives and the counter ions of the complexes can influence their photophysical properties.

In $\mathrm{Cr}^{3+}$, the phosphorescence quantum yield increased from $3.2 \%$ in $\mathrm{H}_{2} \mathrm{O}$ to $4.2 \%$ and $5.4 \%$ in $0.1 \mathrm{M} \mathrm{NaClO}_{4 \text { (aq) }}$ and $0.1 \mathrm{M} \mathrm{HClO}_{4(\mathrm{aq})}$, respectively. It was suggested that the perchlorate ions and the acid protect the charged complex from solvent molecules [78]. A similar effect was found for $\mathbf{C r 8}^{3+}$, which possesses increased lifetimes in the presence of salts (e.g., $\mathrm{NaClO}_{4}$ ) or acids in high concentrations $(>1 \mathrm{M})$. Here, the effect was rationalized by perchlorate ions filling the pockets between the bpy ligands in $\mathbf{C r 8}^{\mathbf{3 +}}$ leading to a rigidification and thus inhibiting distortional non-radiative relaxation (see Sect. 3.3). The influence of the solvent is much less pronounced for $\mathbf{C r} 9^{3+}\left(\tau_{\mathrm{HClO} 4} / \tau\right.$

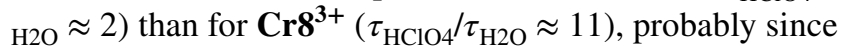
the phen ligand scaffold of $\mathbf{C r} 9^{3+}$ is more rigid on its own [96]. In general, relatively high phosphorescence quantum yields were found for tris(bidentate)chromium(III) polypyridyl complexes like $\mathbf{C r 8}^{3+}(\Phi=0.25 \%), \mathbf{C r}^{3+}(\Phi=1.2 \%)$ and $\left[\mathrm{Cr}^{\mathrm{III}}\left(\mathrm{Ph}_{2} \text { phen }\right)_{3}\right]^{3+} \mathbf{C r 1 2}^{3+}(\Phi=3.0 \%)$ in $1 \mathrm{M} \mathrm{HCl}_{(\mathrm{aq})}$ (Table 1, Scheme 1, $\mathrm{Ph}_{2}$ phen =4,7-diphenyl-1,10-phenanthroline) [82]. For $\mathbf{C r} 4^{2+}$, there was no effect on lifetime or quantum yield when using dilute $\mathrm{HClO}_{4(\mathrm{aq})}$ instead of water [25, 78].

Absorption/emission profiles and lifetimes of the bpy complex $\mathbf{C r 8}^{3+}$ remained unchanged in non-aqueous solvents like $\mathrm{MeOH}, \mathrm{MeCN}$, dimethylformamide (DMF) and ethylene glycol [96]. Yet, the ${ }^{4} \mathrm{~T}_{2} \rightarrow{ }^{2} \mathrm{E}$ ISC efficiency decreased in these solvents [97]. The emission lifetime of the cyanido complex $\mathbf{C r}^{\mathbf{7}^{3-}}$ correlated with solvent polarity [91], while the emission of the en complex $\mathbf{C r} \mathbf{1}^{3+}$ remained unaffected by the presence of $\mathrm{MgCl}_{2}$ up to 5.2 $\mathrm{M}$ [98].

$\mathbf{C r} 4\left[\mathrm{BF}_{4}\right]_{3}$ forms a contact ion pair with one $\left[\mathrm{BF}_{4}\right]^{-}$anion on average in acetonitrile solution, due to the high charge of the complex cation [99]. In fact, the counter ions of $\mathbf{C r 4}{ }^{\mathbf{3 +}}$ affect the phosphorescence lifetime and quantum yield [100]. In acetonitrile solution, $\Phi$ increased from 5.2\% with chloride anions to $13.6 \%$ with tetrakis(3,5-bis(trifluoromethyl)phenyl)borate $\left[\mathrm{BArF}_{24}\right]^{-}$. This change was attributed to reduced self-quenching when employing bulky anions. However, tetraphenylborate $\left[\mathrm{BPh}_{4}\right]^{-}$led to lower quantum yields of $9.2 \%$ likely due to the introduction of additional $\mathrm{C}-\mathrm{H}$ oscillators close to the $\mathrm{Cr}^{\mathrm{III}}$ center in contact ion pairs enabling multiphonon relaxation (see above). The counter ions affected lifetime and quantum yield in parallel. Thus, only the nonradiative relaxation pathways from the long-lived ${ }^{2} \mathrm{E} /{ }^{2} \mathrm{~T}_{1}$ states were influenced by the anions, while the fast evolution from initially excited ${ }^{4} \mathrm{~T}_{2}$ or ${ }^{4} \mathrm{LMCT}$ states to the doublet manifold (ISC, VC, IC) remained unaffected [100].

The Molecular Ruby $\mathbf{C r}^{\mathbf{3 +}}$ features acidic methylene bridges in the ligand due to the high positive charge. Deprotonation of $\mathbf{C r} \mathbf{5}^{\mathbf{3}}$ is reversible and forms a non-emissive complex. Therefore, addition of an acid is required to prevent deprotonation and to harvest the full luminescence potential of $\mathbf{C r} \mathbf{5}^{\mathbf{3}}$. The acidic protons also lead to a stronger interaction with solvent molecules and counter ions via hydrogen bonding. As a result, in deaerated $\mathrm{D}_{2} \mathrm{O} / \mathrm{DClO}_{4}$ quantum yields of $13.4,15.7$ and $20.0 \%$ were obtained for the $\left[\mathrm{BF}_{4}\right]^{-}$, $\left[\mathrm{ClO}_{4}\right]^{-}$and $\left[\mathrm{PF}_{6}\right]^{-}$salts of $\mathbf{C r 5}^{\mathbf{3 +}}$, respectively [73]. 


\section{Tuning emission energy in Molecular Rubies}

In charge-transfer emitters (LMCT, MLCT, LL'CT), it is straightforward to tune excited state energies for example by introducing electron-donating or -withdrawing substituents on the ligand [101-103]. Methods for tuning the energy of metal-centered spin-flip states are not so obvious [27, $73,88]$. Their energies depend on the nephelauxetic effect, i.e., the covalency of the metal-ligand bond and the Racah parameters $B$ and $C[50,57]$. The archetypical Molecular Ruby $\mathrm{Cr}^{3+}$ and many of its congeners emit in the NIR-I spectral region between 720 and $780 \mathrm{~nm}$ [25, 27, 28, 64, $78,85]$. By increasing the metal-ligand covalency with a monoanionic carbazolato ligand in $\left[\mathrm{Cr}^{\mathrm{III}}(\mathrm{dpc})_{2}\right]^{+} \mathbf{C r}^{+}$ $\left(\mathrm{dpc}^{-}=3,6\right.$-di-tert-butyl-1,8-di(pyridine-2-yl)-carbazolato; Scheme 1, Table 1), the emission band shifted to the NIRII peaking at $1067 \mathrm{~nm}$ in frozen solution at $77 \mathrm{~K}$ [87]. The high covalency of the bond between $\mathrm{Cr}^{\mathrm{III}}$ and the anionic ligand $\left(B=470-550 \mathrm{~cm}^{-1}\right)$ decreased the repulsion of the $d$ electrons and led to an unprecedentedly low energy of the spin-flip emission. However, an admixed ${ }^{2}$ LMCT state in $\mathrm{Cr}^{-}{ }^{+}$increased the excited state distortion which facilitated non-radiative relaxation to the ground state leading to a low quantum yield of $\Phi<0.00089 \%$ and a relatively short lifetime of $\tau_{1}=1.4 \mu \mathrm{s}(88 \%)$ and $\tau_{2}=6.3 \mu \mathrm{s}(12 \%)$ at $77 \mathrm{~K}$. In addition, it is plausible to assume that multi-phonon relaxation of the excited state (see above) plays a significant role because the NIR-II emission band might have a large spectral overlap with the absorption bands of the ligands' aromatic C-H overtones [87]. Similarly a low-energy phosphorescence at $910 \mathrm{~nm}$ was found for $\mathrm{fac}-\mathrm{Cr}^{\mathrm{III}}(\mathrm{ppy})_{3} \mathrm{Cr14}$ (ppy = anion of 2-phenylpyridine; Scheme 1, Table 1), an isostructural analog of the famous CT emitter $\operatorname{Ir}^{\mathrm{III}}(\mathrm{ppy})_{3}$, with a lifetime of $9.5 \mu \mathrm{s}$ in 2-MeTHF (2-MeTHF $=2$-methyltetrahydrofuran) at room temperature. At $77 \mathrm{~K}$, the maximum shifted to $890 \mathrm{~nm}$ with shoulders at 910 and $1020 \mathrm{~nm}$ and a lifetime of $48 \mu \mathrm{s}$. The low quantum yield of $0.03 \%$ at room temperature in dichloromethane solution was rationalized with multiphonon quenching via $\mathrm{C}-\mathrm{H}$ oscillators of the ligands, trigonal distortion in the excited state reminiscent of $\left[\mathrm{Cr}^{\mathrm{III}}(\mathrm{bpy})_{3}\right]^{3+} \mathbf{C r 8}^{\mathbf{3 +}}$ and self-quenching enabled by intermolecular $\pi-\pi$ and $\mathrm{CH}-\pi$ interactions of this neutral complex Cr14 [88].

In $\mathrm{Cr}^{\mathrm{III}}$ complexes with amine ligands like $\mathrm{Cr}^{\mathbf{3 +}}, \mathrm{Cr10}^{\mathbf{3 +}}$ or $\left[\mathrm{Cr}^{\mathrm{III}}\left(\mathrm{NH}_{3}\right)_{6}\right]^{3+} \mathbf{C r 1 5}{ }^{3+}$, a weak red emission between 657 and $690 \mathrm{~nm}$ was observed, but lifetimes and quantum yields were poor (Scheme 1, Table 1) [63, 84, 104]. Recently, the emission maximum of a highly emissive Molecular Ruby was successfully blue-shifted to $709 \mathrm{~nm}$ by employing a methylene-bridged tripyridine ligand in $\mathbf{C r} 5^{3+}$ [73]. Compared to $\mathrm{Cr}^{3+}$, this marks an increase of $1200 \mathrm{~cm}^{-1}$ in doublet state energy. This trend was correctly predicted by complete active space self-consistent field calculations with $\mathrm{N}$-electron valence perturbation correction $\operatorname{CASSCF}(7,12)$ NEVPT2) [73].

A theoretical upper limit of the emission energy can be derived from ligand field theory using the Racah parameter $B$ of the central metal ion. Assuming $C / B=4.0$, a ${ }^{2} \mathrm{E}$ energy of $19.5 B$ is predicted for an octahedral $d^{3}$ complex [58]. With $B=918 \mathrm{~cm}^{-1}$ for the free $\mathrm{Cr}^{3+}$ ion [50], this corresponds to $17,900 \mathrm{~cm}^{-1}(559 \mathrm{~nm})$. The doublet state energies are also determined by the ratio $C / B$. This is nicely demonstrated by ruby $\left(\mathrm{Al}_{2} \mathrm{O}_{3}: \mathrm{Cr}^{3+}\right)$ which features a highly ionic metal ligand bond with $B=822 \mathrm{~cm}^{-1}$ but due to the low ratio $C / B=3.2$ merely shows red emission at $694 \mathrm{~nm}$ $\left(14,400 \mathrm{~cm}^{-1}\right)$ [105].

An alternative strategy to ligand design for the tuning of the emission energy is changing the central metal ion. A lower charge and/or extended $d$-orbitals as in $4 d / 5 d$ transition metals result in a lower interelectronic repulsion. Consequently, highly charged central ions like $\mathrm{Mn}^{\mathrm{IV}}$ $\left(B=1064 \mathrm{~cm}^{-1}\right)$ [50] should in principle lead to high spinflip energies. However, in the end the covalence of the metal-ligand bond is the decisive factor, which needs to be considered for each complex individually. A more detailed discussion can be found in Sect. 6 .

\section{Applications}

The phosphorescence of $\mathrm{Cr}^{\mathrm{III}}$ emitters is quenched by triplet dioxygen ${ }^{3} \mathrm{O}_{2}$ via doublet-singlet Dexter-type energy transfer forming ${ }^{1} \mathrm{O}_{2}$ with $61 \%$ quantum yield in the case of $\mathbf{C r} 4^{3+}$. This excited state reactivity allows utilizing $\mathrm{Cr} 4^{3+}$ as an optical oxygen sensor and as photosensitizer for the $\alpha$-cyanation of aliphatic amines via ${ }^{1} \mathrm{O}_{2}$ /trimethylsilylcyanide $[25,74]$.

The complex $\mathbf{C r 1 2}{ }^{\mathbf{3}+}$ (Scheme 1, Table 1) was successfully employed as a photoredox catalyst in radical cationic $[4+2]$ cycloaddition reactions [106]. Photoexcited $\mathbf{C r 1 2}{ }^{3+}$ is reductively quenched by the substrate (e.g., trans-anethol). The resulting radical cation reacts with a diene like isoprene. Interestingly, the catalysis requires the presence of $\mathrm{O}_{2}$ likely functioning as an electron shuttle. Oxygen can oxidize $\mathbf{C r 1 2}{ }^{2+}$ to regenerate the photocatalyst $\mathbf{C r} \mathbf{1 2}^{3+}$ and to form superoxide. Finally, superoxide reduces the cationic intermediate after reaction of the oxidized alkene and the diene yielding the $[4+2]$ cycloaddition product $[86,107]$. This catalytic scheme strongly benefits from the very long excited state lifetime of $13 \mu$ s of $\mathbf{C r 1 2}^{3+}$ in $\mathrm{CH}_{3} \mathrm{NO}_{2}$ even under aerobic conditions [86].

$\mathrm{Cr}^{3+}$ shows dual phosphorescence from its doublet states at 738 and $775 \mathrm{~nm}$ at room temperature because these two states are in thermal equilibrium with an energy 
difference of $650-700 \mathrm{~cm}^{-1}$ [108]. Thus, the complex was employed as a self-referenced ratiometric optical temperature sensor $[108,109]$.

Hydrostatic pressures for example in diamond anvil cells are usually measured optically via the shift in emission energies of ruby's $R_{1} / R_{2}$ lines (approx. -0.77 (3) and -0.84 (3) $\mathrm{cm}^{-1} \mathrm{kbar}^{-1}$ ) [110, 111]. Interestingly, for $\mathbf{C r} 4\left[\mathrm{BF}_{4}\right]_{3}$ much larger shifts of -14.8 and $-9.5 \mathrm{~cm}^{-1} \mathrm{kbar}^{-1}$ were found for the low- and high-energy emission, respectively, in aqueous solution, in methanol and in the solid state. The large barochromic effect is explained by subtle changes in the coordination geometry of the complex induced by high pressures $[72,112]$.

The high doublet energy and long excited state lifetime of the spin-flip state of $\mathbf{C r}^{\mathbf{3}+}$ allowed for a Dexter-type doublet-triplet energy transfer to 9,10-diphenylanthracene followed by efficient green-to-blue triplet-triplet annihilation upconversion $(2 \times 532 \mathrm{~nm} \rightarrow 432 \mathrm{~nm})$ with a high quantum yield of $12.0 \%$ (maximum value is $50 \%$ ) [113]. The long-lived excited states in $\mathrm{Cr}^{\mathrm{III}}$ complexes can also be used to increase the excited state lifetime of lanthanide ions via $\mathrm{Cr}^{\mathrm{III}} \rightarrow \mathrm{Ln}^{\mathrm{III}}$ energy transfer as exemplified by binuclear $\left[\mathrm{Cr}^{\mathrm{III}} \mathrm{Ln}^{\mathrm{III}}\left(\mathrm{L}^{1}\right)_{3}\right]^{6+}\left(\mathrm{Ln}^{\mathrm{III}}=\mathrm{Nd}^{\mathrm{III}}: \mathbf{C r N d}, \mathrm{Ln}^{\mathrm{III}}=\mathrm{Yb}^{\mathrm{III}}\right.$ : CrYb, Fig. 3a and 3b) and trinuclear $\left[\mathrm{Cr}^{\mathrm{III}} \mathrm{Ln}^{, \mathrm{III}} \mathrm{Cr}^{\mathrm{III}}\left(\mathrm{L}^{2}\right)_{3}\right]^{9+}$ helicate complexes $\left(\mathrm{Ln}^{\prime}{ }^{\mathrm{III}}=\mathrm{Nd}^{\mathrm{III}}\right.$ : $\mathbf{C r N d C r}, \mathrm{Ln}^{\prime}{ }^{\mathrm{III}}=\mathrm{Er}^{\mathrm{III}}$ : CrErCr, Ln' ${ }^{\text {III }}=\mathrm{Yb}^{\mathrm{III}}$ : CrYbCr, Fig. 3a, c). Using the ${ }^{4} \mathrm{~A}_{2}$ $\rightarrow{ }^{2} \mathrm{E}$ excitation of the $\mathrm{Cr}^{\mathrm{III}}$ centers at $750 \mathrm{~nm}$, lifetimes in the millisecond region were reached for the lanthanide emissions between 1000 and $1670 \mathrm{~nm}[114,115]$. For $\mathbf{C r N d C r}$ and $\mathbf{C r Y b C r}$ quantum yields of 2.7(1) and 3.0(3) \% were determined, respectively [115]. Furthermore, $\mathbf{C r E r C r}$ (Fig. 3c) yielded green upconverted $\mathrm{Er}^{\mathrm{III}}$ emission $\left({ }^{4} \mathrm{~S}_{3 / 2} \rightarrow\right.$ ${ }^{4} \mathrm{I}_{15 / 2}$ ) with NIR irradiation via a sequential energy transfer upconversion (ETU) process $(2 \times 750 \mathrm{~nm} \rightarrow 543 \mathrm{~nm})$ in the solid state at $10 \mathrm{~K}$ and in frozen $\mathrm{CH}_{3} \mathrm{CN}$ solution at $30 \mathrm{~K}$. The efficiency of the $\mathrm{Cr}^{\mathrm{III}} \rightarrow \mathrm{Er}^{\mathrm{III}}$ energy transfer amounts to $50 \%$ [116].

Alternatively, the Molecular Ruby $\mathbf{C r} 4^{3+}$ operated as energy acceptor in a cooperative upconversion process from the ${ }^{2} \mathrm{~F}_{7 / 2} \rightarrow{ }^{2} \mathrm{~F}_{5 / 2}$ transition of $\mathrm{Yb}^{3+}$ in the $[\mathbf{C r} 4]\left[\mathrm{Yb}^{\mathrm{III}}(\mathrm{dpa})_{3}\right]$ double salt yielding NIR-to-NIR upconverted photons $(2 \times 980 \mathrm{~nm} \rightarrow 775 \mathrm{~nm} ;$ dpa $=2,6$-pyridine-dicarboxylate $)$ [117].

A particularly promising application of spin-flip emission is circularly polarized luminescence (CPL) with potential applications like biosensing, telecommunication and security inks [118-121]. Unlike tpy, ligands like ddpd or dqp ${ }^{\mathrm{OMe}}$ (dqp ${ }^{\mathrm{OMe}}=2,2^{\prime}$-(4-methoxypyridine-2,6-diyl)diquinoline) employed in Molecular Rubies form six-membered chelate rings with boat conformations. Two enantiomers $(P, P)$ and $(M, M)$ arise from the resulting double helix of the ligands around the central ion (Fig. 4). In several instances, a separation was possible using HPLC with chiral stationary phases.
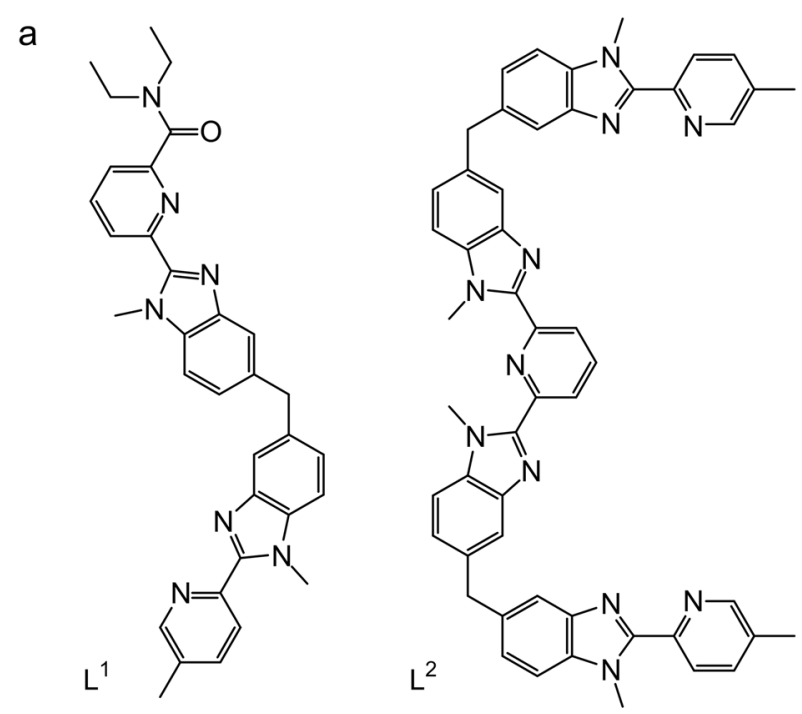

b

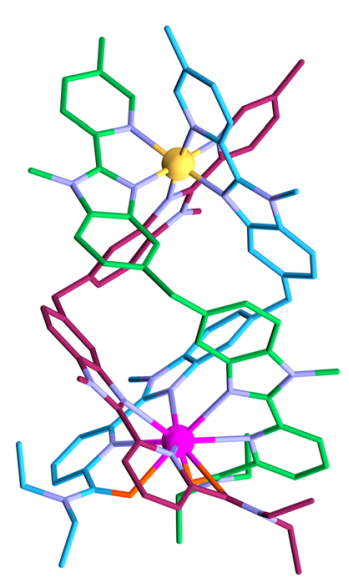

C

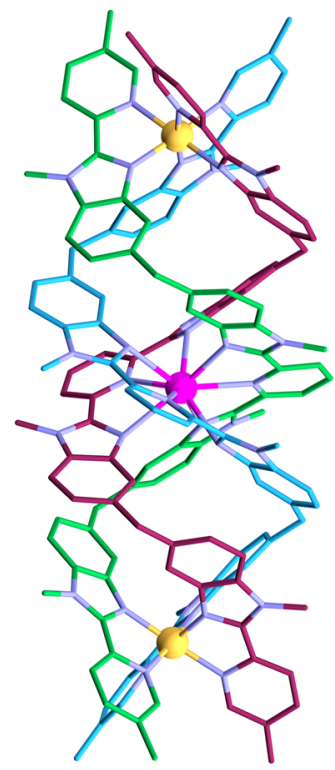

$\left[\mathrm{Cr}^{\prime \prime \prime} \operatorname{Ln}^{\prime \prime \prime}\left(L^{1}\right)_{3}\right]^{6+}$
CrYb: $L n^{\prime \prime \prime}=Y b^{\prime \prime \prime}$
CrNd: $L n^{\prime \prime \prime}=N d^{\prime \prime \prime}$

$\left[\mathrm{Cr}^{\prime \prime \prime} \mathrm{Ln}^{\prime \prime \prime} \mathrm{Cr}^{\prime \prime \prime}\left(\mathrm{L}^{2}\right)_{3}\right]^{9+}$

CrErCr: $L n^{\prime \prime \prime}=\mathrm{Er}{ }^{\prime \prime \prime}$

CrYbCr: $\operatorname{Ln}^{\prime \prime \prime}=Y^{\prime \prime \prime}$

CrNdCr: $L^{\prime \prime \prime}=\mathrm{Nd}^{\prime \prime \prime}$

Fig. 3 Structures of a ligands $\mathrm{L}^{1}$ and $\mathrm{L}^{2}$, b binuclear $\mathrm{Cr}^{\mathrm{III}}-\mathrm{Ln}^{\mathrm{III}}$ complexes and $\mathbf{c}$ trinuclear $\mathrm{Cr}^{\mathrm{III}}-\mathrm{Ln}{ }^{\mathrm{III}}-\mathrm{Cr}^{\mathrm{III}}$ complexes [114-116] with red, green and blue colors used for carbon atoms on different ligands; chromium colored in yellow; lanthanide in violet; nitrogen colored in gray; oxygen colored in orange; hydrogen atoms were omitted for clarity

Apart from rich electronic circular dichroism, the separated enantiomers also showed strong CPL [28, 29, 122-124]. The key figure for quantification is the dissymmetry factor $g_{\text {lum }}$ representing the excess of left-handed polarized over right-handed polarized light intensity $I_{\mathrm{L}}$ and $I_{\mathrm{R}}$ (Eq. 5). The physical description of $g_{\text {lum }}$ (Eq. 5) includes the electronic and magnetic transition dipole moments $\left|\mu_{\mathrm{ab}}\right|$ and $\left|m_{\mathrm{ba}}\right|$, 


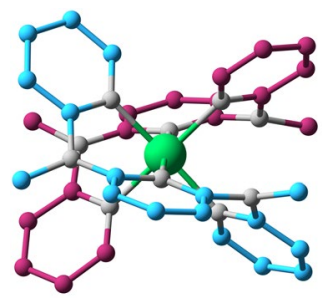

$(M, M)$

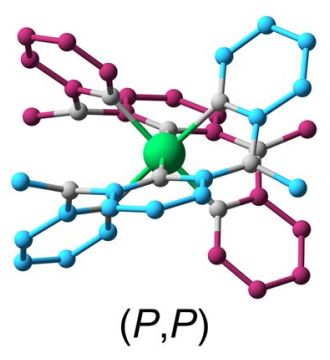

Fig. 4 Molecular structures of enantiomers of $\left[\mathrm{Cr}{ }^{\mathrm{III}}(\mathrm{ddpd})_{2}\right]^{3+} \mathbf{C r} 4^{3+}$ with red and blue colors used for carbon atoms on different ddpd ligands to clarify each ligand's helicity; chromium colored in green; nitrogen colored in gray; hydrogen atoms were omitted for clarity [122]

respectively, as well as the angle $\tau_{\mathrm{ab}}$ between the two vectors. Equation 5 shows that a high dissymmetry factor $g_{\text {lum }}$ is expected for transitions $\mathrm{a} \rightarrow \mathrm{b}$ which are spin-forbidden (low $\left.\left|\mu_{\mathrm{ab}}\right|\right)$ and magnetic dipole allowed (high $\left.\left|m_{\mathrm{ba}}\right|\right)$ [125]. Both conditions are met by the ${ }^{2} \mathrm{E} \rightarrow{ }^{4} \mathrm{~A}_{2}$ transition in Molecular Rubies yielding outstanding $\left|g_{\text {lum }}\right|$ values of 0.09 for $\mathbf{C r} 4^{3+}$ and 0.20 for $\left[\mathrm{Cr}^{\mathrm{III}}\left(\mathrm{dqp}^{\mathrm{OMe}}\right)_{2}\right]^{3+} \mathbf{C r}^{3+}{ }^{3+}$ (Scheme 1, Table 1) $[29,122]$. Dissymmetry factors as high as this are rarely achieved with CT emitters and usually necessitate the use of lanthanide complexes exploiting metal-centered ff-transitions $[123,125,126]$.

$g_{\text {lum }}=\frac{I_{L}-I_{R}}{0.5\left(I_{L}+I_{R}\right)}=\frac{\Delta I}{I} \approx 4 \frac{\left|m_{b a}\right|}{\left|\mu_{a b}\right|} \cos \tau_{a b}$.

Intraconfigurational spin-flip transitions can potentially be exploited in optically addressable qubits. Complexes of $\mathrm{Cr}^{\mathrm{III}}, \mathrm{Cr}^{\mathrm{IV}}, \mathrm{V}^{\mathrm{III}}$ and $\mathrm{Ni}^{\mathrm{II}}$ like $\mathrm{Cr}^{3+}, \mathrm{Cr17}-\mathrm{Cr} 22, \mathrm{V4}, \mathrm{Ni}^{2+}$ and $\mathbf{N i}^{2+}$ (Tables 1 and 2, Schemes 1, 2 and 5) were proposed as suitable candidates [127-132]. Their properties are discussed in more detail below.

\section{Spin-flip emitters based on other transition metals and electronic configurations}

This section highlights spin-flip emissive complexes of $3 d$, $4 d$ and $5 d$ metal ions with suitable $d$ electron configurations.

Table 2 Optical properties of luminescent $\mathrm{V}^{\mathrm{III}}$ and $\mathrm{Cr}^{\mathrm{IV}}$ complexes with emission maximum $\lambda_{\max }$, luminescence lifetime $\tau$ and quantum yield $\Phi$ measured in absence of oxygen

\begin{tabular}{|c|c|c|c|c|c|c|}
\hline Number & Complex & Medium & $\lambda_{\max } / \mathrm{nm}$ & $\tau / \mathrm{ns}$ & $\Phi / \%$ & References \\
\hline $\mathrm{V1}^{3+}$ & {$\left[\mathrm{V}^{\mathrm{III}}(\text { urea })_{6}\right]^{3+}$} & Solid (77 K) & $992,1010,1011,1187$ & - & - & [140] \\
\hline \multirow[t]{2}{*}{$\mathbf{V 2}^{3+}$} & \multirow[t]{2}{*}[\mathrm{V}^{\mathrm{III}}(\mathrm{ddpd})_{2}]{$^{3+}$} & \multirow[t]{2}{*}{$\mathrm{CD}_{3} \mathrm{CN}(298 \mathrm{~K})$} & $982,1088,1109$ & $1351^{\mathrm{a}}$ & $1.8 \times 10^{-4}$ & {$[62]$} \\
\hline & & & $374,447,660$ & $2.2^{\mathrm{b}}$ & 2.1 & {$[62]$} \\
\hline V3 & mer $-\mathrm{V}^{\mathrm{III}} \mathrm{Cl}_{3}(\mathrm{ddpd})$ & Solid (298 K) & $1102,1219,1256$ & 500 & - & [144] \\
\hline \multirow[t]{2}{*}{ V4 } & \multirow[t]{2}{*}{$\mathrm{V}^{\mathrm{III}}\left\{\left(\mathrm{C}_{6} \mathrm{~F}_{5}\right)_{3}\right.$ tren $\}\left(\mathrm{CN}^{t} \mathrm{Bu}\right)$} & 2-MeTHF (77 K) & 1240 & $9220^{c}$ & - & [128] \\
\hline & & $\begin{array}{l}\text { Single crystal } \\
(298 \mathrm{~K})\end{array}$ & 1250 & 3040 & - & {$[128]$} \\
\hline Cr17 & $\mathrm{Cr}^{\mathrm{IV}}\left(\mathrm{CH}_{2} \mathrm{CPh}_{3}\right)_{4}$ & $\begin{array}{l}\mathrm{In} \mathrm{Sn}^{\mathrm{IV}}(\mathrm{L})_{4} \\
\text { host crystal }(4 \mathrm{~K}){ }^{\mathrm{d}}\end{array}$ & $\approx 920$ & - & - & {$[131]$} \\
\hline Cr18 & $\mathrm{Cr}^{\mathrm{IV}}\left(\mathrm{CH}_{2} \mathrm{TMS}\right)_{4}{ }^{e}$ & $\begin{array}{l}\text { In isostructural } \mathrm{Sn}^{\mathrm{IV}} \\
\text { Host crystal }(4 \mathrm{~K})\end{array}$ & 923 & - & - & {$[131]$} \\
\hline Cr19 & $\mathrm{Cr}^{\mathrm{IV}}(\text { cyclohexyl })_{4}$ & $\begin{array}{l}\text { In isostructural Sn }{ }^{\mathrm{IV}} \\
\text { Host crystal }(4 \mathrm{~K})\end{array}$ & 897 & - & - & [131] \\
\hline Cr20 & $\mathrm{Cr}^{\mathrm{IV}}(o \text {-tolyl })_{4}$ & $\begin{array}{l}\text { In isostructural } \mathrm{Sn}^{\mathrm{IV}} \\
\text { Host crystal }(4 \mathrm{~K})\end{array}$ & 1025 & 3300 & - & {$[130,131]$} \\
\hline Cr21 & $\mathrm{Cr}^{\mathrm{IV}}$ (2,3-dimethylphenyl $)_{4}$ & $\begin{array}{l}\text { In isostructural } \mathrm{Sn}^{\mathrm{IV}} \\
\text { Host crystal }(4 \mathrm{~K})\end{array}$ & 1009 & 6900 & - & {$[130,131]$} \\
\hline Cr22 & $\mathrm{Cr}^{\mathrm{IV}}(2,4 \text {-dimethylphenyl })_{4}$ & $\begin{array}{l}\text { In isostructural } \mathrm{Sn}^{\mathrm{IV}} \\
\text { Host crystal }(4 \mathrm{~K})\end{array}$ & 1025 & 5700 & - & {$[130,131]$} \\
\hline
\end{tabular}

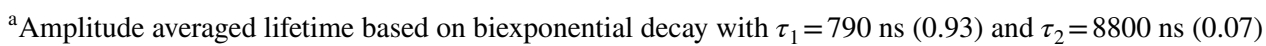

${ }^{\mathrm{b}}$ Amplitude averaged lifetime based on biexponential decay with $\tau_{1}=3.2 \mathrm{~ns}(0.56)$ and $\tau_{2}=8.2 \mathrm{~ns}(0.44)$

${ }^{c}$ Determined at $90 \mathrm{~K}$

${ }^{\mathrm{d}} \mathrm{L}=2$,4-dimethylphenyl

${ }^{\mathrm{e}} \mathrm{CH}_{2} \mathrm{TMS}=($ trimethylsilyl $)$ methyl. 

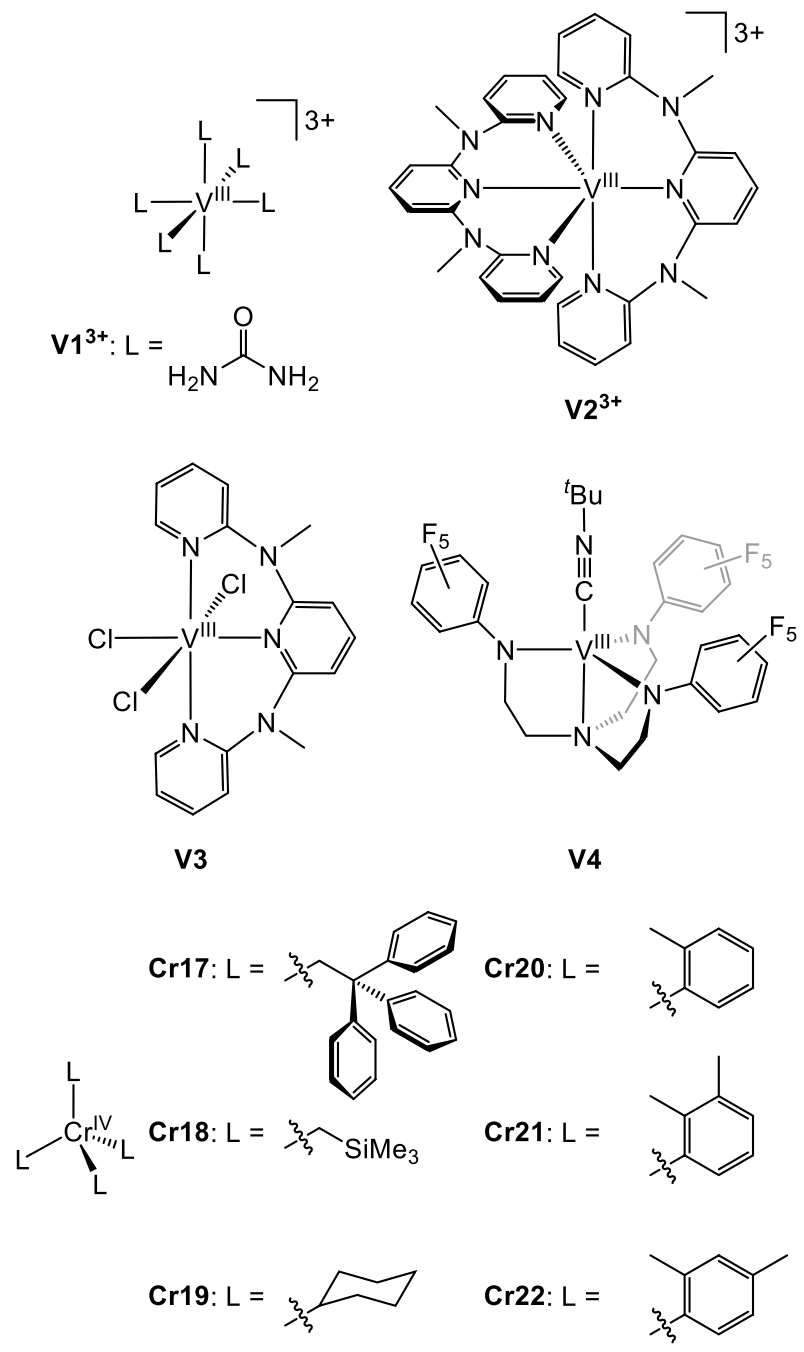

Scheme 2 Structures of luminescent $\mathrm{V}^{\mathrm{III}}$ and $\mathrm{Cr}^{\mathrm{IV}}$ complexes [62, $128,130,131,142,144]$

\section{1 $d^{2}-\mathrm{Ti}^{\mathrm{II}}, \mathrm{VIII}, \mathrm{Cr}^{\mathrm{IV}}, \mathrm{Mo}^{\mathrm{IV}}, \mathrm{Tc}^{\mathrm{V}}, \mathrm{Re}^{\mathrm{V}}$}

The relevant excited states for spin-flip emission in the $d^{2}$ configuration in an octahedral field are the ${ }^{3} \mathrm{~T}_{1}$ ground state, the interconfigurational ${ }^{3} \mathrm{~T}_{2}$ and intraconfigurational ${ }^{1} \mathrm{~T}_{2} /{ }^{1} \mathrm{E}$ excited states (Fig. 1a).

Divalent group 4 metal ions are potential candidates for spin-flip emissive $d^{2}$ complexes [37, 38]. However, stable complexes of, e.g., $\mathrm{Ti}^{\mathrm{iI}}$ are quite rare and their investigation so far focused on electrochemical properties and reactivity [133-139]. Thus, no spin-flip luminescence with $\mathrm{Ti}^{\mathrm{II}}$ complexes has been reported to date, while examples for luminescent solid-state materials containing $\mathrm{Ti}^{2+}$, such as $\mathrm{MgCl}_{2}: \mathrm{Ti}^{2+}$ and $\mathrm{NaCl}: \mathrm{Ti}^{2+}$, exist $[37,38]$.

A weak, structured emission was found for $\left[\mathrm{V}^{\mathrm{III}}(\text { urea })_{6}\right]^{3+}$ $\mathbf{V 1}^{3+}$ at $77 \mathrm{~K}$ in the solid state peaking at $992,1010,1011$ and $1187 \mathrm{~nm}$ (Table 2) [140-142]. Trigonal Jahn-Teller distortion splits the ${ }^{3} \mathrm{~T}_{1}$ ground state by $1400 \mathrm{~cm}^{-1}$ to ${ }^{3} \mathrm{~A}_{1}$ and
${ }^{3} \mathrm{E}$ states. This ground-state splitting of octahedral $d^{2}$ metal complexes is a key difference to $d^{3}$ spin-flip emitters with their orbitally non-degenerate ${ }^{4} \mathrm{~A}_{2}$ ground state (Fig. 1a,b). In $\mathrm{V}^{\mathrm{III}}$ complexes, the total luminescence intensity is distributed to a large number of possible spin-flip transitions ${ }^{1} \mathrm{~T}_{2} /{ }^{1} \mathrm{E}$ $\rightarrow{ }^{3} \mathrm{~T}_{1}$ with differing energies [143].

$\left[\mathrm{V}^{\mathrm{III}}(\mathrm{ddpd})_{2}\right]^{3+} \mathbf{V 2}^{\mathbf{3 +}}$ is the first $\mathrm{V}^{\mathrm{III}}$ complex showing NIR luminescence at room temperature in solution (Scheme 2, Table 2). This was achieved by using the strong $\sigma$-donor ddpd that has been previously employed in the first Molecular Ruby [25, 62]. The ligand field splitting is so large that the complex is located well above the first crossing point $\left({ }^{1} \mathrm{~T}_{2},{ }^{1} \mathrm{E}\right) /{ }^{3} \mathrm{~T}_{2}$, placing the spin-flip states below the interconfigurational ${ }^{3} \mathrm{~T}_{2}$ states in the TS diagram (Fig. 1a). When excited at $306 \mathrm{~nm}, \mathbf{V 2}^{3+}$ shows a weak NIR-II phosphorescence peaking at 982, 1088 and $1109 \mathrm{~nm}$ in solution at $298 \mathrm{~K}$. The bands were assigned to the spin-flip transitions from ${ }^{1} \mathrm{~T}_{2} /{ }^{1} \mathrm{E}$ to the split ${ }^{3} \mathrm{~T}_{1}$ ground state. A quantum yield of $0.00018 \%$ was found for this NIR-II emission in $\mathrm{CD}_{3} \mathrm{CN}$ at room temperature. Low energy excitation at $620 \mathrm{~nm}$ is less efficient in populating the metal-centered ${ }^{1} \mathrm{~T}_{2} /{ }^{1} \mathrm{E}$ states. In butyronitrile at $77 \mathrm{~K}$, the luminescence decayed biexponentially with lifetimes of $\tau_{1}=790 \mathrm{~ns}(93 \%)$ and $\tau_{2}=8800 \mathrm{~ns}$ (7\%). In addition to the NIR-spin-flip emission, blue fluorescence possibly originating from a ${ }^{3} \mathrm{LMCT}$ state was detected at $396 \mathrm{~nm}$ in $\mathrm{CD}_{3} \mathrm{CN}$ at $298 \mathrm{~K}$ with a high quantum yield of $2.1 \%$. This dual emissive behavior was rationalized with an inefficient ISC and fast spin-allowed IC and fluorescence. In contrast to $\mathbf{C r}^{3+}$, non-radiative deactivation of the lowenergy ${ }^{1} \mathrm{~T}_{2} /{ }^{1} \mathrm{E}$ spin-flip states via multiphonon relaxation (electronic-to-vibrational energy transfer to vibrational overtones of $\mathrm{C}-\mathrm{H}$ oscillators) unexpectedly does not play a significant role as evidenced by the very similar lifetimes and quantum yields of the non-deuterated and perdeuterated vanadium(III) complexes [62, 79]. The low quantum yield can then be attributed to a poor ISC efficiency and efficient non-radiative decay pathways beyond multiphonon relaxation. Possibly the inefficient ISC may be caused by the low density of acceptor states in the singlet manifold as $\Delta_{\mathrm{O}}$ in $\mathbf{V 2}^{\mathbf{3 +}}$ lies below the second triplet-singlet crossing point ${ }^{1} \mathrm{~A}_{1} /{ }^{3} \mathrm{~T}_{2}$ in the TS diagram (Fig. 1a) [62].

NIR-II spin-flip emission was also detected for the heteroleptic complex $m e r-\mathrm{V}^{\mathrm{III}} \mathrm{Cl}_{3}(\mathrm{ddpd}) \mathbf{V 3}$ (Scheme 2, Table 2) in the solid state at room temperature with bands at 1102, 1219 and $1256 \mathrm{~nm}$ and a phosphorescence lifetime of $0.5 \mu \mathrm{s}$ [144]. Ligand deuteration significantly increased the phosphorescence lifetime to $3.4 \mu \mathrm{s}$. Transient absorption spectroscopy showed that the long-lived singlet states are populated after $\tau=1.4 \mathrm{ps}$, which is an upper limit for the time constant of the ISC. Trajectory surface hopping simulations within a linear vibronic coupling model arrived at a similar value of $1.7 \pm 0.3 \mathrm{ps}$ [145]. Interestingly, under hydrostatic pressure $\mathbf{V 3}$ showed a hypsochromic shift by $+10 \mathrm{~cm}^{-1} \mathrm{kbar}^{-1}$ 


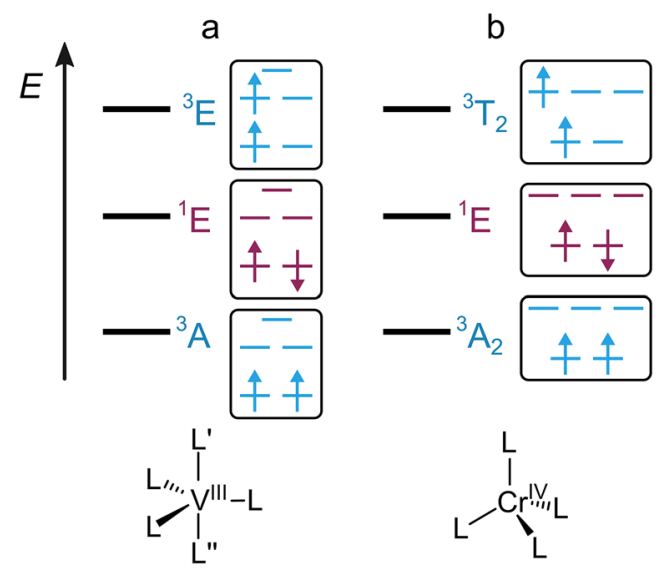

Fig. 5 Schematic energy-level ordering and exemplary microstates in a trigonal-bipyramidal $\mathrm{V}^{\mathrm{III}}$ complex $\mathbf{V} \mathbf{4}$ and $\mathbf{b}$ tetrahedral $\mathrm{Cr}^{\mathrm{IV}}$ complexes Cr17-Cr22 (Scheme 2, Table 2) [128, 130, 147]

in contrast to the bathochromic shifts found for $\mathbf{C r} 4^{3+}$. This positive shift was rationalized by the combined effect of changes in singlet energy and ground state splitting under pressure [144].

Spin-flip emission occurs also in five-coordinate $\mathrm{V}^{\mathrm{III}}\left\{\left(\mathrm{C}_{6} \mathrm{~F}_{5}\right)_{3}\right.$ tren $\}\left(\mathrm{CN}^{t} \mathrm{Bu}\right) \mathbf{V 4}\left(\left\{\left(\mathrm{C}_{6} \mathrm{~F}_{5}\right)_{3} \text { tren }\right\}^{3-}=2,2^{\prime}, 2^{\prime}{ }^{\prime}\right.$ tris[(pentafluorphenyl)amido]trimethylamine; Scheme 2, Table 2) which was proposed as an optically addressable molecular quantum bit candidate [128]. In this coordination geometry, a ${ }^{3} \mathrm{~A}$ ground state and ${ }^{3} \mathrm{E}$ and ${ }^{1} \mathrm{E}$ MC excited states arise (Fig. 5a). Excitation at $640 \mathrm{~nm}$ assigned as a spin-allowed ${ }^{3} \mathrm{~A} \rightarrow{ }^{3} \mathrm{E}$ transition yielded a ${ }^{1} \mathrm{E} \rightarrow{ }^{3} \mathrm{~A}$ emission around $1240 \mathrm{~nm}$ in 2-MeTHF at $77 \mathrm{~K}$ and in single crystals. No emission was detected at room temperature in fluid solution. Long lifetimes of 11.1 and $3.0 \mu$ s were measured of single crystals of $\mathbf{V 4}$ at $4 \mathrm{~K}$ and at room temperature, respectively, substantiating the assignment of the emission as phosphorescence. ISC was found to occur within $<4.2 \mathrm{ps}$ followed by VR with a time constant of $26 \mathrm{ps}$ [128]. The rather slow ISC compared to V3 [144] or $\mathrm{Cr}^{\mathrm{III}}(\mathrm{acac})_{3} \mathbf{C r 3}$ (Scheme 1) $[68,146]$ was attributed to restrictions of vibrational modes along the ISC reaction coordinate imposed by the rigid substituted tren ligand [128].

The TS diagram of tetrahedral $d^{2}$ complexes is analogous to the octahedral $d^{8}$ case (Figs. $1 \mathrm{~d}$ and $5 \mathrm{~b}$ ). Hence spinflip emission from a ${ }^{1} \mathrm{E} \rightarrow{ }^{3} \mathrm{~A}_{2}$ transition could be achieved with a high ligand field splitting in tetrahedral $d^{2}$ complexes [147]. In fact, tetrahedral $\mathrm{Cr}^{\mathrm{IV}}$ complexes with anionic alkyl or aryl ligands Cr17-Cr22 emit between 897 and $1025 \mathrm{~nm}$ at $4 \mathrm{~K}$ and were proposed as optically addressable qubit candidates (Scheme 2, Table 2) [130, 131]. For the investigation, the complexes Cr18-Cr22 were diluted in isostructural $\mathrm{Sn}^{\mathrm{IV}}$ host lattices while a $\mathrm{Sn}^{\mathrm{IV}}$ (2,4-dimethylphenyl) ${ }_{4}$ lattice was used for $\mathrm{Cr}^{\mathrm{IV}}\left(\mathrm{CH}_{2} \mathrm{CPh}_{3}\right)_{4} \mathrm{Cr17}\left(\mathrm{CH}_{2} \mathrm{CPh}_{3}{ }^{-}=2,2,2\right.$-triphenyleth-1-yl). A resulting incompatibility with this host lattice in Cr17 served to explain its broad emission compared to the extremely narrow bandwidths obtained for Cr18-Cr22. Because of the stronger nephelauxetic effect in the aryl complexes $\mathbf{C r 2 0 - C r 2 2}$, their emission is of lower energy than in the alkyl derivatives Cr17-Cr19 [131]. The phosphorescence lifetimes of $\mathbf{C r 2 0}-\mathbf{C r 2 2}$ in the host lattices at $4 \mathrm{~K}$ were determined as 3.3, 5.7 and $6.9 \mu$ s, respectively [130].

Long-lived phosphorescence from oxido and nitrido complexes featuring $\mathrm{M}=\mathrm{O}, \mathrm{O}=\mathrm{M}^{\prime}=\mathrm{O}$ or $\mathrm{M}^{\prime} \equiv \mathrm{N}\left(\mathrm{M}=\mathrm{Mo}^{\mathrm{IV}}\right.$; $\left.\mathrm{M}^{\prime}=\mathrm{Tc}^{\mathrm{V}}, \mathrm{Re}^{\mathrm{V}}, \mathrm{Os}^{\mathrm{VI}}\right)$ moieties is well known [148-154]. Although all of these complexes feature a $d^{2}$ electronic configuration, their emission does not arise from an intraconfigurational spin-flip state but rather from an interconfigurational MC states. The complexes' $D_{4 h}$ symmetry and strong $\pi$-bonds to the nitrido or oxido ligands give rise to a ${ }^{1} \mathrm{~A}_{1}$ ground state with $\left(d_{\mathrm{xy}}\right)^{2}$ configuration and an emissive ${ }^{3} \mathrm{E}$ state with $\left(d_{\mathrm{xy}}\right)^{1}\left(d_{\mathrm{yz}}, \mathrm{d}_{\mathrm{xz}}\right)^{1}$ configuration [148-154], which is distinctly different from the ${ }^{3} \mathrm{~T}_{1}$ ground state and ${ }^{1} \mathrm{~T}_{2} /{ }^{1} \mathrm{E}$ spin-flip states expected for octahedral $d^{2}$ complexes (Fig. 1a) [50].

\section{$6.2 d^{3}-M^{I I I}$, WIII, VII, Mn ${ }^{I V}$ and $\operatorname{Re}^{I V}$}

Luminescent molecular $\mathrm{Cr}^{\mathrm{III}}$ complexes have been known for a long time with many reviews covering this substance class [56, 63, 143, 155, 156, 158]. In contrast to $\mathrm{Cr}^{\mathrm{III}}$, luminescent complexes of $\mathrm{Mo}^{\mathrm{III}}$ and $\mathrm{W}^{\mathrm{III}}$ were hardly investigated. To our knowledge, ten emissive molecular $\mathrm{Mo}^{\mathrm{III}}$ complexes and only one emissive $\mathrm{W}^{\mathrm{III}}$ complex were reported in three publications [159-161]. This is probably due to the fact that $\mathrm{Mo}^{\mathrm{III}}$ and $\mathrm{W}^{\mathrm{III}}$ complexes are less stable than $\mathrm{Cr}^{\mathrm{III}}$ complexes despite their $\left(t_{2 \mathrm{~g}}\right)^{3}$ electronic configuration [162]. It was suggested that the higher ionic radii facilitate decomposition via seven-coordinate intermediates or that decomposition may be catalyzed by byproducts with different oxidation states [162]. In general, intermediate oxidation states like + III are more difficult to stabilize in $5 d$ and $6 d$ transition metal complexes resulting in complexes sensitive to oxidation [163, 164].

$\mathrm{Mo}^{\mathrm{III}}$ and $\mathrm{W}^{\mathrm{III}}$ ions provide a very high intrinsic ligand field splitting due to better overlap of the large $4 d$ and $5 d$ orbitals with orbitals of the coordinating ligands. In addition, the heavier elements enable strong SOC, which is expected to enhance ISC rates [161, 165-167]. Absorption spectroscopy revealed that even with weak $\pi$-donating ligands like chloride in $\left[\mathrm{Mo}^{\mathrm{III}} \mathrm{Cl}_{6}\right]^{3-} \mathbf{M o 1}^{3-}$ the ${ }^{4} \mathrm{~T}_{2}$ state is located well above the ${ }^{2} \mathrm{E} /{ }^{2} \mathrm{~T}_{1} / \mathrm{T}_{2}$ states and thus $\Delta_{\mathrm{O}}$ is past the first and second crossing points in the TS diagram (Fig. 1b) [160]. The emission bands of the known $\mathrm{Mo}^{\mathrm{III}}$ complexes $\mathbf{M o 1}^{3-},\left[\mathrm{Mo}{ }^{\mathrm{III}}(\mathrm{NCS})_{6}\right]^{3-} \mathbf{M o 2}^{3-}$, mer $-\mathrm{Mo}^{\mathrm{III}} \mathrm{Cl}_{3}(\mathrm{~L})_{3}$ $\operatorname{Mo3}-\operatorname{Mo5}(\mathrm{L}=$ py, urea, tu; py = pyridine, tu = thiourea $)$, mer $-\mathrm{Mo}^{\mathrm{III}} \mathrm{Br}_{3}(\text { urea })_{3}$ Mo6, fac-Mo ${ }^{\mathrm{III}}\left(\mathrm{Me}_{3}[9] \mathrm{aneN}_{3}\right) \mathrm{X}_{3}$ 


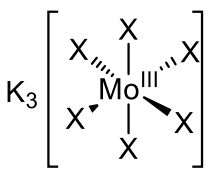

$\mathrm{K}_{3} \operatorname{Mo1}(\mathrm{X}=\mathrm{Cl})$

$\mathrm{K}_{3} \mathrm{Mo2}(\mathrm{X}=\mathrm{NCS})$

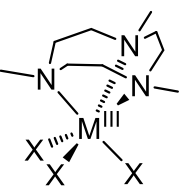

$\operatorname{Mo7}(\mathrm{M}=\mathrm{Mo}, \mathrm{X}=\mathrm{Cl})$

$\operatorname{Mo8}(M=M o, X=B r)$

$\operatorname{Mo9}(M=M o, X=I)$

W1 $(M=W, \quad X=C l)$
$\operatorname{Mo3}(X=\mathrm{Cl}, \mathrm{L}=\mathrm{py})$

Mo4 $(X=C l, L=$ urea $)$

$\operatorname{Mo5}(X=\mathrm{Cl}, \mathrm{L}=\mathrm{tu})$

$\operatorname{Mo6}(X=B r, L=$ urea $)$

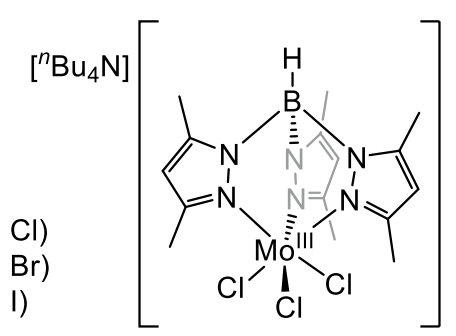

$\left[{ }^{n} \mathrm{Bu}_{4} \mathrm{~N}\right] \mathrm{Mo10}$
Scheme 3 Structures of luminescent Mo ${ }^{\mathrm{III}}$ and $\mathrm{W}^{\mathrm{III}}$ complexes [159161]

Mo7-Mo9 $\left(\mathrm{Me}_{3}[9] \mathrm{aneN}_{3}=1,4,7\right.$-trimethyl-1,4,7-triazacyclononane; $\mathrm{X}=\mathrm{Cl}, \mathrm{Br}, \mathrm{I})$ and $\mathrm{fac}-\left[\mathrm{Mo}^{\mathrm{III}}\left\{\mathrm{HB}\left(\mathrm{Me}_{2} \mathrm{Pz}\right)_{3}\right\}\right.$ $\left.\mathrm{Cl}_{3}\right]^{-} \mathbf{M o 1 0}^{-}\left(\left\{\mathrm{HB}\left(\mathrm{Me}_{2} \mathrm{Pz}\right)_{3}\right\}^{-}=\operatorname{tris}(3,5-\right.$ dimethyl-1H-pyrazol-1-yl)hydroborate) appear between 1090 and $1400 \mathrm{~nm}$ with emission lifetimes of several hundred nanoseconds and poor quantum yields of $0.0061-0.012 \%$ (Scheme 3, Table 3) $[160,161]$. Multiphonon relaxation via $\mathrm{C}-\mathrm{H}$ oscillators of the ligands or solvent molecules might play an important role in the deactivation of the excited states. Another reason for the poor quantum yields measured for Mo7-Mo9 might be that despite the high SOC in Mo ${ }^{\mathrm{III}}$ [165], ISC could be slow due to a low density of doublet states in the region of the initially excited ${ }^{4} \mathrm{~T}_{2}$ state at the FC geometry. For $\mathrm{W}^{\mathrm{III}} \mathrm{Cl}_{3}\left(\mathrm{Me}_{3}[9] \mathrm{aneN}_{3}\right) \mathbf{W} \mathbf{1}$ (Scheme 3, Table 3) the emission peaked at $1400 \mathrm{~nm}$, but the complex was too unstable for a more detailed investigation [161]. The trend of the energies going from $\mathrm{Cr}^{\mathrm{III}}$ to $\mathrm{Mo}^{\mathrm{III}}$ and $\mathrm{W}^{\mathrm{III}}$ can be explained with respect to the weaker interelectronic repulsion in this series $\left(\mathrm{Cr}^{3+}: B=918 \mathrm{~cm}^{-1}, \mathrm{Mo}^{3+}: B=610 \mathrm{~cm}^{-1}\right)[50,161]$.

Investigations of novel $\mathrm{Mo}^{\mathrm{III}}$ and $\mathrm{W}^{\mathrm{III}}$ emitters may offer insights on the effects that very high ligand field splittings $\Delta_{\mathrm{O}}$ have on the efficiency of the ISC processes and the radiative and non-radiative rates for the spin-flip state relaxation. Applying the lessons learned from the Molecular Rubies might help in the design and synthesis of stable $\mathrm{Mo}^{\mathrm{III}}$ and $\mathrm{W}^{\mathrm{III}}$ complexes with strong emission in the NIR-II spectral region.

Vanadium(II) complexes also feature a $d^{3}$ electronic configuration and are thus potential candidates for spinflip emission similar to $\mathrm{Cr}^{\mathrm{III}}$. The Racah parameter $B\left(\mathrm{~V}^{2+}\right)=766 \mathrm{~cm}^{-1}$ of the free ion is lower compared to $B\left(\mathrm{Cr}^{3+}\right)=918 \mathrm{~cm}^{-1}[50]$ indicating lower doublet energies for $\mathrm{V}^{\mathrm{II}}$ complexes [89]. However, the lower oxidation state also leads to a lower intrinsic ligand field splitting $\Delta_{\mathrm{O}}$ [171]. In addition, a relatively facile oxidation of $\mathrm{V}^{2+}$ to $\mathrm{V}^{3+}$ may generate low-energy MLCT states. In fact, early studies on tris(bidentate)vanadium(II) complexes using bpy, bpy derivatives and phen $\mathbf{V 5}^{2+}-\mathbf{V 8}^{\mathbf{2 +}}$ (Scheme 4) concluded that their lowest excited states have ${ }^{4}$ MLCT character. These complexes featured excited state lifetimes in the low nanosecond region and no luminescence [172]. The excited state assignment was recently called into question and a mixed ${ }^{2} \mathrm{MC} /{ }^{2} \mathrm{MLCT}$ state was proposed instead based on
Table 3 Optical properties of luminescent $d^{3} \mathrm{Mo}^{\mathrm{III}}$, $\mathrm{W}^{\mathrm{III}}$, $\mathrm{Mn}^{\mathrm{IV}}$ and $\mathrm{Re}^{\mathrm{IV}}$ complexes with emission maxima $\lambda_{\max }$, luminescence lifetimes $\tau$ and quantum yields $\Phi$ at room temperature

\begin{tabular}{|c|c|c|c|c|c|c|}
\hline Number & Complex & Medium & $\lambda_{\max } / \mathrm{nm}$ & $\tau / \mathrm{ns}$ & $\Phi / \%$ & References \\
\hline $\mathrm{K}_{3} \mathrm{Mo1}$ & $\mathrm{K}_{3}\left[\mathrm{Mo}^{\mathrm{III}} \mathrm{Cl}_{6}\right]$ & Conc. $\mathrm{HCl}_{(\mathrm{aq})}$ & 1095 & 480 & - & {$[160]$} \\
\hline $\mathrm{K}_{3} \mathrm{Mo2}$ & $\mathrm{K}_{3}\left[\mathrm{Mo}^{\mathrm{III}}(\mathrm{NCS})_{6}\right]$ & $\mathrm{MeCN}$ & 1350 & 760 & - & {$[160]$} \\
\hline Mo3 & $\mathrm{Mo}^{\mathrm{III}} \mathrm{Cl}_{3}(\text { py })_{3}$ & Solid & 1400 & - & - & {$[161]$} \\
\hline Mo4 & $\mathrm{Mo}^{\mathrm{III}} \mathrm{Cl}_{3}(\text { urea })_{3}$ & Solid & 1095 & - & - & [159] \\
\hline Mo5 & $\mathrm{Mo}^{\mathrm{III}} \mathrm{Cl}_{3}(\mathrm{tu})_{3}$ & Solid & 1090 & - & - & [159] \\
\hline Mo6 & $\mathrm{Mo}^{\mathrm{III}} \mathrm{Br}_{3}(\text { urea })_{3}$ & Solid & 1105 & - & - & [159] \\
\hline Mo7 & $\mathrm{Mo}^{\mathrm{III}}\left(\mathrm{Me}_{3}[9] \mathrm{aneN}_{3}\right) \mathrm{Cl}_{3}$ & $\mathrm{MeCN}$ & 1120 & 960 & 0.0061 & [ [161] \\
\hline Mo8 & $\mathrm{Mo}^{\mathrm{III}}\left(\mathrm{Me}_{3}[9] \mathrm{aneN}_{3}\right) \mathrm{Br}_{3}$ & $\mathrm{MeCN}$ & 1130 & 800 & 0.0096 & $5[161]$ \\
\hline Mo9 & $\mathrm{Mo}^{\mathrm{III}}\left(\mathrm{Me}_{3}[9] \mathrm{aneN}_{3}\right) \mathrm{I}_{3}$ & $\mathrm{MeCN}$ & 1160 & 450 & 0.012 & $2[161]$ \\
\hline$\left[{ }^{n} \mathrm{Bu}_{4} \mathrm{~N}\right] \mathrm{Mo10}$ & {$\left[{ }^{n} \mathrm{Bu}_{4} \mathrm{~N}\right]\left[\mathrm{Mo}^{\mathrm{III}}\left\{\mathrm{HB}\left(\mathrm{Me}_{2} \mathrm{Pz}\right)_{3}\right\} \mathrm{Cl}_{3}\right]$} & $\mathrm{MeCN}$ & $>1250$ & - & - & {$[161]$} \\
\hline W1 & $\mathrm{W}^{\mathrm{III}}\left(\mathrm{Me}_{3}[9] \mathrm{aneN}_{3}\right) \mathrm{Cl}_{3}$ & Solid & 1400 & - & - & [161] \\
\hline $\mathrm{K}_{2} \mathrm{Mn1}$ & $\mathrm{K}_{2}\left[\mathrm{Mn}^{\mathrm{IV}} \mathrm{Cl}_{6}\right]$ & $a$ & 820 & - & - & {$[168,169]$} \\
\hline \multirow[t]{2}{*}{$\operatorname{Mn} 2(\mathrm{OTf})_{2}$} & \multirow[t]{2}{*}[\mathrm{Mn}^{\mathrm{IV}}\{\mathrm{PhB}(\mathrm{MeIm})_{3}\}_{2}]{$(\mathrm{OTf})_{2}$} & \multirow[t]{2}{*}{ Solid } & $600-750$ & 50 & - & {$[42,43]$} \\
\hline & & & 814 & 1500 & - & {$[42,43]$} \\
\hline$\left[{ }^{n} \mathrm{Bu}_{4} \mathrm{~N}\right]_{2} \mathbf{R e} \mathbf{1}$ & {$\left[{ }^{n} \mathrm{Bu}_{4} \mathrm{~N}\right]_{2}\left[\mathrm{Re}^{\mathrm{IV}} \mathrm{Cl}_{6}\right]$} & $\mathrm{MeCN}$ & 1340 & $40-140$ & $<0.02$ & {$[160,170]$} \\
\hline$\left[{ }^{n} \mathrm{Bu}_{4} \mathrm{~N}\right]_{2} \mathbf{R e} 2$ & {$\left[{ }^{n} \mathrm{Bu}_{4} \mathrm{~N}\right]_{2}\left[\mathrm{Re}^{\mathrm{IV}} \mathrm{Br}_{6}\right]$} & $\mathrm{MeCN}$ & 1380 & - & - & {$[170]$} \\
\hline
\end{tabular}

${ }^{\text {a }}$ The measurements were performed in solution, but the detailed conditions were not reported 


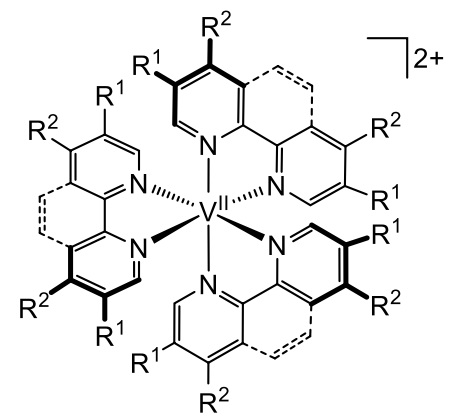

V $5^{2+}: R^{1}=R^{2}=H$, without dotted bonds

$\mathbf{V 6}^{2+}: \mathrm{R}^{1}=\mathrm{CH}_{3}, \mathrm{R}^{2}=\mathrm{H}$, without dotted bonds

$\mathbf{V 7}^{2+}: \mathrm{R}^{1}=\mathrm{H}, \mathrm{R}^{2}=\mathrm{CH}_{3}$, without dotted bonds

$\mathbf{V}^{2+}: \mathrm{R}^{1}=\mathrm{R}^{2}=\mathrm{H}$, with dotted bonds

Scheme 4 Structures of $\mathrm{V}^{\mathrm{II}}$ complexes discussed in the manuscript

electrochemical, quantum chemical and transient absorption studies [89]. The partial ${ }^{2}$ MLCT character leads to geometric distortion facilitating non-radiative decay compared to $\mathrm{Cr}^{\mathrm{III}}$ complexes with their nested doublet excited states [25]. Crystal structures of $\left[\mathrm{V}^{\mathrm{II}}(\text { bpy })_{3}\right]^{2+} \mathbf{V 5}^{\mathbf{2 +}}$ and $\left[\mathrm{V}^{\mathrm{II}}(\text { phen })_{3}\right]^{2+}$ $\mathbf{V 8}^{2+}$ (Scheme 4) further revealed a significant trigonal distortion in the ground state. According to quantum chemical calculations, ISC pathways differ between $\mathbf{V 5}^{2+} / \mathbf{V 8}^{2+}$ and their $\mathrm{Cr}^{\mathrm{III}}$ homologues $\mathbf{C r 8}^{3+} / \mathbf{C r} \mathbf{9}^{3+}$. Both findings were rationalized with a stronger metal-ligand $\pi$-interactions in the $\mathrm{V}^{\mathrm{II}}$ complexes [173].

Complexes of the heavier homologues $\mathrm{Nb}^{\mathrm{II}}$ and $\mathrm{Ta}^{\mathrm{II}}$ are rare and no spin-flip emission has been reported to date [137, 174-178].

For the $d^{3}$-ion $\mathrm{Mn}^{\mathrm{IV}}$, a very early report stated that $\mathrm{K}_{2}\left[\mathrm{Mn}^{\mathrm{IV}} \mathrm{Cl}_{6}\right] \mathrm{K}_{2} \mathrm{Mn1}$ emits at $820 \mathrm{~nm}$ in solution (Scheme 5, Table 3) $[168,169]$. Apart from this, the only reported emissive complex is $\left[\mathrm{Mn}^{\mathrm{IV}}\left\{\mathrm{PhB}(\mathrm{MeIm})_{3}\right\}_{2}\right](\mathrm{OTf})_{2} \operatorname{Mn2}(\mathrm{OTf})_{2}$ $\left(\left\{\mathrm{PhB}(\mathrm{MeIm})_{3}\right\}^{-}=\right.$phenyltris (3-methylimidazol-2-yl)borate, Scheme 5, Table 3) [42, 43]. This hexacarbene complex shows a long-lived ${ }^{2} \mathrm{E} \rightarrow{ }^{4} \mathrm{~A}_{2}$ spin-flip phosphorescence at $814 \mathrm{~nm}$ and a weak ${ }^{4} \mathrm{LMCT}$ fluorescence between 600 and $750 \mathrm{~nm}$ in the solid state at room temperature. When considering the higher Racah parameter of free $\mathrm{Mn}^{4+}\left(1064 \mathrm{~cm}^{-1}\right)$ compared to $\mathrm{Cr}^{3+}\left(918 \mathrm{~cm}^{-1}\right)$ [50], higher doublet state energies should be accessible in $\mathrm{Mn}^{\mathrm{IV}}$ complexes. In Mn2(OTf) however, the emission energy is lower than in most $\mathrm{Cr}^{\text {III }}$ complexes due to a high covalency of the bonds between the $\mathrm{Mn}^{\mathrm{IV}}$ ion and the anionic tricarbene ligands (nephelauxetic effect) [42, 43, 57].

To the best of our knowledge, $\left[{ }^{n} \mathrm{Bu}_{4} \mathrm{~N}\right]_{2}\left[\mathrm{Re}^{\mathrm{IV}} \mathrm{X}_{6}\right](\mathrm{X}=\mathrm{Cl}$, Br) $\left[{ }^{n} \mathrm{Bu}_{4} \mathrm{~N}\right]_{2} \operatorname{Re} 1$ and $\left[{ }^{n} \mathrm{Bu}{ }_{4} \mathrm{~N}\right]_{2} \operatorname{Re} 2$ (Scheme 5, Table 3) present the only emissive molecular $\mathrm{Re}^{\mathrm{IV}}$ complexes in solution reported so far $[160,170]$. Excitation at 360 and $414 \mathrm{~nm}$ in MeCN leads to NIR-II phosphorescence at 1340 and $1380 \mathrm{~nm}$, respectively. For Re1 ${ }^{2-}$, lifetimes of 80 and $140 \mathrm{~ns}$
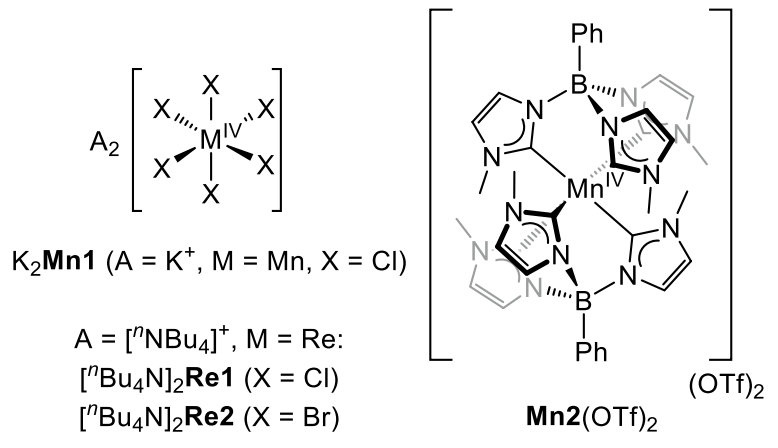

Scheme 5 Structures of luminescent $\mathrm{Mn}^{\mathrm{IV}}$ and $\mathrm{Re}^{\mathrm{IV}}$ complexes [42, $43,160,168-170]$

and an estimated upper limit of $0.02 \%$ for the quantum yield were reported [160, 170]. Re2 ${ }^{2-}$ showed a phosphorescence lifetime of $40 \mathrm{~ns}$ and photosolvation upon LMCT excitation with UV light [179]. Analogous to the $\mathrm{Mo}^{\mathrm{III}}$ and $\mathrm{W}^{\mathrm{III}}$ cases, the extended $5 d$ orbitals and low interelectronic repulsion in $\mathrm{Re}^{\mathrm{IV}}$ lead to high-energy ${ }^{4} \mathrm{~T}_{2}$ states and very low lying doublet states. The challenges accompanied with the heavier group 6 metal ions outlined above apply for $\mathrm{Re}^{\mathrm{IV}}$ as well.

\section{3 $d^{4}-\mathrm{Cr}^{\prime \prime}, \mathrm{Mo}^{\prime \prime}, \mathrm{WII}, \mathrm{Mn}^{\mathrm{III}}$ and $\mathrm{Re}^{\mathrm{III}}$}

The $d^{4}$ complexes are a special case among the electronic configurations discussed in this section. Depending on $\Delta_{\mathrm{O}}$, they can be high-spin or low-spin, resulting in dramatically different energy-level ordering (Fig. 1c). States of three different multiplicities (singlet, triplet, quintet) become relevant. Spin-flip emission is only conceivable in lowspin $d^{4}$ complexes. A very high $\Delta_{\mathrm{O}}(\gg 38 B$ for $C / B=4)$ is required to establish the spin-flip states ${ }^{1} \mathrm{~T}_{2}$ and ${ }^{1} \mathrm{E}$ as the lowest excited states below the high-spin state ${ }^{5} \mathrm{E}$ (Fig. 1c) [58]. The $d^{4}$ configuration is different from the others since deactivation of the potential spin-flip state via a ${ }^{1} \mathrm{~T}_{1} \rightarrow{ }^{5} \mathrm{E}$ transition would entail a change of the total spin of $\Delta S=2$ instead of just 1. However, while efficient ISC processes with $\Delta S=2$ are relatively rare, they cannot be excluded [180, 181]. Another challenge in this electronic configuration might be that the ${ }^{5} \mathrm{E}$ high-spin state always lies below the lowest triplet $\mathrm{MC}$ state ${ }^{3} \mathrm{E}$. A relaxation cascade ${ }^{3} \mathrm{E} \rightarrow$ ${ }^{1} \mathrm{~T}_{2} /{ }^{1} \mathrm{E}$ after ${ }^{3} \mathrm{~T}_{1} \rightarrow{ }^{3} \mathrm{E}$ excitation is thus probably impeded by non-radiative deactivation of the ${ }^{3} \mathrm{E}$ state via the ${ }^{5} \mathrm{E}$ state similar to certain $d^{6}-\mathrm{Fe}^{\mathrm{II}}$ complexes [19]. Therefore, in a potential $d^{4}$ spin-flip emitter, the ${ }^{1} \mathrm{~T}_{2}$ and ${ }^{1} \mathrm{E}$ states need to be populated via other routes, e.g., CT states. Finally, similar to the $d^{2}$ electron configuration, the ${ }^{3} \mathrm{~T}_{1}$ ground state of the lowspin $d^{4}$ electron configuration is orbitally degenerate giving rise to Jahn-Teller distortions (Fig. 1a,c). Overall, spin-flip emission from $d^{4}$ transition metal complexes has not been achieved yet for molecular systems. In principle complexes 
of group 6, ions in the oxidation state + II are potential candidates. However, there are only few examples of low-spin octahedral $\mathrm{Cr}^{\mathrm{II}}$ complexes requiring exceptionally strong ligands like $\mathrm{CN}^{-}[182,183]$. The reduced Molecular Ruby $\left[\mathrm{Cr}^{\mathrm{II}}(\mathrm{ddpd})_{2}\right]^{2+} \mathbf{C r 4}^{2+}$ shows spin-crossover at room temperature and dark excited states with microsecond lifetimes [184]. Further preparative and handling challenges for divalent group 6 metal ions include their sensitivity to oxidation, dimerization or cluster formation [185-190].

Other candidates for $d^{4}$ spin-flip emission are, e.g., $\mathrm{Mn}^{\mathrm{III}}$, $\mathrm{Tc}^{\mathrm{III}}$ and $\mathrm{Re}^{\mathrm{III}}$. However, known emissive $\mathrm{Mn}^{\mathrm{III}}$ complexes only show luminescence from ligand-centered transitions [191-194]. While octahedral Tc ${ }^{\mathrm{III}}$ and $\mathrm{Re}^{\mathrm{III}}$ complexes are quite common [195, 196], to the best of our knowledge no spin-flip emission has been reported so far.

Due to the very high $\Delta_{\mathrm{O}}$ required for spin-flip emission in the $d^{4}$ case, complexes of $4 d$ and $5 d$ transition metal ions seem to be promising candidates.

\section{$6.4 d^{8}-\mathrm{Ni}^{\prime \prime}, \mathrm{Pd}$ " and Pt"}

In an octahedral ligand field, $d^{8}$ ions like $\mathrm{Ni}^{\mathrm{II}}$ possess a ${ }^{3} \mathrm{~A}_{2}$ ground state, a ${ }^{3} \mathrm{~T}_{2}$ excited state and a ${ }^{1} \mathrm{E}$ spin-flip state (Fig. 1d). Compared to the other $d$ electron configurations, the ${ }^{1} \mathrm{E}$ state in $d^{8}$ is unique because the spin-flip occurs in the $e_{\mathrm{g}}{ }^{*}$ orbitals with $\sigma$-instead of $\pi$-symmetry. Interestingly, the ${ }^{1} \mathrm{~g}$ state consists of an unpaired and a spin-paired microstate (Fig. 1d). Population of the spin-paired microstate might lead to excited state Jahn-Teller distortion facilitating nonradiative decay to the ground state.

In principle, a strong ligand field could raise the ${ }^{3} \mathrm{~T}_{2}$ state above the ${ }^{1} \mathrm{E}$ state and enable spin-flip phosphorescence. Octahedral $\mathrm{Ni}^{\mathrm{II}}$ complexes with strong donor ligands like phen, tpm, bpy, tpy and ddpd $\left(\mathbf{N i 1}^{\mathbf{2 +}}-\mathbf{N i 5}^{\mathbf{2 +}}\right.$; tpm $=$ tris(pyrid-2-yl)methane; Scheme 6) show ligand field splittings of $17-18 B$ which are close to the ${ }^{3} \mathrm{~T}_{2}{ }^{1} \mathrm{E}$ crossing point in the TS diagram (Fig. 1d) [129, 197-201], while homo- and heteroleptic complexes with poly(pyrazolyl) methane ligands showed a lower $\Delta_{\mathrm{O}}$ of 11-15B [202]. Absorption spectroscopy revealed that the ${ }^{3} \mathrm{~T}_{2}$ and ${ }^{1} \mathrm{E}$ states are not sufficiently separated with ${ }^{1} \mathrm{E}$ transitions detected as shoulders on the ${ }^{3} \mathrm{~T}_{2}$ bands. In this case, the spin-forbidden ${ }^{3} \mathrm{~A}_{2} \rightarrow{ }^{1} \mathrm{E}$ absorptions are enhanced by intensity borrowing from the nearby ${ }^{3} \mathrm{~T}_{2}$ band [201]. The lowest energy adiabatic state is strongly anharmonic due to coupling with components of the ${ }^{3} \mathrm{~T}_{2}$ state via SOC which reduces the spin-flip character [203]. In summary, a ligand field splitting $\Delta_{\mathrm{O}} \gg 18 B$ is necessary to bring spin-flip luminescence within reach [200]. However, as the classical example of $\left[\mathrm{Ni}^{\mathrm{II}}(\mathrm{CN})_{4}\right]^{2-}$ illustrates, a square-planar coordination geometry with a singlet ground state is favored with very strong ligands [204]. Thus, a balance between these two extremes is necessary for spin-flip emission.
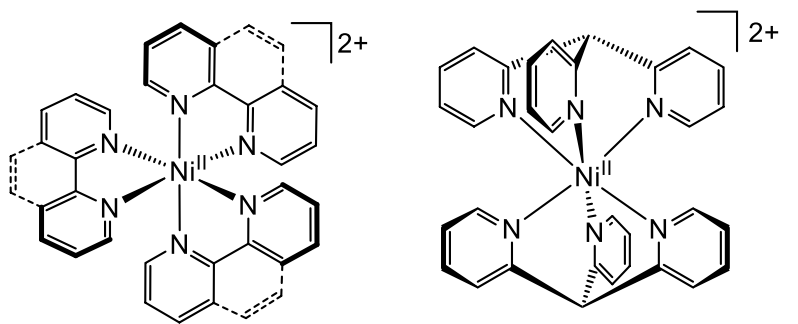

$\mathrm{Ni}^{2+}$ (with dotted bonds) $\mathrm{Ni}^{2+}$ (without dotted bonds)

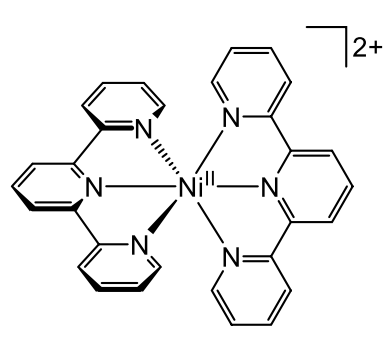

$\mathrm{Ni}^{2+}$
$\mathrm{Ni}^{2+}$

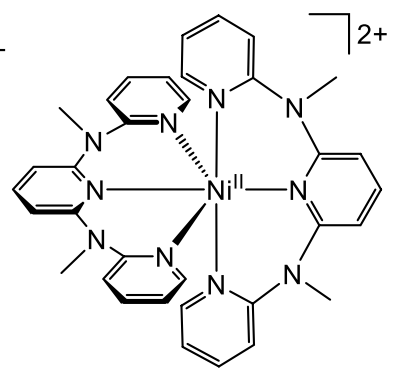

$\mathrm{Ni}^{2+}$
Scheme 6 Structures of $\mathrm{Ni}^{\mathrm{II}}$ complexes discussed in the manuscript

It was reported that $\mathbf{N i 1}^{\mathbf{2 +}}$ and $\mathbf{N i 2}{ }^{2+}$ are emissive in the solid state at $150 \mathrm{~K}$ [129]. However, these findings have been called into question since the reported emission bands for $\mathbf{N i 1}^{\mathbf{2 +}}$ and $\mathbf{N i 2}{ }^{\mathbf{2 +}}$ are almost superimposable, which is unlikely considering their different symmetry [143].

The heavier homologues $\mathrm{Pd}^{\mathrm{II}}$ and $\mathrm{Pt}^{\mathrm{II}}$ prefer a square-planar coordination geometry due to their high intrinsic ligand field splitting [185]. Pseudooctahedral complexes of $\mathrm{Pd}^{\mathrm{II}}$ and $\mathrm{Pt}^{\mathrm{II}}$ are very rare and often require sophisticated ligands to avoid the formation of a square-planar geometry [205-210]. No spin-flip phosphorescence in these types of complexes was reported to date.

\section{Conclusion}

The numerous examples of spin-flip luminescent complexes in this review substantiate that metal-centered states can be more than just non-radiative relaxation pathways for chargetransfer states, but that spin-flip chromophores constitute a useful class of phosphorescent complexes complementary to charge-transfer chromophores. A deeper understanding of the requirements for efficient spin-flip emission has given rise to the emerging class of highly luminescent $\mathrm{Cr}^{\text {III }}$ complexes (Molecular Rubies) and the first luminescent $\mathrm{V}^{\mathrm{III}}$ complexes. This marks substantial progress in the ongoing endeavor to establish photoactive complexes based on earthabundant metals as sustainable alternatives to precious or rare earth metal complexes [11, 19, 158]. In this context, circularly polarized luminescence is a promising application 
of enantiopure chiral spin-flip emitters, which makes full use of their unique excited state properties [123].

This review also highlighted many open venues for more fundamental research. It is still a challenge to tune the relative energies of the relevant states to achieve, e.g., highenergy spin-flip emission. In addition, the role of the density of high-energy ${ }^{2} \mathrm{~T}_{2}$ doublet states for efficient intersystem crossing in excited $\mathrm{Cr}^{\mathrm{III}}$ complexes remains unclear to this date. $4 d$ and $5 d$ complexes of $\mathrm{Mo}^{\mathrm{III}}, \mathrm{W}^{\mathrm{III}}$ or $\mathrm{Re}^{\mathrm{IV}}$ offer ideal conditions to study $d^{3}$ spin-flip emission beyond the second quartet-doublet crossing point in the Tanabe-Sugano diagram. For some metal ions like $\mathrm{Ni}^{\mathrm{iI}}$, reports on spin-flip emission are limited to doped solids [46], while convincing evidence in molecular systems is lacking. Here, it remains a challenge to establish a sufficiently high ligand field splitting that separates the initially excited interconfigurational states and the intraconfigurational spin-flip states without resulting in a square-planar coordination geometry.

Supplementary Information The online version contains supplementary material available at https://doi.org/10.1007/s43630-022-00186-3.

Acknowledgements The authors would like to thank Prof. Dr. Christian Reber, Dr. Christoph Förster and Nathan Roy East for constructive criticism of the manuscript. Parts of this research were conducted using the supercomputer ELWETRITSCH and advisory services offered by the Technical University of Kaiserslautern (https://elwe.rhrk.uni-kl. $\mathrm{de} /$ ), which is a member of the AHRP.

Author contributions WRK conceptualized the article, performed the literature search and wrote the article. JM provided support in writing of the article. KH provided the idea and general concept for the article and critically revised the work. All authors read and approved the final manuscript.

Funding Open Access funding enabled and organized by Projekt DEAL. Financial support from the Deutsche Forschungsgemeinschaft [DFG, Priority Program SPP 2102 "Light-controlled reactivity of metal complexes" (HE 2778/13-1)] is gratefully acknowledged. W. R. K. is grateful to the Chemical Industry Funds for a Kekulé Fellowship.

Availability of data and material Supporting Information for quantum chemical calculations.

Code availability Not applicable.

\section{Declarations}

Conflicts of interest The authors declare no conflict of interest.

Ethics approval Not applicable.

Consent to participate Not applicable.

Consent for publication Not applicable.

Open Access This article is licensed under a Creative Commons Attribution 4.0 International License, which permits use, sharing, adaptation, distribution and reproduction in any medium or format, as long as you give appropriate credit to the original author(s) and the source, provide a link to the Creative Commons licence, and indicate if changes were made. The images or other third party material in this article are included in the article's Creative Commons licence, unless indicated otherwise in a credit line to the material. If material is not included in the article's Creative Commons licence and your intended use is not permitted by statutory regulation or exceeds the permitted use, you will need to obtain permission directly from the copyright holder. To view a copy of this licence, visit http://creativecommons. org/licenses/by/4.0/.

\section{References}

1. Bizzarri, C., Spuling, E., Knoll, D. M., Volz, D., \& Bräse, S. (2018). Sustainable metal complexes for organic light-emitting diodes (OLEDs). Coordination Chemistry Reviews, 373, 49-82. https://doi.org/10.1016/j.ccr.2017.09.011

2. Li, X., Xie, Y., \& Li, Z. (2021). Diversity of luminescent metal complexes in OLEDs: Beyond traditional precious metals. Chemistry - An Asian Journal, 16(19), 2817-2829. https://doi.org/10. 1002/asia.202100784

3. Twilton, J., Le, C., Zhang, P., Shaw, M. H., Evans, R. W., \& MacMillan, D. W. C. (2017). The merger of transition metal and photocatalysis. Nature Reviews Chemistry. https://doi.org/10. 1038/s41570-017-0052

4. Imran, M., Ramzan, M., Qureshi, A. K., Khan, M. A., \& Tariq, M. (2018). Emerging applications of porphyrins and metalloporphyrins in biomedicine and diagnostic magnetic resonance imaging. Biosensors, 8(4), 95. https://doi.org/10.3390/bios8040095

5. Chou, P.-T., \& Chi, Y. (2006). Osmium- and ruthenium-based phosphorescent materials: Design, photophysics, and utilization in OLED fabrication. European Journal of Inorganic Chemistry, 2006(17), 3319-3332. https://doi.org/10.1002/ejic. 200600364

6. Liu, Z., Bian, Z., \& Huang, C. (2010). Luminescent iridium complexes and their applications. In H. Bozec \& V. Guerchais (Eds.), Molecular organometallic materials for optics (pp. 113-142). Springer. https://doi.org/10.1007/978-3-642-01866-4_4

7. Mauro, M., Aliprandi, A., Septiadi, D., Kehr, N. S., \& de Cola, L. (2014). When self-assembly meets biology: Luminescent platinum complexes for imaging applications. Chemical Society Reviews, 43(12), 4144-4166. https://doi.org/10.1039/c3cs60453e

8. Parker, D., Fradgley, J. D., \& Wong, K.-L. (2021). The design of responsive luminescent lanthanide probes and sensors. Chemical Society Reviews, 50(14), 8193-8213. https://doi.org/10.1039/ d $1 \mathrm{cs} 00310 \mathrm{k}$

9. Shum, J., Leung, P.K.-K., \& Lo, K.K.-W. (2019). Luminescent ruthenium(II) polypyridine complexes for a wide variety of biomolecular and cellular applications. Inorganic Chemistry, 58(4), 2231-2247. https://doi.org/10.1021/acs.inorgchem.8b02979

10. Wenger, O. S. (2019). Is iron the new ruthenium? Chemistry--A European Journal, 25(24), 6043-6052. https://doi.org/10.1002/ chem. 201806148

11. Förster, C., \& Heinze, K. (2020). Photophysics and photochemistry with Earth-abundant metals-fundamentals and concepts. Chemical Society Reviews, 49(4), 1057-1070. https://doi.org/10. $1039 / \mathrm{c} 9 \mathrm{cs} 00573 \mathrm{k}$

12. Braun, J. D., Lozada, I. B., Kolodziej, C., Burda, C., Newman, K. M. E., van Lierop, J., Davis, R. L., \& Herbert, D. E. (2019). Iron(II) coordination complexes with panchromatic absorption and nanosecond charge-transfer excited state lifetimes. Nature Chemistry, 11(12), 1144-1150. https://doi.org/10.1038/ s41557-019-0357-z 
13. Carey, M. C., Adelman, S. L., \& McCusker, J. K. (2019). Insights into the excited state dynamics of $\mathrm{Fe}(\mathrm{II})$ polypyridyl complexes from variable-temperature ultrafast spectroscopy. Chemical Science, 10(1), 134-144. https://doi.org/10.1039/c8sc04025g

14. Fredin, L. A., Pápai, M., Rozsályi, E., Vankó, G., Wärnmark, K., Sundström, V., \& Persson, P. (2014). Exceptional excited-state lifetime of an iron(II)-N-heterocyclic carbene complex explained. Journal of Physical Chemistry Letters, 5(12), 2066-2071. https:// doi.org/10.1021/jz500829w

15. Dierks, P., Kruse, A., Bokareva, O. S., Al-Marri, M. J., Kalmbach, J., Baltrun, M., Neuba, A., Schoch, R., Hohloch, S., Heinze, K., Seitz, M., Kühn, O., Lochbrunner, S., \& Bauer, M. (2021). Distinct photodynamics of $\kappa-\mathrm{N}$ and $\kappa-\mathrm{C}$ pseudoisomeric iron(II) complexes. Chemical Communications, 57(54), 66406643. https://doi.org/10.1039/d1cc01716k

16. Dierks, P., Päpcke, A., Bokareva, O. S., Altenburger, B., Reuter, T., Heinze, K., Kühn, O., Lochbrunner, S., \& Bauer, M. (2020). Ground- and excited-state properties of iron(II) complexes linked to organic chromophores. Inorganic Chemistry, 59(20), 1474614761. https://doi.org/10.1021/acs.inorgchem.0c02039

17. Reuter, T., Kruse, A., Schoch, R., Lochbrunner, S., Bauer, M., \& Heinze, K. (2021). Higher MLCT lifetime of carbene iron(II) complexes by chelate ring expansion. Chemical Communications, 57(61), 7541-7544. https://doi.org/10.1039/d1cc02173g

18. Woodhouse, M. D., \& McCusker, J. K. (2020). Mechanistic origin of photoredox catalysis involving iron(II) polypyridyl chromophores. Journal of the American Chemical Society, 142(38), 16229-16233. https://doi.org/10.1021/jacs.0c08389

19. Dierks, P., Vukadinovic, Y., \& Bauer, M. (2022). Photoactive iron complexes: more sustainable, but still a challenge. Inorganic Chemistry Frontiers. https://doi.org/10.1039/D1QI01112J

20. Chábera, P., Kjær, K. S., Prakash, O., Honarfar, A., Liu, Y., Fredin, L. A., Harlang, T. C. B., Lidin, S., Uhlig, J., Sundström, V., Lomoth, R., Persson, P., \& Wärnmark, K. (2018). FeII hexa $\mathrm{N}$-heterocyclic carbene complex with a 528 ps metal-to-ligand charge-transfer excited-state lifetime. Journal of Physical Chemistry Letters, 9(3), 459-463. https://doi.org/10.1021/acs.jpclett. 7b02962

21. Larsen, C. B., Braun, J. D., Lozada, I. B., Kunnus, K., Biasin, E., Kolodziej, C., Burda, C., Cordones, A. A., Gaffney, K. J., \& Herbert, D. E. (2021). Reduction of electron repulsion in highly covalent $\mathrm{Fe}$-amido complexes counteracts the impact of a weak ligand field on excited-state ordering. Journal of the Chemical Society. https://doi.org/10.1021/jacs.1c06429

22. Leis, W., Argüello Cordero, M. A., Lochbrunner, S., Schubert, H., \& Berkefeld, A. (2022). A photoreactive iron(II) complex luminophore. Journal of the Chemical Society. https://doi.org/ 10.1021/jacs.1c13083

23. Viaene, L., \& D'Olieslager, J. (1987). Luminescence from and absorption by the ${ }^{3} \mathrm{~T}_{1 \mathrm{~g}}$ level of the hexacyanocobaltate(III) ion. Inorganic Chemistry, 26(6), 960-962. https://doi.org/10.1021/ ic00253a039

24. Kaufhold, S., Rosemann, N. W., Chábera, P., Lindh, L., Bolaño Losada, I., Uhlig, J., Pascher, T., Strand, D., Wärnmark, K., Yartsev, A., \& Persson, P. (2021). Microsecond photoluminescence and photoreactivity of a metal-centered excited state in a hexacarbene-co(III) complex. Journal of the American Chemical Society, 143(3), 1307-1312. https://doi.org/10.1021/jacs.0c121 51

25. Otto, S., Grabolle, M., Förster, C., Kreitner, C., Resch-Genger, U., \& Heinze, K. (2015). [Cr(ddpd $\left.)_{2}\right]^{3+}$ : A molecular, water-soluble, highly NIR-emissive ruby analogue. Angewandte Chemie International Edition, 54(39), 11572-11576. https://doi.org/10. 1002/anie.201504894

26. Förster, C., Dorn, M., Reuter, T., Otto, S., Davarci, G., Reich, T., Carrella, L., Rentschler, E., \& Heinze, K. (2018). Ddpd as expanded terpyridine dramatic effects of symmetry and electronic properties in first row transition metal complexes. Inorganics, 6(3), 86. https://doi.org/10.3390/inorganics6030086

27. Doistau, B., Collet, G., Bolomey, E. A., Sadat-Noorbakhsh, V., Besnard, C., \& Piguet, C. (2018). Heteroleptic ter-bidentate $\mathrm{Cr}(\mathrm{III})$ complexes as tunable optical sensitizers. Inorganic Chemistry, 57(22), 14362-14373. https://doi.org/10.1021/acs. inorgchem. $8 \mathrm{~b} 02530$

28. Jiménez, J.-R., Doistau, B., Cruz, C. M., Besnard, C., Cuerva, J. M., Campaña, A. G., \& Piguet, C. (2019). Chiral molecular ruby $\mathrm{Cr}(\mathrm{dqp})_{2}{ }^{3+}$ with long-lived circularly polarized luminescence. Journal of the American Chemical Society, 141(33), 13244-13252. https://doi.org/10.1021/jacs.9b06524

29. Jiménez, J.-R., Poncet, M., Míguez-Lago, S., Grass, S., Lacour, J., Besnard, C., Cuerva, J. M., Campaña, A. G., \& Piguet, C. (2021). Bright long-lived circularly polarized luminescence in chiral chromium(III) complexes. Angewandte Chemie International Edition, 60(18), 10095-10102. https://doi.org/10.1002/ anie. 202101158

30. Flint, C. (1971). A vibronic analysis of the transition in solid $\mathrm{Cs}_{2} \mathrm{MnF}_{6}$. Journal of Molecular Spectroscopy, 37(3), 414-422. https://doi.org/10.1016/0022-2852(71)90173-1

31. Chodos, S. L., Black, A. M., \& Flint, C. D. (1976). Vibronic spectra and lattice dynamics of $\mathrm{Cs}_{2} \mathrm{MnF}_{6}$ and $\mathrm{A}_{2}^{1} \mathrm{M}^{\mathrm{IV}} \mathrm{F}_{6}: \mathrm{MnF}_{2}{ }^{-}$. The Journal of Chemical Physics, 65(11), 4816-4824. https:// doi.org/10.1063/1.432952

32. Flint, C. D., \& Lang, P. F. (1987). Substitution reactions and luminescence spectra of the mixed complexes [ReClxBr 6-x]2-. Journal of the Chemical Society, Dalton Transactions, 8, 19291932. https://doi.org/10.1039/DT9870001929

33. Flint, C. D., \& Lang, P. F. (1986). Luminescence spectra of the mixed complexes [TcClxBr 6-x]2-. Journal of the Chemical Society, Dalton Transactions, 5, 921-923. https://doi.org/10. 1039/DT9860000921

34. Preetz, W., Peters, G., \& Bublitz, D. (1996). Preparation and spectroscopic investigations of mixed octahedral complexes and clusters. Chemical Reviews, 96(3), 977-1026. https://doi.org/10. 1021/cr940393i

35. Suyver, J. F., Aebischer, A., Biner, D., Gerner, P., Grimm, J., Heer, S., Krämer, K. W., Reinhard, C., \& Güdel, H. U. (2005). Novel materials doped with trivalent lanthanides and transition metal ions showing near-infrared to visible photon upconversion. Optical Materials, 27(6), 1111-1130. https://doi.org/10.1016/j. optmat.2004.10.021

36. Reber, C., Guedel, H. U., Meyer, G., Schleid, T., \& Daul, C. A. (1989). Optical spectroscopic and structural properties of $\mathrm{V}^{3+}$-doped fluoride, chloride, and bromide elpasolite lattices. Inorganic Chemistry, 28(16), 3249-3258. https://doi.org/10. 1021/ic00315a034

37. Jacobsen, S. M., \& Güdel, H. U. (1989). Higher excited state luminescence in $\mathrm{Ti}^{2+}: \mathrm{MgCl}_{2}$ Dynamics of radiative and nonradiative processes. Journal of Luminescence, 43(3), 125-137. https://doi.org/10.1016/0022-2313(89)90009-4

38. Wenger, O. S., \& Güdel, H. U. (2001). Dual luminescence and excited-state dynamics in $\mathrm{Ti}^{2+}$ doped $\mathrm{NaCl}$. The Journal of Physical Chemistry B, 105(19), 4181-4187. https://doi.org/10.1021/ jp004183n

39. Flint, C. D., \& Paulusz, A. G. (1981). Infrared and visible luminescence spectra of MoCl63- and $\mathrm{MoBr}$ 63- in cubic elpasolite crystals. Molecular Physics, 44(4), 925-938. https://doi.org/10. 1080/00268978100102891

40. Flint, C. D., \& Paulusz, A. G. (1980). High resolution infrared and visible luminescence spectra of OsCl62- and $\mathrm{OsBr} 62$ - in cubic crystals. Molecular Physics, 41(4), 907-923. https://doi. org/10.1080/00268978000103241 
41. Ji, H., Hou, X., Molokeev, M. S., Ueda, J., Tanabe, S., Brik, M. G., Zhang, Z., Wang, Y., \& Chen, D. (2020). Ultrabroadband red luminescence of $\mathrm{Mn}^{4+}$ in $\mathrm{MgAl}_{2} \mathrm{O}_{4}$ peaking at $651 \mathrm{~nm}$. Dalton Transactions, 49(17), 5711-5721. https://doi.org/10.1039/ D0DT00931H

42. Harris, J. P., Reber, C., Colmer, H. E., Jackson, T. A., Forshaw, A. P., Smith, J. M., Kinney, R. A., \& Telser, J. (2017). Near-infrared ${ }^{2} \mathrm{E}_{\mathrm{g}} \rightarrow{ }^{4} \mathrm{~A}_{2 \mathrm{~g}}$ and visible LMCT luminescence from a molecular bis-(tris(carbene)borate) manganese(IV) complex. Canadian Journal of Chemistry, 95(5), 547-552. https://doi.org/10.1139/ cjc-2016-0607

43. Harris, J. P., Reber, C., Colmer, H. E., Jackson, T. A., Forshaw, A. P., Smith, J. M., Kinney, R. A., \& Telser, J. (2020). Correction: Near-infrared ${ }^{2} \mathrm{E}_{\mathrm{g}} \rightarrow{ }^{4} \mathrm{~A}_{2 \mathrm{~g}}$ and visible LMCT luminescence from a molecular bis-(tris(carbene)borate) manganese(IV) complex. Canadian Journal of Chemistry, 98(5), 250. https://doi.org/ 10.1139/cjc-2020-0119

44. Bussiére, G., Beaulac, R., Cardinal-David, B., \& Reber, C. (2001). Coupled electronic states in trans- $\mathrm{MCl}_{2}\left(\mathrm{H}_{2} \mathrm{O}\right)_{4}{ }^{\mathrm{n+}}$ complexes $\left(\mathrm{M}: \mathrm{Ni}^{2+}, \mathrm{Co}^{2+}, \mathrm{V}^{3+}, \mathrm{Cr}^{3+}\right)$ probed by absorption and luminescence spectroscopy. Coordination Chemistry Reviews, 219-221, 509-543. https://doi.org/10.1016/S0010-8545(01) 00349-6

45. Atanasov, M., Andreici Eftimie, E.-L., Avram, N. M., Brik, M. G., \& Neese, F. (2021). First-principles study of optical absorption energies, ligand field and spin-hamiltonian parameters of $\mathrm{Cr}^{3+}$ ions in emeralds. Inorganic Chemistry. https://doi.org/10. 1021/acs.inorgchem.1c02650

46. Wenger, O. S., Bénard, S., \& Güdel, H. U. (2002). Crystal field effects on the optical absorption and luminescence properties of $\mathrm{Ni}^{2+}$-doped chlorides and bromides: Crossover in the emitting higher excited state. Inorganic Chemistry, 41(23), 5968-5977. https://doi.org/10.1021/ic020347y

47. Monteiro, J. H. S. K. (2020). Recent advances in luminescence imaging of biological systems using lanthanide(III) luminescent complexes. Molecules. https://doi.org/10.3390/molecules 250920 89

48. Yuan, J., \& Wang, G. (2006). Lanthanide-based luminescence probes and time-resolved luminescence bioassays. Trends Analyt. Chem., 25(5), 490-500. https://doi.org/10.1016/j.trac.2005.11. 013

49. Wei, C., Ma, L., Wei, H., Liu, Z., Bian, Z., \& Huang, C. (2018). Advances in luminescent lanthanide complexes and applications. Science China Technological Science, 61(9), 1265-1285. https:// doi.org/10.1007/s11431-017-9212-7

50. Lever, A. B. P. (1968). Inorganic electronic spectroscopy (1st ed.). Elsevier.

51. Ballhausen, C. J. (1962). Introduction to ligand field theory. McGraw-Hill Book Company.

52. Tanabe, Y., \& Sugano, S. (1954). On the absorption spectra of complex ions I. Journal of the Physical Society of Japan, 9(5), 753-766. https://doi.org/10.1143/jpsj.9.753

53. Tanabe, Y., \& Sugano, S. (1954). On the absorption spectra of complex ions II. Journal of the Physical Society of Japan, 9(5), 766-779. https://doi.org/10.1143/JPSJ.9.766

54. Figgis, B. N., \& Hitchman, M. A. (2000). Ligand field theory and its applications. Wiley-VCH.

55. Zare, D., Doistau, B., Nozary, H., Besnard, C., Guénée, L., Suffren, Y., Pelé, A.-L., Hauser, A., \& Piguet, C. (2017). Cr ${ }^{\mathrm{III}}$ as an alternative to $\mathrm{Ru}^{\mathrm{II}}$ in metallo-supramolecular chemistry. Dalton Transactions, 46(28), 8992-9009. https://doi.org/10.1039/c7dt0 $1747 \mathrm{~b}$

56. Otto, S., Dorn, M., Förster, C., Bauer, M., Seitz, M., \& Heinze, K. (2018). Understanding and exploiting long-lived near-infrared emission of a molecular ruby. Coordination Chemistry Reviews, 359, 102-111. https://doi.org/10.1016/j.ccr.2018.01.004
57. Jørgensen, C. K. (1963). Spectroscopy of transition-group complexes. In: Advances in chemical physics, (pp. 33-146). Wiley. https://doi.org/10.1002/9780470143513.ch2.

58. Oppenheim, J. \& Miller, J. (2021), Tanabe-Sugano for Mathematica. Retrieved December 07, 2021, from https://github.com/ JulesOpp/Tanabe-Sugano. Accessed 07 Dec 2021

59. Kaufhold, S., \& Wärnmark, K. (2020). Design and synthesis of photoactive iron N-heterocyclic carbene complexes. Catalysts, 10(1), 132. https://doi.org/10.3390/catal10010132

60. Tang, Y., Zhao, S., Long, B., Liu, J.-C., \& Li, J. (2016). On the nature of support effects of metal dioxides $\mathrm{MO}_{2}(\mathrm{M}=\mathrm{Ti}, \mathrm{Zr}, \mathrm{Hf}$, $\mathrm{Ce}, \mathrm{Th})$ in single-atom gold catalysts: importance of quantum primogenic effect. Journal of Physical Chemistry C, 120(31), 17514-17526. https://doi.org/10.1021/acs.jpcc.6b05338

61. McCusker, J. K. (2019). Electronic structure in the transition metal block and its implications for light harvesting. Science, 363(6426), 484-488. https://doi.org/10.1126/science.aav9104

62. Dorn, M., Kalmbach, J., Boden, P., Päpcke, A., Gómez, S., Förster, C., Kuczelinis, F., Carrella, L. M., Büldt, L. A., Bings, N. H., Rentschler, E., Lochbrunner, S., González, L., Gerhards, M., Seitz, M., \& Heinze, K. (2020). A vanadium(III) complex with blue and NIR-II spin-flip luminescence in solution. Journal of the American Chemical Society, 142(17), 7947-7955. https:// doi.org/10.1021/jacs.0c02122

63. Kirk, A. D., \& Porter, G. B. (1980). Luminescence of chromium(III) complexes. Journal of Physical Chemistry, 84(8), 887-891. https://doi.org/10.1021/j100445a020

64. Jiménez, J.-R., Doistau, B., Besnard, C., \& Piguet, C. (2018). Versatile heteroleptic bis-terdentate $\mathrm{Cr}(\mathrm{III})$ chromophores displaying room temperature millisecond excited state lifetimes. Chemical Communications, 54(94), 13228-13231. https://doi. org/10.1039/c8cc07671e

65. Whuler, A., Brouty, C., Spinat, P. \& Herpin, P. (1977). Structure du complexe actif hydraté (+)-Cr(en $)_{3} \mathrm{Cl}_{3} \cdot 2 \mathrm{H}_{2} \mathrm{O}$. Etude de la configuration absolue et du désordre conformationnel, Acta Crystallogr. B Struct. Sci., 33(9), 2877-2885. https://doi.org/10. 1107/S0567740877009674.

66. Ando, H., Iuchi, S., \& Sato, H. (2012). Theoretical study on ultrafast intersystem crossing of chromium(III) acetylacetonate. Chemical Physics Letters, 535, 177-181. https://doi.org/10. 1016/j.cplett.2012.03.043

67. Penfold, T. J., Gindensperger, E., Daniel, C., \& Marian, C. M. (2018). Spin-vibronic mechanism for intersystem crossing. Chemical Reviews, 118(15), 6975-7025. https://doi.org/10.1021/ acs.chemrev.7b00617

68. Juban, E. A., \& McCusker, J. K. (2005). Ultrafast dynamics of ${ }^{2} \mathrm{E}$ state formation in $\mathrm{Cr}(\mathrm{acac})_{3}$. Journal of the American Chemical Society, 127(18), 6857-6865. https://doi.org/10.1021/ja042153i

69. Ballardini, R., Varani, G., Wasgestian, H. F., Moggi, L., \& Balzani, V. (1973). Role of the excited states in the photochemical and photophysical behavior of tris(ethylenediamine) chromium(III) in aqueous solutions. Journal of Physical Chemistry, 77(25), 2947-2951. https://doi.org/10.1021/j100643a004

70. Adamson, A. W. (1967). Photochemistry of complex ions. IV. Role of quartet excited states in the photochemistry of chromium(III) complexes. The Journal of Physical Chemistry, 71(4), 798-808. https://doi.org/10.1021/j100863a003

71. Knochenmuss, R., Reber, C., Rajasekharan, M. V., \& Güdel, H. U. (1986). Broadband near-infrared luminescence of $\mathrm{Cr}^{+3}$ in the elpasolite lattices $\mathrm{Cs}_{2} \mathrm{NaInCl}_{6}, \mathrm{Cs} 2_{\mathrm{N}} \mathrm{aYCl} 6$ and $\mathrm{Cs}_{2} \mathrm{~N}_{\mathrm{N}} \mathrm{YBr}_{6}$. The Journal of Chemical Physics, 85(8), 4280-4289. https://doi.org/ $10.1063 / 1.451801$

72. Otto, S., Harris, J. P., Heinze, K., \& Reber, C. (2018). Molecular ruby under pressure. Angewandte Chemie International Edition, 57(34), 11069-11073. https://doi.org/10.1002/anie.201806755 
73. Reichenauer, F., Wang, C., Förster, C., Boden, P., Ugur, N., Báez-Cruz, R., Kalmbach, J., Carrella, L. M., Rentschler, E., Ramanan, C., Niedner-Schatteburg, G., Gerhards, M., Seitz, M., Resch-Genger, U., \& Heinze, K. (2021). Strongly red-emissive molecular ruby $\mathrm{Cr}(\mathrm{bpmp})_{2}{ }^{3+}$ surpasses $\mathrm{Ru}(\mathrm{bpy})_{3}{ }^{2+}$. Journal of the American Chemical Society, 143(30), 11843-11855. https:// doi.org/10.1021/jacs.1c05971

74. Otto, S., Nauth, A. M., Ermilov, E., Scholz, N., Friedrich, A., Resch-Genger, U., Lochbrunner, S., Opatz, T., \& Heinze, K. (2017). Photo-chromium: sensitizer for visible-light-induced oxidative $\mathrm{C}-\mathrm{H}$ bond functionalization-electron or energy transfer? ChemPhotoChem, 1(8), 344-349. https://doi.org/10.1002/ cptc. 201700077

75. Fukuda, R., Walters, R. T., Macke, H., \& Adamson, A. W. (1979). Rate of primary photoproduct formation for aqueous tris(ethylenediamine)chromium( $3+$ ) and chloropentaamminechromium(2+). Journal of Physical Chemistry, 83(16), 20972103. https://doi.org/10.1021/j100479a009

76. Barbour, J. C., Kim, A. J. I., deVries, E., Shaner, S. E., \& Lovaasen, B. M. (2017). Chromium(III) bis-arylterpyridyl complexes with enhanced visible absorption via incorporation of intraligand charge-transfer transitions. Inorganic Chemistry, 56(14), 8212-8222. https://doi.org/10.1021/acs.inorgchem.7b009 53

77. Yardley, J. T., \& Beattie, J. K. (1972). Lifetime of the ${ }^{4} \mathrm{~T}_{2 \mathrm{~g}}$ state of tris(2,4-pentanedionato)chromium(III) reexamined. Journal of the American Chemical Society, 94(25), 8925-8926. https:// doi.org/10.1021/ja00780a057

78. Treiling, S., Wang, C., Förster, C., Reichenauer, F., Kalmbach, J., Boden, P., Harris, J. P., Carrella, L. M., Rentschler, E., ReschGenger, U., Reber, C., Seitz, M., Gerhards, M., \& Heinze, K. (2019). Luminescence and light-driven energy and electron transfer from an exceptionally long-lived excited state of a noninnocent chromium(III) complex. Angewandte Chemie International Edition, 58(50), 18075-18085. https://doi.org/10.1002/ anie. 201909325

79. Wang, C., Otto, S., Dorn, M., Kreidt, E., Lebon, J., Sršan, L., Di Martino-Fumo, P., Gerhards, M., Resch-Genger, U., Seitz, M., \& Heinze, K. (2018). Deuterated molecular ruby with record luminescence quantum yield. Angewandte Chemie International Edition, 57(4), 1112-1116. https://doi.org/10.1002/anie.20171 1350

80. Chen, S.-N., \& Porter, G. B. (1970). Lifetime of the ${ }^{4} T_{2 g}$ state of chromium(III) complexes. Journal of the American Chemical Society, 92(7), 2189-2190. https://doi.org/10.1021/ja00710a096

81. Barker, K. D., Barnett, K. A., Connell, S. M., Glaeser, J. W., Wallace, A. J., Wildsmith, J., Herbert, B. J., Wheeler, J. F., \& Kane-Maguire, N. A. P. (2001). Synthesis and characterization of heteroleptic $\mathrm{Cr}$ (diimine) ${ }_{3}{ }^{3+}$ complexes. Inorganica Chimica Acta, 316(1-2), 41-49. https://doi.org/10.1016/S0020-1693(01) 00377-2

82. McDaniel, A. M., Tseng, H.-W., Damrauer, N. H., \& Shores, M. P. (2010). Synthesis and solution phase characterization of strongly photooxidizing heteroleptic $\mathrm{Cr}(\mathrm{III})$ tris-dipyridyl complexes. Inorganic Chemistry, 49(17), 7981-7991. https://doi.org/ 10.1021/ic1009972

83. Serpone, N., Jamieson, M. A., Henry, M. S., Hoffman, M. Z., Bolletta, F., \& Maestri, M. (1979). Excited-state behavior of polypyridyl complexes of chromium(III). Journal of the American Chemical Society, 101, 2907-2916. https://doi.org/10.1021/ ja00505a019

84. Perkovic, M. W., Heeg, M. J., \& Endicott, J. F. (1991). Stereochemical perturbations of the relaxation behavior of (2E) chromium(III). Ground-state x-ray crystal structure, photophysics, and molecular mechanics simulations of the quasi-cage complex [4,4',4"-ethylidynetris(3-azabutan-1-amine)]chromium tribromide. Inorganic Chemistry, 30(16), 3140-3147. https://doi. org/10.1021/ic00016a009

85. Otto, S., Förster, C., Wang, C., Resch-Genger, U., \& Heinze, K. (2018). A strongly luminescent chromium(III) complex acid. Chemistry--A European Journal, 24(48), 12555-12563. https:// doi.org/10.1002/chem.201802797

86. Higgins, R. F., Fatur, S. M., Shepard, S. G., Stevenson, S. M., Boston, D. J., Ferreira, E. M., Damrauer, N. H., Rappé, A. K., \& Shores, M. P. (2016). Uncovering the roles of oxygen in $\mathrm{Cr}(\mathrm{III})$ photoredox catalysis. Journal of the American Chemical Society, 138(16), 5451-5464. https://doi.org/10.1021/jacs.6b02723

87. Sinha, N., Jiménez, J.-R., Pfund, B., Prescimone, A., Piguet, C., \& Wenger, O. S. (2021). A near-infrared-II emissive chromium(III) complex. Angewandte Chemie (International ed. in English), 60(44), 23722-23728. https://doi.org/10.1002/anie. 202106398

88. Stein, L., Boden, P., Naumann, R., Förster, C., Niedner Schatteburg, G., \& Heinze, K. (2022). The overlooked NIR luminescence of the $\operatorname{Ir}(\mathrm{ppy})_{3}$ analogue $\mathrm{Cr}(\mathrm{ppy})_{3}$. Chemical Communications. https://doi.org/10.1039/D2CC00680D

89. Dill, R. D., Portillo, R. I., Shepard, S. G., Shores, M. P., Rappé, A. K., \& Damrauer, N. H. (2020). Long-lived mixed ${ }^{2}$ MLCT/ MC states in antiferromagnetically coupled $\mathrm{d}^{3}$ vanadium(II) bipyridine and phenanthroline complexes. Inorganic Chemistry, 59(20), 14706-14715. https://doi.org/10.1021/acs.inorgchem. 0c01950

90. Laporte, O., \& Meggers, W. F. (1925). Some rules of spectral structure. Journal of the Optical Society of America, 11(5), 459. https://doi.org/10.1364/JOSA.11.000459

91. Dannöhl-Fickler, R., Kelm, H., \& Wasgestian, F. (1975). Solvent and temperature dependence of the phosphorescence decay time of hexacyanochromate(III). Journal of Luminescence, 10(2), 103-112. https://doi.org/10.1016/0022-2313(75)90038-1

92. McDaniel, A. M., Tseng, H.-W., Hill, E. A., Damrauer, N. H., Rappé, A. K., \& Shores, M. P. (2013). Syntheses and photophysical investigations of $\mathrm{Cr}$ (III) hexadentate iminopyridine complexes and their tris(bidentate) analogues. Inorganic Chemistry, 52(3), 1368-1378. https://doi.org/10.1021/ic302055r

93. Xiang, H., Cheng, J., Ma, X., Zhou, X., \& Chruma, J. J. (2013). Near-infrared phosphorescence: Materials and applications. Chemical Society Reviews, 42(14), 6128-6185. https://doi.org/ $10.1039 / \mathrm{c} 3 \mathrm{cs} 60029 \mathrm{~g}$

94. Scattergood, P. A. (2020). Recent advances in chromium coordination chemistry: luminescent materials and photocatalysis. In N. J. Patmore \& P. I. P. Elliott (Eds.), Organometallic chemistry (pp. 1-34). Royal Society of Chemistry. https://doi.org/10.1039/ 9781788017077-00001

95. Kreidt, E., Kruck, C., \& Seitz, M. (2018). Nonradiative deactivation of lanthanoid luminescence by multiphonon relaxation in molecular complexes. In J.-C.G. Bünzli, V. K. Pecharsky, G.-Y. Adachi, K. A. Gschneidner, \& E. LeRoy (Eds.), Handbook on the physics and chemistry of rare earths (pp. 35-79). Amsterdam, Oxford: North-Holland. https://doi.org/10.1016/bs.hpcre.2018. 04.001

96. Henry, M. S. (1977). Prolongation of the lifetime of the ${ }^{2} E$ state of tris(2,2'-bipyridine)chromium(III) ion by anions in aqueous solution. Journal of the American Chemical Society, 99(18), 6138-6139. https://doi.org/10.1021/ja00460a068

97. Henry, M. S., \& Hoffman, M. Z. (1978). Solution medium effects on the photophysics and photochemistry of polypyridyl complexes of chromium(III). In M. S. Wrighton (Ed.), Inorganic and organometallic photochemistry (pp. 91-114). American Chemical Society. https://doi.org/10.1021/ba-1978-0168.ch006

98. Wasgestian, H. F., Ballardini, R., Varani, G., Moggi, L., \& Balzani, V. (1973). Quenching of the tris(ethylenediamine) chromium(III) phosphorescence by some transition metal ions 
in aqueous solutions. Journal of Physical Chemistry, 77(22), 2614-2617. https://doi.org/10.1021/j100640a007

99. Basu, U., Otto, S., Heinze, K., \& Gasser, G. (2019). Biological evaluation of the NIR-emissive ruby analogue $\left[\mathrm{Cr}(\mathrm{ddpd})_{2}\right]\left[\mathrm{BF}_{4}\right]_{3}$ as a photodynamic therapy photosensitizer. European Journal of Inorganic Chemistry, 2019(1), 37-41. https://doi.org/10.1002/ ejic. 201801023

100. Wang, C., Kitzmann, W. R., Weigert, F., Förster, C., Wang, X., Heinze, K., \& Resch-Genger, U. (2022). Matrix effects on photoluminescence and oxygen sensitivity of a molecular ruby. ChemPhotoChem. https://doi.org/10.1002/cptc.202100296

101. Luo, L.-J., Su, Q.-Q., Cheng, S.-C., Xiang, J., Man, W.-L., Shu, W.-M., Zeng, M.-H., Yiu, S.-M., Ko, C.-C., \& Lau, T.-C. (2020). Tunable luminescent properties of tricyanoosmium nitrido complexes bearing a chelating $\mathrm{O}^{\wedge} \mathrm{N}$ ligand. Inorganic Chemistry, 59(7), 4406-4413. https://doi.org/10.1021/acs.inorgchem.9b035 54

102. Coppo, P., Plummer, E. A., \& de Cola, L. (2004). Tuning iridium(III) phenylpyridine complexes in the "almost blue" region. Chemical Communications, 15, 1774-1775. https://doi. org/10.1039/b406851c

103. Duvenhage, M. M., Visser, H. G., Ntwaeaborwa, O. M., \& Swart, H. C. (2014). The effect of electron donating and withdrawing groups on the morphology and optical properties of $\mathrm{Alq}_{3}$. Physica B: Condens Matter, 439, 46-49. https://doi.org/10.1016/j. physb.2013.11.049

104. Chatterjee, K. K., \& Forster, L. S. (1964). Electronic transitions in chromium(III) complexes-IV radiative and non-radiative transition probabilities. Spectrochimica Acta, 20(10), 1603-1609. https://doi.org/10.1016/0371-1951(64)80139-9

105. Witzke, H. (1971). Semi-empirical evaluations of the Racah B and $\mathrm{C}$ parameters from the crystal field spectra of chromium(III) complexes. Theoretica Chimica Acta, 20(2), 171-185. https://doi. org/10.1007/BF00569263

106. Stevenson, S. M., Shores, M. P., \& Ferreira, E. M. (2015). Photooxidizing chromium catalysts for promoting radical cation cycloadditions. Angewandte Chemie International Edition, 54(22), 6506-6510. https://doi.org/10.1002/anie.201501220

107. Yang, Y., Liu, Q., Zhang, L., Yu, H., \& Dang, Z. (2017). Mechanistic investigation on oxygen-mediated photoredox diels-alder reactions with chromium catalysts. Organometallics, 36(3), 687-698. https://doi.org/10.1021/acs.organomet.6b00886

108. Otto, S., Scholz, N., Behnke, T., Resch-Genger, U., \& Heinze, K. (2017). Thermo-chromium: A contactless optical molecular thermometer. Chemistry-A European Journal, 23(50), 1213112135. https://doi.org/10.1002/chem.201701726

109. Wang, C., Otto, S., Dorn, M., Heinze, K., \& Resch-Genger, U. (2019). Luminescent TOP nanosensors for simultaneously measuring temperature, oxygen, and $\mathrm{pH}$ at a single excitation wavelength. Analytical Chemistry, 91(3), 2337-2344. https://doi.org/ 10.1021/acs.analchem. 8 b05060

110. Forman, R. A., Piermarini, G. J., Barnett, J. D., \& Block, S. (1972). Pressure measurement made by the utilization of ruby sharp-line luminescence. Science, 176(4032), 284-285. https:// doi.org/10.1126/science.176.4032.284

111. Chijioke, A. D., Nellis, W. J., Soldatov, A., \& Silvera, I. F. (2005). The ruby pressure standard to 150GPa. Journal of Applied Physics, 98(11), 114905. https://doi.org/10.1063/1.2135877

112. Reber, C., Grey, J. K., Lanthier, E., \& Frantzen, K. A. (2011). Pressure-induced change of d-d luminescence energies, vibronic structure and band intensities in transition metal complexes. In J. P. Fackler \& L. Falvello (Eds.), Techniques in inorganic chemistry (pp. 233-254). Taylor \& Francis. https://doi.org/10.1080/ 02603590500403909

113. Wang, C., Reichenauer, F., Kitzmann, W. R., Kerzig, C., Heinze, K. \& Resch-Genger, U. (2021). Efficient Triplet-Triplet
Annihilation Upconversion Sensitized by a Second-Generation Molecular Ruby via an Underexplored Energy Transfer Mechanism, submitted.

114. Imbert, D., Cantuel, M., Bünzli, J.-C.G., Bernardinelli, G., \& Piguet, C. (2003). Extending lifetimes of lanthanide-based nearinfrared emitters $(\mathrm{Nd}, \mathrm{Yb})$ in the millisecond range through $\mathrm{Cr}$ (III) sensitization in discrete bimetallic edifices. Journal of the American Chemical Society, 125(51), 15698-15699. https:// doi.org/10.1021/ja0386501

115. Aboshyan-Sorgho, L., Nozary, H., Aebischer, A., Bünzli, J.C.G., Morgantini, P.-Y., Kittilstved, K. R., Hauser, A., Eliseeva, S. V., Petoud, S., \& Piguet, C. (2012). Optimizing millisecond time scale near-infrared emission in polynuclear chrome(III)lanthanide(III) complexes. Journal of the American Chemical Society, 134(30), 12675-12684. https://doi.org/10.1021/ja304 009b

116. Aboshyan-Sorgho, L., Besnard, C., Pattison, P., Kittilstved, K. R., Aebischer, A., Bünzli, J.-C.G., Hauser, A., \& Piguet, C. (2011). Near-infrared $\rightarrow$ visible light upconversion in a molecular trinuclear d-f-d complex. Angewandte Chemie International Edition, 50(18), 4108-4112. https://doi.org/10.1002/anie.201100095

117. Kalmbach, J., Wang, C., You, Y., Förster, C., Schubert, H., Heinze, K., Resch-Genger, U., \& Seitz, M. (2020). Near-IR to near-IR upconversion luminescence in molecular chromium ytterbium salts. Angewandte Chemie International Edition, 59(42), 18804-18808. https://doi.org/10.1002/anie.202007200

118. Bünzli, J.-C.G., \& Eliseeva, S. V. (2010). Lanthanide NIR luminescence for telecommunications, bioanalyses and solar energy conversion. Journal of Rare Earths, 28(6), 824-842. https://doi. org/10.1016/S1002-0721(09)60208-8

119. MacKenzie, L. E., \& Pal, R. (2021). Circularly polarized lanthanide luminescence for advanced security inks. Nature Reviews Chemistry, 5(2), 109-124. https://doi.org/10.1038/ s41570-020-00235-4

120. Hao, C., Xu, L., Sun, M., Zhang, H., Kuang, H., \& Xu, C. (2019). Circularly polarized light triggers biosensing based on chiral assemblies. Chemistry--A European Journal, 25(53), 1223512240. https://doi.org/10.1002/chem.201901721

121. Zinna, F., \& Di Bari, L. (2015). Lanthanide circularly polarized luminescence: Bases and applications. Chirality, 27(1), 1-13. https://doi.org/10.1002/chir.22382

122. Dee, C., Zinna, F., Kitzmann, W. R., Pescitelli, G., Heinze, K., Di Bari, L., \& Seitz, M. (2019). Strong circularly polarized luminescence of an octahedral chromium(III) complex. Chemical Communications, 55(87), 13078-13081. https://doi.org/10. 1039/c9cc06909g

123. Poncet, M., Benchohra, A., Jiménez, J.-R., \& Piguet, C. (2021). Chiral chromium(III) complexes as promising candidates for circularly polarized luminescence. ChemPhotoChem, 5(10), 880-892. https://doi.org/10.1002/cptc.202100146

124. Doistau, B., Jiménez, J.-R., \& Piguet, C. (2020). Beyond chiral organic (p-Block) chromophores for circularly polarized luminescence: The success of d-block and f-block chiral complexes. Frontiers in Chemistry, 8, 555. https://doi.org/10.3389/fchem. 2020.00555

125. Kreidt, E., Arrico, L., Zinna, F., Di Bari, L., \& Seitz, M. (2018). Circularly polarised luminescence in enantiopure samarium and europium cryptates. Chemistry--A European Journal, 24(51), 13556-13564. https://doi.org/10.1002/chem.201802196

126. Arrico, L., Di Bari, L., \& Zinna, F. (2021). Quantifying the overall efficiency of circularly polarized emitters. Chemistry--A European Journal, 27(9), 2920-2934. https://doi.org/10.1002/ chem.202002791

127. Fataftah, M. S., Zadrozny, J. M., Coste, S. C., Graham, M. J., Rogers, D. M., \& Freedman, D. E. (2016). Employing forbidden transitions as qubits in a nuclear spin-free chromium complex. 
Journal of the American Chemical Society, 138(4), 1344-1348. https://doi.org/10.1021/jacs.5b11802

128. Fataftah, M. S., Bayliss, S. L., Laorenza, D. W., Wang, X., Phelan, B. T., Wilson, C. B., Mintun, P. J., Kovos, B. D., Wasielewski, M. R., Han, S., Sherwin, M. S., Awschalom, D. D., $\&$ Freedman, D. E. (2020). Trigonal bipyramidal V ${ }^{3+}$ complex as an optically addressable molecular qubit candidate. Journal of the American Chemical Society, 142, 20400-20408. https:// doi.org/10.1021/jacs.0c08986

129. Wojnar, M. K., Laorenza, D. W., Schaller, R. D., \& Freedman, D. E. (2020). Nickel(II) metal complexes as optically addressable qubit candidates. Journal of the American Chemical Society, 142(35), 14826-14830. https://doi.org/10.1021/jacs.0c06909

130. Bayliss, S. L., Laorenza, D. W., Mintun, P. J., Kovos, B. D., Freedman, D. E., \& Awschalom, D. D. (2020). Optically addressable molecular spins for quantum information processing. Science, 370(6522), 1309-1312. https://doi.org/10.1126/science. abb 9352

131. Laorenza, D. W., Kairalapova, A., Bayliss, S. L., Goldzak, T., Greene, S. M., Weiss, L. R., Deb, P., Mintun, P. J., Collins, K. A., Awschalom, D. D., Berkelbach, T. C., \& Freedman, D. E. (2021). Tunable $\mathrm{Cr}^{4+}$ molecular color centers. Journal of the American Chemical Society. https://doi.org/10.1021/jacs.1c10145

132. Lenz, S., Bamberger, H., Hallmen, P. P., Thiebes, Y., Otto, S., Heinze, K., \& van Slageren, J. (2019). Chromium(III)-based potential molecular quantum bits with long coherence times. Physical Chemistry Chemical Physics: PCCP, 21(13), 69766983. https://doi.org/10.1039/C9CP00745H

133. Wijeratne, G. B., Zolnhofer, E. M., Fortier, S., Grant, L. N., Carroll, P. J., Chen, C.-H., Meyer, K., Krzystek, J., Ozarowski, A., Jackson, T. A., Mindiola, D. J., \& Telser, J. (2015). Electronic structure and reactivity of a well-defined mononuclear complex of Ti(II). Inorganic Chemistry, 54(21), 10380-10397. https://doi. org/10.1021/acs.inorgchem.5b01796

134. Reinholdt, A., Pividori, D., Laughlin, A. L., DiMucci, I. M., MacMillan, S. N., Jafari, M. G., Gau, M. R., Carroll, P. J., Krzystek, J., Ozarowski, A., Telser, J., Lancaster, K. M., Meyer, K., \& Mindiola, D. J. (2020). A mononuclear and high-spin tetrahedral $\mathrm{Ti}^{\mathrm{II}}$ complex. Inorganic Chemistry, 59(24), 17834-17850. https://doi.org/10.1021/acs.inorgchem.0c02586

135. Jensen, J. A., Wilson, S. R., Schultz, A. J., \& Girolami, G. S. (1987). Divalent titanium chemistry. Synthesis, reactivity, and $\mathrm{x}$-ray and neutron diffraction studies of $\mathrm{Ti}(\mathrm{BH} 4) 2$ (dmpe) 2 and $\mathrm{Ti}(\mathrm{CH} 3) 2$ (dmpe)2. Journal of the American Chemical Society, 109(26), 8094-8096. https://doi.org/10.1021/ja00260a029

136. Beaumier, E. P., Pearce, A. J., See, X. Y., \& Tonks, I. A. (2019). Modern applications of low-valent early transition metals in synthesis and catalysis. Nature Reviews Chemistry, 3(1), 15-34. https://doi.org/10.1038/s41570-018-0059-x

137. Araya, M. A., Cotton, F. A., Matonic, J. H., \& Murillo, C. A. (1995). An efficient reduction process leading to titanium(II) and niobium(II): Preparation and structural characterization of trans- $\mathrm{MCl}_{2}(\mathrm{py})_{4}$ compounds, $\mathrm{M}=\mathrm{Ti}, \mathrm{Nb}$, and $\mathrm{Mn}$. Inorganic Chemistry, 34(22), 5424-5428. https://doi.org/10.1021/ic001 26a009

138. Fortier, S., \& Gomez-Torres, A. (2021). Redox chemistry of discrete low-valent titanium complexes and low-valent titanium synthons. Chemical Communications, 57(80), 10292-10316. https://doi.org/10.1039/D1CC02772G

139. Kayal, A., Kuncheria, J., \& Lee, S. C. (2001). Bishydrotris(pyrazol-1-yl)boratotitanium(II): A stable $\mathrm{Tp}_{2} \mathrm{M}$ complex of singular reactivity. Chemical Communications, 23, 2482-2483. https://doi.org/10.1039/B108115B

140. Dingle, R., McCarthy, P. J., \& Ballhausen, C. J. (1969). Crystal spectra of hexaurea complexes. III. Optical and magnetic properties of crystals containing the hexaurea vanadium (III) Ion. The
Journal of Chemical Physics, 50(5), 1957-1962. https://doi.org/ 10.1063/1.1671314

141. Flint, C. D., \& Greenough, P. (1972). Luminescence spectrum of the V(urea) ${ }_{6}{ }^{3+}$ ion. Chemical Physics Letters, 16(2), 369-370. https://doi.org/10.1016/0009-2614(72)80294-X

142. Beaulac, R., Tregenna-Piggott, P. L. W., Barra, A.-L., Weihe, H., Luneau, D., \& Reber, C. (2006). The electronic ground state of V(urea) ${ }_{6}^{3+}$ probed by NIR luminescence, electronic Raman, and high-field EPR spectroscopies. Inorganic Chemistry, 45(8), 3399-3407. https://doi.org/10.1021/ic051709f

143. Dorn, M., East, N. R., Förster, C., Kitzmann, W. R., Moll, J., Reichenauer, F., Reuter, T., Stein, L., \& Heinze, K. (2022). d-d and charge transfer photochemistry of $3 \mathrm{~d}$ metal complexes. In J. Reedijk (Ed.), Comprehensive inorganic chemistry III. Elsevier.

144. Dorn, M., Kalmbach, J., Boden, P., Kruse, A., Dab, C., Reber, C., Niedner-Schatteburg, G., Lochbrunner, S., Gerhards, M., Seitz, M., \& Heinze, K. (2021). Ultrafast and long-time excited state kinetics of an NIR-emissive vanadium(III) complex I: Synthesis, spectroscopy and static quantum chemistry. Chemical Science, 12(32), 10780-10790. https://doi.org/10.1039/d1sc02137k

145. Zobel, J. P., Knoll, T., \& González, L. (2021). Ultrafast and longtime excited state kinetics of an NIR-emissive vanadium(III) complex II. Elucidating triplet-to-singlet excited-state dynamics. Chemica Science, 12(32), 10791-10801. https://doi.org/10. 1039/d1sc02149d

146. Juban, E. A., Smeigh, A. L., Monat, J. E., \& McCusker, J. K. (2006). Ultrafast dynamics of ligand-field excited states. Coordination Chemistry Reviews, 250, 1783-1791. https://doi.org/10. 1016/J.CCR.2006.02.010

147. Brik, M., Avram, N., \& Avram, C. (2005). Crystal field analysis of the ground and excited state absorption of $\mathrm{a} \mathrm{Cr}^{4+}$ ion in $\mathrm{LiAlO}_{2}$ and $\mathrm{LiGaO}_{2}$ crystals. Central European Journal of Physics, 3(4), 508-524. https://doi.org/10.2478/BF02475609

148. Neyhart, G. A., Bakir, M., Boaz, J., Vining, W. J., \& Patrick Sullivan, B. (1991). Photophysics and photochemistry of rhenium(V)-nitrogen triple bonds. Coordination Chemistry Reviews, 111, 27-32. https://doi.org/10.1016/0010-8545(91) 84007-R

149. Savoie, C., \& Reber, C. (1998). Emitting state energies and vibronic structure in the luminescence spectra of transdioxorhenium(V) complexes. Coordination Chemistry Reviews, 171, 387-398. https://doi.org/10.1016/S0010-8545(98)90059-5

150. Yam, V.W.-W., \& Che, C.-M. (1990). Photochemistry and photophysics of trans-d ${ }^{2}$-dioxo complexes of osmium(VI). Coordination Chemistry Reviews, 97, 93-104. https://doi.org/10.1016/ 0010-8545(90)80082-5

151. Ikeda, H., Ito, A., Sakuda, E., Kitamura, N., Takayama, T., Sekine, T., Shinohara, A., \& Yoshimura, T. (2013). Excitedstate characteristics of tetracyanidonitridorhenium(V) and -technetium(V) complexes with N-heteroaromatic ligands. Inorganic Chemistry, 52(11), 6319-6327. https://doi.org/10.1021/ ic302463v

152. Sasaki, K., Yamate, H., Yoshino, H., Miura, H., Shimoda, Y., Miyata, K., Onda, K., Ohtani, R., \& Ohba, M. (2020). Vapor switching of the luminescence mechanism in a $\operatorname{Re}(\mathrm{V})$ complex. Chemical Communications, 56(85), 12961-12964. https://doi. org/10.1039/D0CC05462C

153. Lanthier, E., Bendix, J., \& Reber, C. (2010). Pressure-dependent luminescence spectroscopy of molybdenum(IV) oxo complexes. Dalton Transactions, 39(15), 3695-3705. https://doi.org/10. 1039/b924242b

154. Isovitsch, R. A., Beadle, A. S., Fronczek, F. R., \& Maverick, A. W. (1998). Electronic absorption spectra and phosphorescence of oxygen-containing molybdenum(IV) complexes. Inorganic Chemistry, 37(17), 4258-4264. https://doi.org/10.1021/ic971 $186 \mathrm{e}$ 
155. Kirk, A. D. (1981). Chromium(III) photochemistry and photophysics. Coordination Chemistry Reviews, 39(1-2), 225-263. https://doi.org/10.1016/s0010-8545(00)80515-9

156. Forster, L. S. (1990). The photophysics of chromium(III) complexes. Chemical Reviews, 90(2), 331-353. https://doi.org/10. 1021/cr00100a001

157. Kjær, K. S., van Driel, T. B., Harlang, T. C. B., Kunnus, K., Biasin, E., Ledbetter, K., Hartsock, R. W., Reinhard, M. E., Koroidov, S., Li, L., Laursen, M. G., Hansen, F. B., Vester, P., Christensen, M., Haldrup, K., Nielsen, M. M., Dohn, A. O., Pápai, M. I., Møller, K. B., ... Gaffney, K. J. (2019). Finding intersections between electronic excited state potential energy surfaces with simultaneous ultrafast X-ray scattering and spectroscopy. Chemical Science, 10(22), 5749-5760. https://doi.org/10.1039/c8sc0 $4023 \mathrm{k}$

158. Wegeberg, C., \& Wenger, O. S. (2021). Luminescent first-row transition metal complexes. JACS Au. https://doi.org/10.1021/ jacsau. $1 \mathrm{c} 00353$

159. Schläfer, H., Gausmann, H., \& Witzke, H. (1966). Phosphorescence of molybdenum (III) complexes. Journal of Molecular Spectroscopy, 21(1-4), 125-129. https://doi.org/10.1016/00222852(66)90131-7

160. Yao, Q., \& Maverick, A. W. (1988). Near-infrared luminescence of octahedral molybdenum(III) and rhenium(IV) complexes in solution. Inorganic Chemistry, 27(10), 1669-1670. https://doi. org/10.1021/ic00283a001

161. Mohammed, A. K., Isovitsch, R. A., \& Maverick, A. W. (1998). Solution photophysics, one-electron photooxidation, and photoinitiated two-electron oxidation of molybdenum(III) complexes. Inorganic Chemistry, 37(11), 2779-2785. https://doi. org/10.1021/ic970955r

162. Cornioley-Deuschel, C., \& von Zelewsky, A. (1987). Stability of d3 diimine complexes: molybdenum(III) vs chromium(III). Inorganic Chemistry, 26(6), 962-963. https://doi.org/10.1021/ ic00253a040

163. Stiefel, E. I. (1977). The coordination and bioinorganic chemistry of molybdenum. In S. J. Lippard (Ed.), Progress in inorganic chemistry (pp. 1-223). Wiley. https://doi.org/10.1002/97804 70166239.ch1

164. Young, C. G. (2004). Molybdenum. In J. A. McCleverty \& T. J. Meyer (Eds.), Comprehensive coordination chemistry II (pp. 415-527). Elsevier/Pergamon. https://doi.org/10.1016/B0-08043748-6/03033-4

165. Dunn, T. M. (1961). Spin-orbit coupling in the first and second transition series. Transactions of the Faraday Society, 57, 1441. https://doi.org/10.1039/TF9615701441

166. Koseki, S., Matsunaga, N., Asada, T., Schmidt, M. W., \& Gordon, M. S. (2019). Spin-orbit coupling constants in atoms and ions of transition elements: comparison of effective core potentials, model core potentials, and all-electron methods. Journal of Physical Chemistry A, 123(12), 2325-2339. https://doi.org/10. 1021/acs.jpca.8b09218

167. Morrison, C. A. (1992). Crystal fields for transition-metal ions in laser host materials. Springer.

168. Fleischauer, P. D., \& Fleischauer, P. (1970). Photoluminescence of transition metal coordination compounds. Chemical Reviews, 70(2), 199-230. https://doi.org/10.1021/cr60264a002

169. Sartori, G., Cervone, E., \& Cancellieri, P. (1963). The electronic structure of $\mathrm{d}^{3}$ complexes using ligand field theory. Atti della Accademia Nazionale dei Lincei, Classe di Scienze Fisiche, Matematiche e Naturali, 35, 226.

170. Maverick, A. W., Lord, M. D., Yao, Q., \& Henderson, L. J. (1991). Photophysics and photochemistry of hexachlororhenate(IV) and hexabromorhenate(IV). Inorganic Chemistry, 30(3), 553-558. https://doi.org/10.1021/ic00003a040
171. Holleman, A. F., \& Wiberg, N. (2017). Hollemann Wiberg, Grundlagen und Hauptgruppenelemente, Band 1 (103rd ed.). De Gruyter.

172. Fujita, I., Yazaki, T., Torii, Y., \& Kobayashi, H. (1972). Electronic absorption spectra of tris(2,2'-bipyridine)- and Tris $(1,10$ phenanthroline) complexes of Vanadium(II) and Chromium(II). Bulletin Chemical Society of Japan, 45(7), 2156-2161. https:// doi.org/10.1246/bcsj.45.2156

173. Joyce, J. P., Portillo, R. I., Nite, C. M., Nite, J. M., Nguyen, M. P., Rappé, A. K., \& Shores, M. P. (2021). Electronic structures of $\mathrm{Cr}$ (III) and V(II) polypyridyl systems: Undertones in an isoelectronic analogy. Inorganic Chemistry, 60(17), 12823-12834. https://doi.org/10.1021/acs.inorgchem.1c01129

174. Kee, T. (1998). Niobium and tantalum 1995. Coordination Chemistry Reviews, 169(1), 129-152. https://doi.org/10.1016/ S0010-8545(98)00004-6

175. Wexler, P. A., Wigley, D. E., Koerner, J. B., \& Albright, T. A. (1991). Preparation, properties, and bonding analysis of tantalum(II) $\eta^{6}$-arene complexes. Organometallics, 10(7), 23192327. https://doi.org/10.1021/om00053a039

176. Thiyagarajan, B., Michalczyk, L., Bollinger, J. C., \& Bruno, J. W. (1996). Generation of organoniobium(II) radicals and synthesis of heterometallic niobium-mercury compounds. Organometallics, 15(11), 2588-2590. https://doi.org/10.1021/om960152w

177. Tayebani, M., Gambarotta, S., \& Yap, G. (1998). C-H versus $\mathrm{C}-\mathrm{N}$ bond cleavage promoted by niobium(II) amide. Organometallics, 17(17), 3639-3641. https://doi.org/10.1021/om980298q

178. Noh, W., \& Girolami, G. S. (2008). Mono(cycloheptatrienyl) tantalum chemistry: Synthesis and characterization of new tantalum halide, hydride, and alkyl species. Inorganic Chemistry, 47(22), 10682-10691. https://doi.org/10.1021/ic8015035

179. Cohen, J. L., \& Hoggard, P. E. (2009). Photosolvation reactions of hexabromorhenate(IV). Inorganica Chimica Acta, 362(2), 580-582. https://doi.org/10.1016/j.ica.2008.03.119

180. McCusker, J. K., Walda, K. N., Dunn, R. C., Simon, J. D., Magde, D., \& Hendrickson, D. N. (1993). Subpicosecond ${ }^{1}$ MLCT $->{ }^{5} T_{2}$ intersystem crossing of low-spin polypyridyl ferrous complexes. Journal of the American Chemical Society, 115(1), 298-307. https://doi.org/10.1021/ja00054a043

181. Shari'atiVura-Weis, Y. J. (2021). Ballistic $\Delta \mathrm{S}=2$ intersystem crossing in a cobalt cubane following ligand-field excitation probed by extreme ultraviolet spectroscopy. Physical Chemistry Chemical Physics: PCCP. https://doi.org/10.1039/D1CP04136C

182. Scarborough, C. C., Sproules, S., Doonan, C. J., Hagen, K. S., Weyhermüller, T., \& Wieghardt, K. (2012). Scrutinizing lowspin $\mathrm{Cr}(\mathrm{II})$ complexes. Inorganic Chemistry, 51(12), 6969-6982. https://doi.org/10.1021/ic300882r

183. Eaton, J. P., \& Nicholls, D. (1981). The complex cyanides of chromium(II) and chromium(0). Transition Metal Chemistry, 6(4), 203-206. https://doi.org/10.1007/BF00618223

184. Becker, P. M., Förster, C., Carrella, L. M., Boden, P., Hunger, D., van Slageren, J., Gerhards, M., Rentschler, E., \& Heinze, K. (2020). Spin crossover and long-lived excited states in a reduced molecular ruby. Chemistry--A European Journal, 26(32), 71997204. https://doi.org/10.1002/chem.202001237

185. Holleman, A. F., \& Wiberg, N. (2017). Hollemann Wiberg, Nebengruppenelemente, Lanthanoide, Actinoide, Transactinoide, Band 2 (103rd ed.). De Gruyter.

186. Cotton, F. A., Eglin, J. L., \& Wiesinger, K. J. (1992). Synthesis and characterization of molybdenum species: Dinuclear and mononuclear species of the molecular formulas $\left[\mathrm{Mo}_{2}\left(\mathrm{O}_{2} \mathrm{CCH}_{3}\right)_{2}(\mathrm{LL})_{2}\right]\left[\mathrm{BF}_{4}\right]_{2}$ and $\left[\mathrm{Mo}(\mathrm{O})(\mathrm{F})(\mathrm{LL})_{2}\right]\left[\mathrm{BF}_{4}\right]$ where $\mathrm{LL}=$ bis-phosphine. The use of $\left[\mathrm{Mo}\left(\mathrm{NCCH}_{3}\right)_{10}\right]\left[\mathrm{BF}_{4}\right]_{4}$ as a source for the $\left[\mathrm{Mo}_{2}\right]^{4+}$ core. Inorganica Chimica Acta, 195, 11-23. 
187. Cotton, F. A., \& Wiesinger, K. J. (1992). Decakis(Acetonitrile) Dimolybdenum(II) Tetrafluoroborate(1-). Inorganic Syntheses, 29, 134-137.

188. Holste, G. (1975). $\mathrm{Mo}_{2}\left(\mathrm{CH}_{3} \mathrm{COO}\right)_{4}, \mathrm{Mo}_{2}\left(\mathrm{C}_{6} \mathrm{H}_{5} \mathrm{COO}\right)_{4}$ und $\left[\mathrm{Mo}_{6} \mathrm{Cl}_{8}\right] \mathrm{Cl}_{2}\left(\mathrm{CH}_{3} \mathrm{COO}\right)_{2}$. Zeitschrift für Anorganische und Allgemeine Chemie, 414(1), 81-90. https://doi.org/10.1002/zaac. 19754140111

189. Johnson, K. D., \& Powell, G. L. (2008). Microwave-assisted synthesis of dimolybdenum tetracarboxylates and a decanuclear osmium cluster. Journal of Organometallic Chemistry, 693(8-9), 1712-1715. https://doi.org/10.1016/j.jorganchem.2007.11.036

190. Maverick, A. W., Najdzionek, J. S., MacKenzie, D., Nocera, D. G., \& Gray, H. B. (1983). Spectroscopic, electrochemical, and photochemical properties of molybdenum(II) and tungsten(II) halide clusters. Journal of the American Chemical Society, 105(7), 1878-1882. https://doi.org/10.1021/ja00345a034

191. Eltayeb, N. E., Teoh, S. G., Kusrini, E., Adnan, R., \& Fun, H. K. (2010). The manganese(III) complex with chelating Schiff base ligand: X-ray structure, spectroscopic and computational studies. Spectrochimica Acta Part A: Molecular and Biomolecular Spectroscopy, 75(1), 453-457. https://doi.org/10.1016/j.saa.2009.11. 006

192. Majumder, A., Goswami, S., Batten, S. R., Salah El Fallah, M., Ribas, J., \& Mitra, S. (2006). Catalytic oxidation of 3,5-di-tertbutylcatechol by a manganese(III) 18-azametallacrown- 6 compound: Synthesis, crystal structure, fluorescence, magnetic and kinetic investigation. Inorganica Chimica Acta, 359(8), 23752382. https://doi.org/10.1016/j.ica.2006.01.045

193. Makarska-Bialokoz, M., Pratviel, G., \& St. Radzki. (2008). The influence of solvent polarity on spectroscopic properties of 5-[4-(5-carboxy-1-butoxy)-phenyl]-10,15,20-tris(4-N-methylpyridiniumyl)porphyrin and its complexes with $\mathrm{Fe}(\mathrm{III})$ and Mn(III) ions. Journal of Molecular Structure, 875(1-3), 468477. https://doi.org/10.1016/j.molstruc.2007.05.026

194. Sun, E., Shi, Y., Zhang, P., Zhou, M., Zhang, Y., Tang, X., \& Shi, T. (2008). Spectroscopic properties and cyclic voltammetry on a series of meso-tetra(p-alkylamidophenyl)porphyrin liquid crystals and their Mn complexes. Journal of Molecular Structure, 889(1-3), 28-34. https://doi.org/10.1016/j.molstruc.2008.01.014

195. Abram, U. (2004). Rhenium. In J. A. McCleverty \& T. J. Meyer (Eds.), Comprehensive coordination chemistry II (pp. 271-402). Elsevier/Pergamon. https://doi.org/10.1016/B0-08-043748-6/ 04177-3

196. Alberto, R. (2004). Technetium. In J. A. McCleverty \& T. J. Meyer (Eds.), Comprehensive coordination chemistry II (pp. 127-270). Elsevier/Pergamon. https://doi.org/10.1016/B0-08043748-6/04022-6

197. Hancock, R. D., \& McDougall, G. J. (1977). The role of electronic delocalization over the chelate ring in stabilizing complexes of 2,2'-bipyridyl. Journal of the Chemical Society Dalton Transactions, 1, 67-70. https://doi.org/10.1039/dt9770000067

198. Robinson, M. A., Curry, J. D., \& Busch, D. H. (1963). Complexes derived from strong field ligands. XVII. Electronic spectra of octahedral Nickel(II) complexes with ligands of the $\alpha$-diimine and closely related classes. Inorganic Chemistry, 2(6), 11781181. https://doi.org/10.1021/ic50010a021
199. Henke, W., \& Reinen, D. (1977). Spektroskopische Untersuchungen zum Jahn-Teller-Effekt des $\mathrm{Cu}^{2+}$-Ions in Terpyridin-Komplexen $\mathrm{Cu}(\text { terpy })_{2} \mathrm{X}_{2} \cdot \mathrm{nH} 2 \mathrm{O}\left[\mathrm{X}=\mathrm{NO}, \mathrm{ClO}, \mathrm{Br}^{-}\right]$. Zeitschrift für Anorganische und Allgemeine Chemie, 436(1), 187-200. https:// doi.org/10.1002/zaac.19774360123

200. Dorn, M., Mack, K., Carrella, L. M., Rentschler, E., Förster, C., \& Heinze, K. (2018). Structure and electronic properties of an expanded terpyridine complex of Nickel(II) $\left[\mathrm{Ni}(\mathrm{ddpd})_{2}\right]\left(\mathrm{BF}_{4}\right)_{2}$. Zeitschrift für Anorganische und Allgemeine Chemie, 644(14), 706-712. https://doi.org/10.1002/zaac.201800101

201. González, E., Rodrigue-Witchel, A., \& Reber, C. (2007). Absorption spectroscopy of octahedral nickel(II) complexes: A case study of interactions between multiple electronic excited states. Coordination Chemistry Reviews, 251(3-4), 351-363. https:// doi.org/10.1016/j.ccr.2006.08.011

202. Nolet, M.-C., Michaud, A., Bain, C., Zargarian, D., \& Reber, C. (2006). Allowed and forbidden d-d transitions in poly(3,5dimethylpyrazolyl)methane complexes of nickel(II). Photochemistry and Photobiology, 82(1), 57-63. https://doi.org/10.1562/ 2005-06-28-RA-593

203. Dab, C., East, N. R., Förster, C., Heinze, K. \& Reber, C. (2022). to be submitted.

204. Oppenheim, J. J., McNicholas, B. J., Miller, J., \& Gray, H. B. (2019). Electronic Structure of Tetracyanonickelate(II). Inorganic Chemistry, 58(22), 15202-15206. https://doi.org/10.1021/ acs.inorgchem.9b02135

205. Giordano, T. J., Butler, W. M., \& Rasmussen, P. G. (1978). Platinum and palladium complexes of thienylpyridine. 2. Quasioctahedral divalent-metal compounds. Inorganic Chemistry, 17, 1917-1922.

206. Takeda, N., Shimizu, D., \& Tokitoh, N. (2005). Synthesis and structure of a distorted octahedral palladium(II) complex coordinated with a tetrathioether ligand tethered with bulky substituents. Inorganic Chemistry, 44(23), 8561-8568. https://doi.org/ 10.1021/ic050944v

207. Pointillart, F., Train, C., Villain, F., Moulin, C. C. D., Gredin, P., Chamoreau, L.-M., Gruselle, M., Aullon, G., Alvarez, S., \& Verdaguer, M. (2007). Six-fold oxygen-coordinated triplet $(\mathrm{S}=1)$ palladium(II) moieties templated by tris(bipyridine) ruthenium(II) ions. Journal of the American Chemical Society, 129(5), 1327-1334. https://doi.org/10.1021/ja066817v

208. Takeda, N., Isobe, T., \& Tokitoh, N. (2007). Synthesis of an acyclic diselenodithioether ligand tethered with bulky substituents and its application to the synthesis of a distorted octahedral palladium(II) complex. Heteroatom Chemistry, 18(5), 549-556. https://doi.org/10.1002/hc.20339

209. Das, D., Vats, B. G., Kannan, S., Maity, D. K., \& Drew, M. G. (2013). Steric effects in pyrazole palladium(II) compounds: Synthetic, structural, and theoretical studies of a highly distorted octahedral palladium(II) pyrazole compound. Polyhedron, 54, 104-109. https://doi.org/10.1016/j.poly.2013.01.051

210. Safin, D. A., Babashkina, M. G., \& Garcia, Y. (2013). First paramagnetic $\mathrm{Pd}(\mathrm{II})$ complex with a $\mathrm{PdN}_{4} \mathrm{~S}_{2}$ coordination core. Dalton Transactions, 42(4), 902-905. https://doi.org/10.1039/ C2DT32505E 